\title{
Revision of the genera Habetia Kirby, 1906 and Parahabetia gen. nov. from New Guinea (Orthoptera, Tettigoniidae, Conocephalinae, Agraeciini)
}

\section{SIGFRID INGRISCH}

Zoological Research Museum Alexander Koenig (ZFMK), Adenauerallee 160, D-53113 Bonn, Germany.

I"S.Ingrisch@leibniz-zfmk.de; † https://orcid.org/0000-0002-8624-0472

\section{Table of contents}

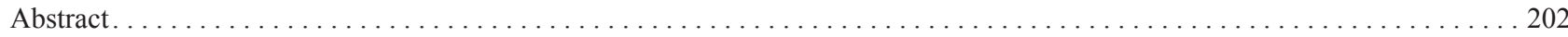

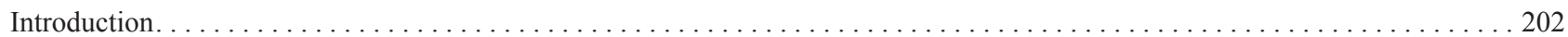

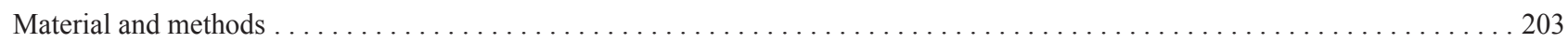

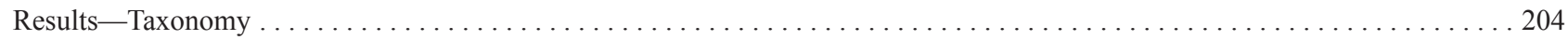

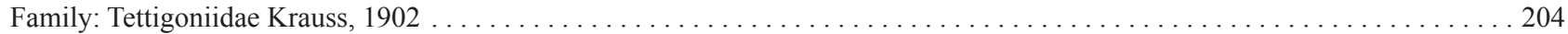

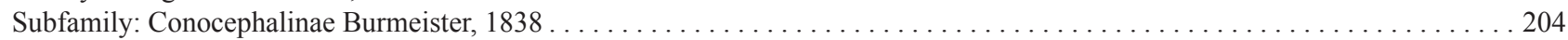

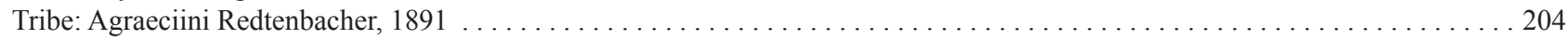

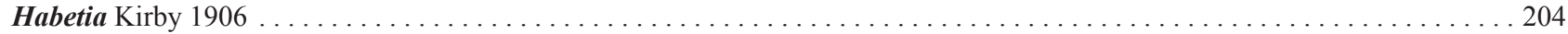

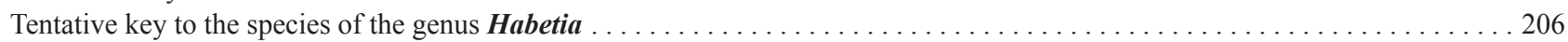

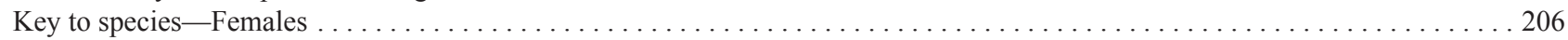

Key to

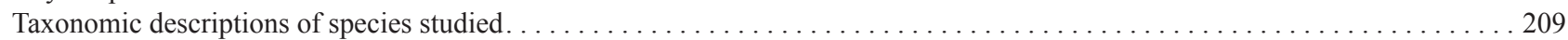

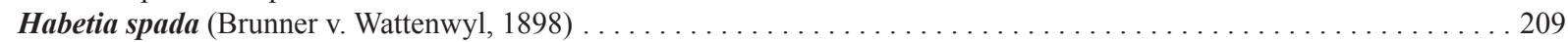

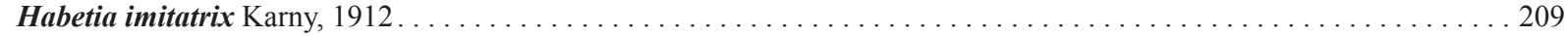

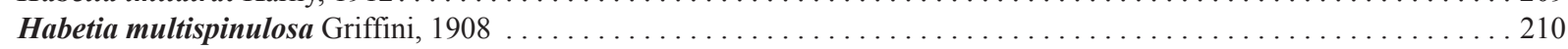

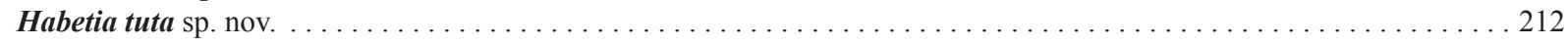

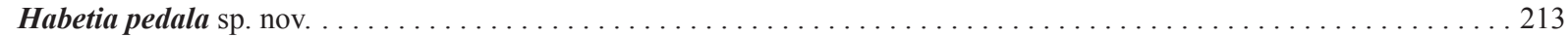

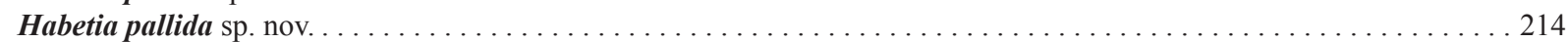

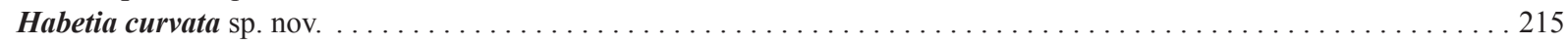

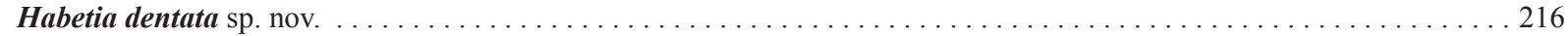

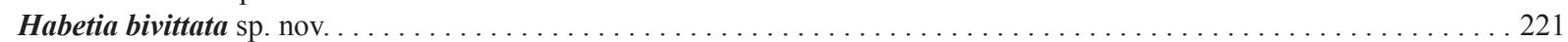

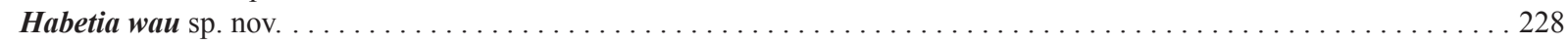

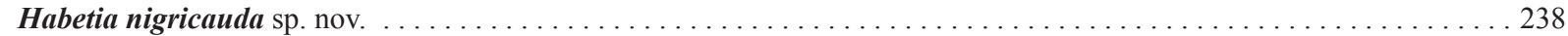

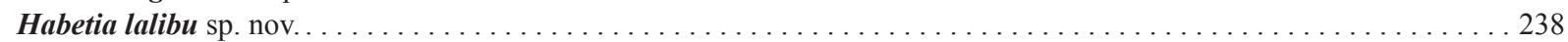

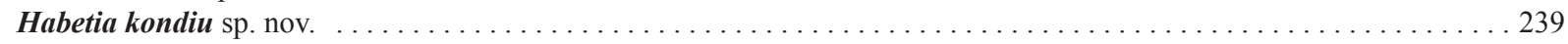

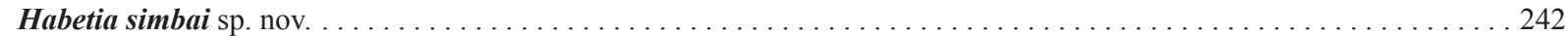

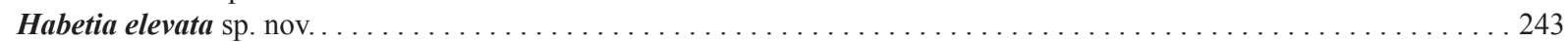

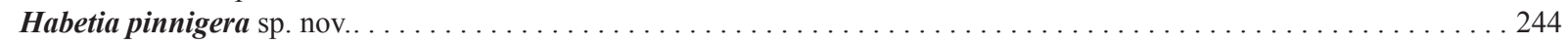

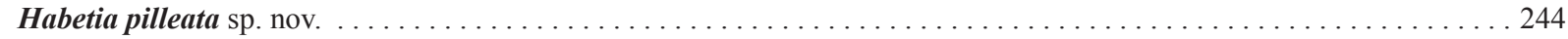

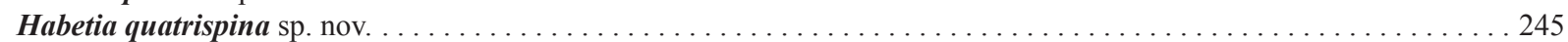

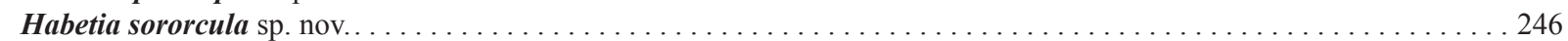

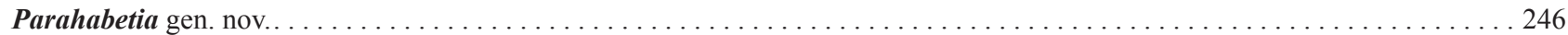

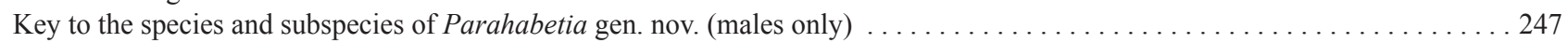

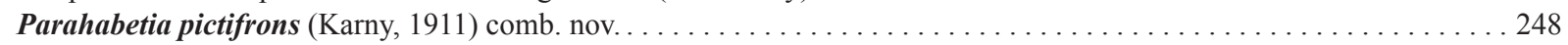

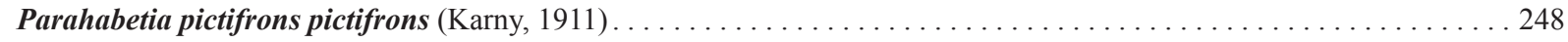

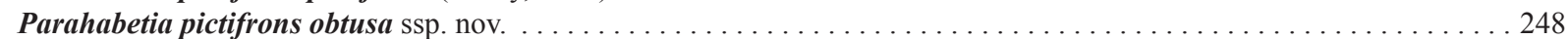

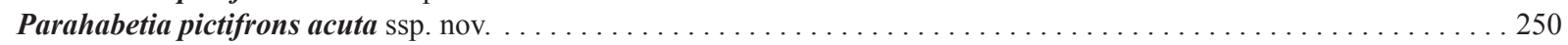

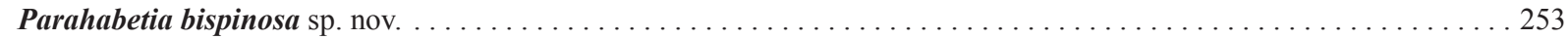

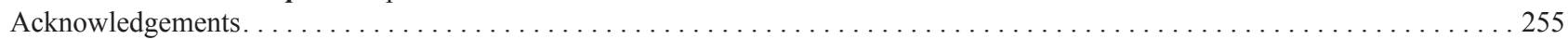

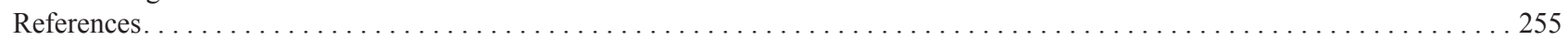




\section{Abstract}

The genus Habetia Kirby, 1906 previously known from only four species or subspecies is revised based on unidentified specimens found in museum collections. H. multispinulosa Griffini, 1908 is given full species status, while $H$. pictifrons Karny, 1911 is removed from Habetia based on male and female characters and becomes the type species of the new genus Parahabetia gen. nov. Sixteen new species are described in Habetia, and one new species and two new subspecies in Parahabetia. The most significant characters for the differentiation of species of Habetia are male tenth abdominal tergite, cerci, subgenital plate, and male internal genitalia with the titillators that basically form a pair of roughly Ushaped sclerites that vary between species from simple, curved sclerites to modified structures with additional sclerotized branches and the sclerites can be connected with septa to form complex shapes. In contrast, males of Parahabetia have elongate titillators provided at end with a crest. In the larger species of Habetia the stridulatory file on the underside of the male left tegmen has a step in pre-apical area that is missing in the smaller species; one species with a weak step is intermediate between both groups. Unique modifications of single species in Habetia are an apical dorsal extension of the male subgenital plate in H. imitatrix Karny, 1912 and a hardened phallus sheath between phallus and subgenital plate in H. tuta sp. nov. Females of Habetia have straight ovipositors that vary in length and in the shape of the dorsal margin between species. Females can also be differentiated by species specific modifications of the subgenital plate. In Parahabetia the ovipositor is rather short and curved similar to the condition in the genus Philmontis Willemse, 1966 but has the apical area slightly recurved. Keys to the species of both genera are provided. Habetia species have been found throughout New Guinea except so far for Papua Barat; although they were mainly found in the North and the East. Parahabetia species are currently only known from the East of New Guinea. The following species and subspecies are described as new: Habetia bivittata sp. nov., H. curvata sp. nov., H. dentata sp. nov., H. elevata sp. nov., H. kondiu sp. nov., H. lalibu sp. nov., H. nigricauda sp. nov., H. pallida sp. nov., H. pedala sp. nov., H. pilleata sp. nov., H. pinnigera sp. nov., H. quatrispina sp. nov., H. simbai sp. nov., H. sororcula sp. nov., H. tuta sp. nov., H. wau sp. nov., Parahabetia bispinosa sp. nov., P. pictifrons obtusa ssp. nov., P. pictifrons acuta ssp. nov.

Key words: Orthoptera, katydids, new species, new combinations, new genus, Indonesia, Papua New Guinea

\section{Introduction}

The genus name Habetia was introduced by Kirby (1906) for a species that had been established by Brunner v. W. (1898) under the name Agroecia spada for a single female specimen with strongly prolonged ovipositor. Prior to Kirby (1906), Dohrn (1905) had already proposed a new genus name Orthoxiphus with Brunner's species as typus generis. That generic name proved, however, to be a homonym of Orthoxiphus Saussure, 1899, thus Kirby's name is the valid one. Only three more species group names have so far been added to Habetia: The first was Habetia spada variety multispinulosa Griffini, 1908 also with a single female as type. Later, Karny (1911 and 1912b) described two more species in that genus: H. pictifrons Karny, 1911 and H. imitatrix Karny, 1912. Both species were described from a single male. In the latter publication, Karny (1912b) also reports male and female of $H$. spada from the Toricelli Mountains, which appears strange, since these mountains are quite remote from the type locality of $H$. spada (Konstantinhafen = Enke Port), while the type locality of H. imitatrix Karny, 1912, Bongu, is very close to that of H. spada. Both, H. spada and H. pictifrons were also mentioned in Karny (1926) without providing new localities or other new information.

Habetia thus contained to date only four taxa at the species-group level: H. spada (Brunner, 1898) with two subspecies, H. spada spada (Brunner, 1898) and H. spada multispinulosa Griffini, 1908, both described after a single female, and the species H. imitatrix Karny, 1912 and H. pictifrons Karny, 1911, which were both described after a single male (Cigliano et al. 2021). Of the latter species (H. pictifrons) another male became known that had been correctly identified by the late Fer Willemse (specimen in NBC) and of which photos had been taken during the DORSA project (Lampe et al. 2005) that are also available via OSF (Cigliano et al. 2021). All these specimens have been re-examined for the current study except for the holotype of $H$. pictifrons which could not be traced but of which images had been included in Karny (1911, 1912a). For the present study, the first female and four more males related to $H$. pictifrons became available. Despite similarities in the shape of body, face, pronotum, and slightly abbreviated wings of these specimens with typical Habetia, they differ strikingly in important diagnostic characters as male cerci and titillators, as well as in the shapes of the female subgenital plate and especially the ovipositor, thus that they must be regarded as belonging to a different genus. At the time when Karny (1911) described H. pictifrons only two females of Habetia had been known. Already in Karny (1912a) is written that the diagnostic characters listed for Habetia males refer only to H. pictifrons and they may look different in other species of the genus. 
The current study is based on the re-examination of the types of the formerly described species, only the type of $H$. pictifrons could not be traced, and on specimens found in the unidentified cabinets of various museum collections as listed under depositories. These specimens had been collected between 1890 and 1988. In total, about 130 specimens have been examined, which allowed a revision of the genus. The collections also contained a female related to $H$. pictifrons, which also gives evidence that this species does not belong to Habetia, but a new genus has to be established for this and an undescribed related species.

\section{Material and methods}

The basis for this study was laid during the mid-nineties of the last century during the preparation of a monograph of the Oriental Agraeciini (Ingrisch 1998). The type of H. multispinulosa Griffini, 1908 in MCSN Genoa was reexamined at that time, and the specimens in MBBJ Bogor were studied and labeled during a visit in 1995. During that visit, the habitus of the specimens studied were documented by classical photography and line drawings of details. The specimens examined and labeled by Karny (1912) were studied during the DORSA project (Lampe et al. 2005), and the holotype of $H$. spada (Brunner, 1898) and some unidentified specimens were examined during a visit in NMW Wien. At those visits, documentation of the specimens was done as line drawings with aid of a camera lucida mounted at a stereo microscope and taking photographic images with classical photography or with photographic equipment available at the collections. The majority of the specimens, however, was studied recently on loan with the following equipment.

For study and documentation of diagnostic characters, the male specimens were moistened, the titillators extracted from the body and cleaned in $\mathrm{KOH}$ solution and then stored in $70 \%$ alcohol. At the end of the study, they were glued with water soluble glue to cardboard and pinned below the specimens. The general habitus of the specimens studied was photographed using a Canon 500D mounted to a copy-stand; most microscopic images documenting details of wings, cerci and titillators were done with a Canon 6D mounted to the photo adapter of a Motic M5. The microscopic images were processed with CaptureOne and stacked with Zerene Stacker. Habitus images were photographed together with a piece of scale paper. Microscopic images were done at one of four fixed magnifications. For each magnification also a micrometer was photographed that allowed to add scales to the finished images. Measurements of the stridulatory apparatus were done with Adobe Photoshop CS6. The length of the stridulatory file has been taken as a straight line from the first to the last tooth without considering that the file is curved at both ends.

The specimens studied had been labelled with locality names that were in use at the time of collection, none with exact coordinates. Geographical coordinates given in this publication are approximate values that have been investigated by search in Google Maps (2021), a Gazetteer of The Papua Insects Foundation (2019), or World Airport Codes (2020). For tracing the geographical position of historical German names, Kiepe \& Provinsky (2011) proved to be useful. The biogeographic work done by researchers of the BPBM is documented in Gressitt (1982).

The abbreviation KAE followed by a numeral is the collection number of the Kaiserin-Augustafluß-Expedition [Sepik River Expedition] 1912.

The number of spines on the ventral margin of the femora follows the formula: (1) fore femur, (2) mid femur, (3) hind femur, a anterior margin, $p$ posterior margin.

Depositories

BPBM Bernice B. Bishop Museum, Honolulu, Hawaii, USA

ISNB Institut Royal des Sciences Naturelles de Belgique, Brussels, Belgium

MBBJ Museum Zoologicum Bogoriense, Bogor [now in Cibinong], Indonesia

MCSN Museo Civico di Storia Naturale "Giacomo Doria", Genoa, Italy

NBC Naturalis Biodiversity Center (including Willemse Collection), Leiden, the Netherlands

NHM The Natural History Museum, London, UK

NMW Naturhistorisches Museum Wien, Austria

SMTD Senckenberg Naturhistorische Sammlungen, Museum für Tierkunde, Dresden, Germany

ZMB Museum für Naturkunde (formerly Zoologisches Museum), Berlin, Germany

ZSM Zoologische Staatssammlung München, Germany 


\section{Results-Taxonomy}

Family: Tettigoniidae Krauss, 1902

\section{Subfamily: Conocephalinae Burmeister, 1838}

\section{Tribe: Agraeciini Redtenbacher, 1891}

\section{Habetia Kirby 1906}

Figs 1-19

Habetia Kirby 1906: 260; Karny 1909: 26; Karny 1911: 339; Karny 1912a: 21; Karny 1912b: 5; Karny 1926: 197; Otte. 1997: 29; Cigliano et al. 2021._Agroecia Brunner 1898: 266.—Orthoxiphus Dohrn 1905: 240.—Spada Karny 1907: 67.

Type species of Habetia: Agroecia spada Brunner, by monotypy (= Habetia spada), inherited from replaced name.

Generic diagnosis. Medium sized to moderately large but always narrow, slender species of nearly uniform coloration, in preserved specimens yellowish to light or medium brown; basic color of alive specimens unknown, at least some specimens might be green when alive. Face of same color as body, few species with a pair of black lateral bands and very rarely (only 2 specimens seen) face fully black; mandibles black in some species, of general color in others; antennal scrobae can be also partly darkened. Legs of general color, only the genicular area between hind femur and tibia black in some species. Tegmina of general color; cells between veinlets often darkened, but the intensity of the dark color and the area of tegmen concerned variable between specimens and species. Rarely, one species so far, the black color extends over a larger part of the body.

Face long-oval; fastigium verticis little projecting, the furrow between fastigium verticis and fastigium frontis only slightly expressed; all three ocelli present. Pronotum narrow elongate, disc with anterior margin convex or sometimes slightly concave in middle, dorsal surface convex, transverse furrows weak, posterior margin varying from slightly convex to truncate; apical area of disc often slightly elevated but not conspicuous; lateral lobes rather narrow, ventral margin faintly concave or substraight, descending posteriorly; area above thoracic auditory spiracle oval, little conchate; humeral sinus only faintly indicated. All femora with spines on both ventral margins. Prosternum with a pair of medium long spines. Hind knee lobes bi-spinose.

The genus Habetia has a similar habitus as the genus Philmontis Willemse, 1966, which is also in need of revision. Both genera share the general habitus with low lateral lobes of pronotum, also the male cerci show some basic similarity in that they have the apical area in-curved or with internal projection and a pre-apical widening of the cercus stem that arises however from dorsal margin in Habetia while from ventral margin in the type species of Philmontis, P. nigrofasciatus Willemse, 1966. The basic structure of the male titillators differs however strongly between both genera. The male titillators of Habetia are so far known unique and consist basically of a pair of sclerotized, curved stabs that are in some species nearly U-shaped curved. That most simple shape is modified by proximal and distal expansions connected by soft septa in the derived forms, while in Philmontis the titillators are simpler with compressed and sclerotized basal and central areas that are moderately widened and little out curved, while in apical area they are semi-sclerotized and terminate into an apical crest. The females of both genera differ strikingly by the shape of the ovipositor, which is prolonged and straight in Habetia but short and curved in Philmontis. Both genera differ also by the basic general coloration that is mostly of uniformly light color in Habetia but with extended black ornamentation, at least with black lateral bands on pronotum and tegmen in Philmontis.

Description. Fastigium verticis conical, shorter than scapus; ventral margin compressed, separated by a shallow sinuosity from fastigium frontis. Frons shining, sub-smooth with few shallowly impressed dots. Pronotum shining, sub-smooth; disc with lateral angles rounded, only in very apical area shouldered and disc faintly raised and flattened; anterior margin broadly rounded but truncate or slightly concave in middle; posterior margin slightly convex, almost straight, or truncate, in few species distinctly convex; first transverse sulcus little expressed, interrupted in middle; second sulcus distinct on paranota. Paranota longer than high; ventral margin slightly concave or almost straight, weakly descending posteriorly, ventro-posterior angle little produced, humeral sinus hardly expressed. Prosternal spines of medium length, shorter than coxa, only little varying between species. Mesosternal lobes varying from obtuse angular to little conical; metasternal lobes rounded or angularly rounded with hind margin often nearly 
truncate; medial plate with a spine at both posterior angles. Wings varying from just covering abdomen to distinctly surpassing hind knees; tegmen narrow, anterior margin convex in proximal area, narrowing posteriorly, in apical fourth to third with sub-parallel fore and hind margins; tip rounded; male stridulatory area free or only basal area little covered; hind wings of about same length as tegmen.

All femora with spines on both ventral margins, on ventro-external margin of hind femur spines often start behind basal quarter or third or rarely nearly in mid-length and increase in size toward end of femur; on ventrointernal margin of hind femur the spines start closer to base and are very small or minute in basal half, and often, but not in all species, there are long gaps between successive spines in apical half, and only a few distinct or long spines near tip, in other species there are no large gaps and the spines increase regularly in size to tip. Knee lobes of fore and mid femur with a spine on both sides, posterior spine on anterior femur often small; hind femur bi-spinose on both sides, as exception in very few specimens only uni-spinose on one hind femur but not on both. Anterior tibia with tibial tympana conchate, anterior surface below tympana convex or flattened with both angles rounded, posterior angles provided with spines.

Coloration. Most species of uniformly light general color, in museum specimens yellowish or brown, in few with remnants of green; alive individuals might be often green. Face of general color, only few species with black ornaments; mandibles either of general color or partly or fully black. Tegmen usually with little suspicious dark spots within cells, in some individuals or species these dark spots very conspicuous thus that the tegmen appears brown with the veins and veinlets yellowish. Female ovipositor for the greatest part light brown, sometimes darkened.

Male. Cerci elongate, little curved or nearly straight, with a subapical or apical internal process that usually divides at tip; cercus trunk at least in apical area with a dorsal rim or other elevation varying in shape between species. Subgenital plate in basal area broad, apical area varying between species; the apical margin can be incised, subtruncate, projecting, or divided into a pair of more or less upcurved projections that carry the short styli at tip.

Male phallus. The basic shape of the sclerotized parts of the male phallus consists in the simplest form of a pair of about $U$-shaped titillators that have the basal area connected by a very narrow septum but are still somewhat moveable against each other, with the very base free, faintly widened, and little curved, while the end of the titillators is truncate or rounded without modifications. That basic shape is found, with variations, in the largest species of the genus. In two of them, the subgenital plate shows unique modifications. In most species of the genus the titillators are modified and can become highly complex in some of them. One of the most common modification is the division of both titillators at about the curvature into pairs of basal and apical branches. While the basal branches are rather short and less modified, the apical branches are prolonged and modified in various ways. The structure can become more complex by semi-sclerotized septa between the basal and the re-curved apical area or by the separation of the apical areas from the basal branches. Apart from that there exists a pair of elongate lateral sclerites that are formed of a central spindle with three projecting lamellae that are widest in about mid-length, narrow at both ends; and there is also a pair of small rounded sclerites in the membranes on top of the titillators. The latter two pairs of sclerites are rather uniform between species except for size.

Female. Subgenital plate variable between species, often with basal area rather strongly upcurved on both sides, ventral disc prolonged behind and terminating into a pair of usually upcurved, spine-like projections. Ovipositor laterally compressed and long to very long and, except at base, straight, with shape and length varying between species; the dorsal margin varies and can be straight, convex, or strongly raised. The valves of the ovipositor are laterally compressed and obtuse at tip thus probably not strong enough to burrow into the soil. The ovipositor might be adapted to deposit eggs into the leaf-sheaths of tall grasses or other plants. Oviposition in plant tissue is also known for other Conocephalinae.

Discussion. The genus Habetia comprises species with very long ovipositor, which is about one and a half time as long as the body from head to tip, and other species, in which the ovipositor is about as long as the body. In both groups the female subgenital plate ends into a pair of long apical projections with acute tip, and in most species the baso-lateral area of the subgenital plate is, to a variable degree, extended dorsad. In few species it is only faintly or not dorsally extended, e.g., in the type species $H$. spada. The males that belong to species with very long female ovipositor have so far known always sclerotized but simple, strongly curved and thus nearly U-shaped titillators, while males of species with moderately long female ovipositor have more complex titillators by adding additional branches or connecting septa between more basal and apical areas. But their basic shape is also based on the Ushaped curvature. An intermediate species is $H$. dentata sp. nov. that has simple titillators as in the first group but the female subgenital plate resembles more the species in the second group. 
Regarding the male subgenital plate, there are several species-specific modifications. But in most species, they consist of a basal disc with convex and upcurved lateral margins, that are toward end narrowed and with straight or little concave lateral margins and then end into narrow extensions with the styli at tip. In the males that belong to species with long female ovipositor the apical extensions are rather short, while in the second group the apical extensions are usually strongly prolonged and usually upcurved. From the species of the first group, the subgenital plate of $H$. pedala sp. nov. is most closely to an intermediate form.

The stridulatory file on the underside of the male left tegmen also shows a difference between both groups of species. In the large species there is a distinct step in the subapical area of the file that is missing in the file of the smaller species. However, in $H$. dentata, that agrees in titillators with the species of the first group, there is a weak step in subapical area of the file, which is thus intermediate between the shapes of the files in both groups.

A common character uniting both groups is the basic shape of the male cerci that are cylindrical or slightly conical and little curved mediad or substraight. They carry in apical area a dorsal carina or a crest and are provided at or little before end with a compressed internal projection that is at end divided into two short branches, which vary however between species in size, length, and orientation, in few species one of the apical branches is reduced. Only $H$. dentata has that basic shape of the cerci more strongly modified.

\section{Tentative key to the species of the genus Habetia}

Remarks. (1) As not all species covered by the current publication are known from both sexes, it is advisable to run through the keys for both sexes. When the results are identic one may be certain of the outcome. (2) The key is mainly based on external characters to ease identification even of alive specimens. In case of doubt, it is however advisable to check also the male titillators especially if there is any evidence that it might belong to an unknown species not covered by the current publication.

\section{Key to species-Females}

1. Large species. Females with very long ovipositor $(55-70 \mathrm{~mm})$ which is about twice as long as the hind femur or longer and has the dorsal margin sub-straight or slightly convex and not or only little widened in basal half or around mid-length (Figs

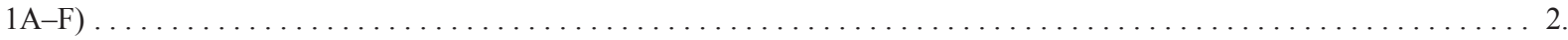
Medium sized species. Females with ovipositor about as long as hind femur or little longer or shorter (19-33 mm); rarely (1 species only) almost 1.5 times as long as hind femur; the dorsal ovipositor valves are in some species markedly widened with strongly convex dorsal margin, but in most species only little widened or as narrow as in the species with long ovipositor (Figs

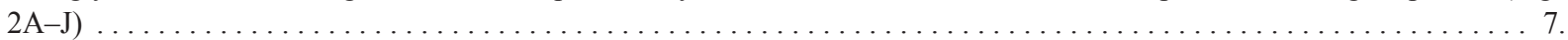

2. Subgenital plate nearly flat but slightly up-bent from both sides of midline, with a medial furrow, lateral margins straight and little converging toward hind margin; with little angularly incised apical margin; from apical lateral angles with up-bent spine-

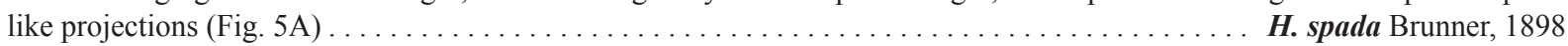
Subgenital plate of different shape; often with strongly up-curved lateral margins that are often dorso-laterally extended in basal

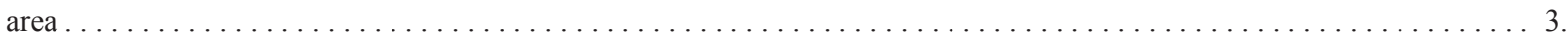

3. Subgenital plate with surface from apical margin to about half the length of the plate replaced by a thin, semi-membranous surface with sub-truncate apical margin (Figs $5 \mathrm{~B}-\mathrm{C}$ ); lateral margins only little upcurved, only at base with a narrow, dorsally projecting lobe; lateral margins of disc projecting at end into upcurved spine-like projections from apical lateral angles (Fig. $7 \mathrm{~K}) \ldots \ldots \ldots \ldots \ldots \ldots \ldots \ldots \ldots \ldots \ldots \ldots \ldots \ldots \ldots \ldots \ldots \ldots \ldots \ldots \ldots \ldots$. multispinulosa Griffini, 1908 Subgenital plate without semi-membranous apical area, strongly sclerotized throughout; dorsally expanded lateral areas wider

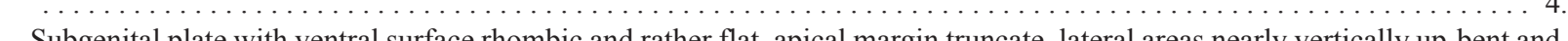
mainly in basal area, strongly extended dorsad; spine-like projections arising from apical lateral angles rather short and thin

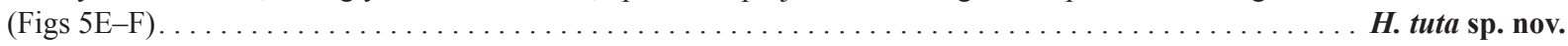
Subgenital plate of different shape; apical spine-like projections longer and/or stouter $\ldots \ldots \ldots \ldots \ldots \ldots \ldots \ldots$.

5. Subgenital plate nearly bowl-shaped with apical and lateral areas more strongly upcurved, apical margin angularly incised, apical spine-like projections very stout in proximal area, curved dorso-mediad while narrowing posteriorly into acute tip (Fig.

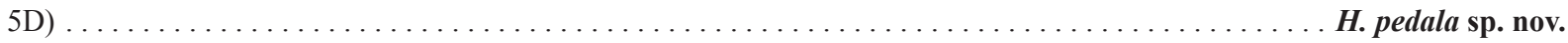
Subgenital plate with lateral areas strongly upcurved but apical margin only little upcurved except for upcurved apical spines; apical margin sub-truncate, spine-like projections rather narrow, running parallel or only little approaching toward tip (Figs

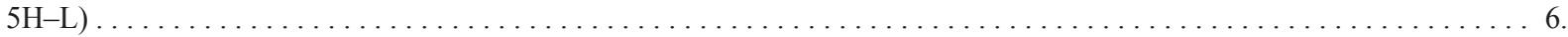

6. Subgenital plate in ventral view with more strongly converging lateral margins, also the apical, spine-like projections distinctly converging; the septum connecting the bases of these projections wider and faintly bilobate (Fig. 5G) ... H. curvata sp. nov. 
Subgenital plate in ventral view with more or less converging lateral margins, the apical, spine-like projections are nearly straight, pointing nearly apico-dorsad, apical margin of disc between bases of these projections narrowly upcurved and straight

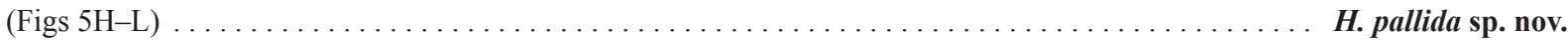

7. Subgenital plate with four acute projections; one pair arising from the upper ends of the lateral margins and the other pair from

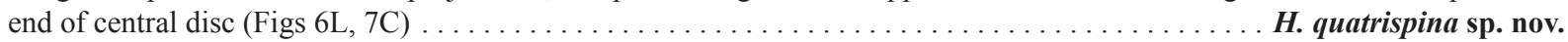
Subgenital plate with only one pair of apical spine-like projections at end of central disc $\ldots \ldots \ldots \ldots \ldots \ldots \ldots \ldots$.

8. Face with a pair of black lateral stripes, rarely interrupted, or fully black (Figs $4 \mathrm{~A}-\mathrm{D}) \ldots \ldots \ldots \ldots \ldots \ldots$.

- $\quad$ Face of uniformly light color, but often mandibles black; also, the antennal scrobae can be darkened (Figs 4E-L) ..... . 10.

9. Subgenital plate with basal and lateral areas angularly upcurved in a roughly $90^{\circ}$-angle and at very base bent again anteriorly and little widened laterally; apical margin only little incised, ending into two short lateral lobes; from subapical area of disc with a semi-oval, compressed, projecting lobe covering apical incision of plate in middle (Fig. 6F). Ovipositor behind basal stricture

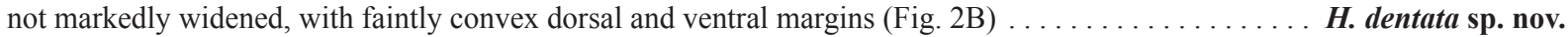
Subgenital plate not angularly upcurved at base, but in basal area with long dorso-lateral expansions; disc of plate elongate, terminating into a pair of long, subacute, apical lobes, long and widely incised in between (Figs 6A-B, 7A-B). Ovipositor behind basal stricture markedly widened and then gradually narrowed to tip (Fig. 2A) . . . . . . . . H. bivittata sp. nov.

10. Ovipositor with dorsal valves markedly widened with strongly concave dorsal margin (Fig. 2C). Subgenital plate in ventral view with a nearly rectangular carinate ventral projection in apical half that has rounded angles and ends into two triangular projections (Figs 6J); that structure is properly the apical margin, which is not visible in strict lateral view (Fig. 7M) . . . . .

H. elevata sp. nov. Ovipositor with dorsal valves not or only slightly widened with dorsal margin little concave or nearly sub-straight around midlength. Subgenital plate of different shape, terminating into a pair of narrow lateral projections that are visible in strict lateral

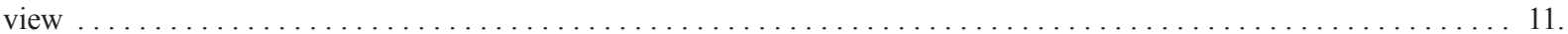

11. Subgenital plate with central area rather narrow with curved and strongly sloping lateral margins that terminate into narrow triangular, upcurved and approaching projections with acute tip, apical margin incised in between; basal area of plate in center little, towards lateral margins strongly bulging, upcurved and forming a wide, compressed lateral rim along both sides of the

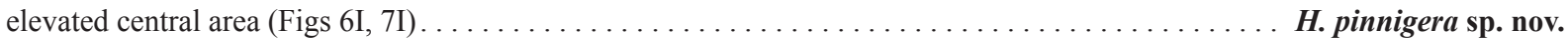
Subgenital plate of different shape; dorsally projecting lateral lobes restricted to basal area of plate $\ldots \ldots \ldots \ldots \ldots 12$.

12. Subgenital plate with up-bent lateral areas narrowing towards dorsal end but dorsal end triangularly widened and separated from preceding area by a furrow $($ Figs $6 \mathrm{~K}, 7 \mathrm{H}) \ldots \ldots \ldots \ldots \ldots \ldots \ldots \ldots \ldots \ldots \ldots \ldots \ldots \ldots \ldots \ldots \ldots$ sorcula sp. nov. Subgenital plate with up-bent lateral areas often rather high and rounded at dorsal end; in dried specimens often furrowed or folded along midline of ascending area, which might however be a deformation caused by the drying process (compare Figs $7 \mathrm{~F}$

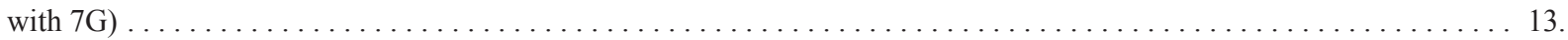

13. Disc of subgenital plate with a wide transverse furrow in sub-basal area, either markedly outlined at posterior end or gradually merging into the posterior area of disc that is also little sunk-in between the stiffened lateral margins; lateral margins of disc

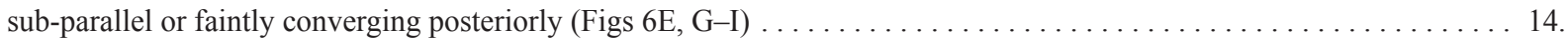
Disc of subgenital plate with a narrow transverse furrow in sub-basal area and with lateral margins more strongly approaching posteriorly with surface of disc in more apical area at same level with the lateral margins (Figs 6C-D) . . . . . . . .

14. Subgenital plate rather wide with concave anterior margin; baso-lateral projections only little upcurved, in lateral view dorsal margin between basal widening and apical projections only little declining (Fig. 7E); in ventral view, strengthened lateral margins of disc only slightly approaching each other posteriorly; apical margin with wide concave incision between acute,

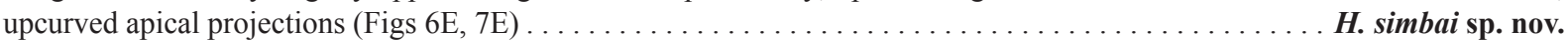
Disc of subgenital plate with basal margin moderately concave, lateral margins of basal area rather largely upcurved into compressed baso-lateral projections, in lateral view dorsal margin between basal widening and apical projections strongly declining (Fig. 7D); in ventral view, behind narrow anterior margin with a wide oval groove with swollen margins; afterward the swollen lateral areas running subparallel but continuously narrowing into long projections with subacute tips (Figs 6G-H)

H. kondiu sp. nov.

15. Ovipositor shorter than body (Fig. 2J). Hind knees black. Subgenital plate mostly dark brown and black, darker in lateral areas than in center; baso-lateral extensions more strongly up-bent, little visible from below, with nearly parallel margins and rounded end (Fig. 7N-O); disc at end roundly incised with acute apico-lateral projections that are only little upcurved (Fig. 6C) . . . . .

H. nigricauda sp. nov. Ovipositor about as long as body. Hind knees of general color or with only small black spots. Subgenital plate of general color, rarely with a broad brown band in middle; baso-lateral extensions less strongly up-curved, clearly visible from below (Fig. 6D), in lateral view long-oval in dried specimens often folded (Figs 7F-G); disc at end subtruncate or faintly concave with acute projecting apico-lateral projections that are more strongly upcurved (Fig. $7 \mathrm{~F}) \ldots \ldots \ldots \ldots \ldots \ldots \ldots \ldots \boldsymbol{H} \ldots \ldots \boldsymbol{w}$ sp. nov.

\section{Key to species-Males}

1. Subgenital plate with apical margin narrow or wide, convex or truncate with projection from dorsal surface, or incised for no more than one quarter of the total length of the subgenital plate (Figs 11A-E). Phallus with a pair of sclerotized, separate and strongly curved titillators with simple or widened apical areas that are not divided into basal and apical branches or without

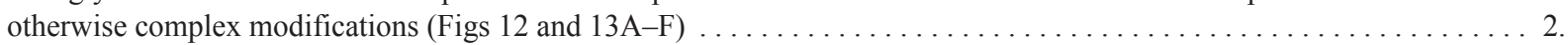
Subgenital plate in about apical third divided into a pair of narrow and widely spaced lateral lobes curved dorso-posteriorly or even curved dorso-anteriorly and then not fully visible from below (Figs 10E, G, 11F-K). Phallus with a pair of sclerotized 
titillators usually of complex shape and often divided at curvature into basal and apical branches (Figs 15-16); if simply curved and not divided then sub-basal areas of titillators fused and tips provided with teeth (Figs $13 \mathrm{G}-\mathrm{H}) \ldots \ldots \ldots \ldots$.

2. Subgenital plate with small styli closely approached to each other, narrow apical margin between bases of styli truncate or little convex, surpassed by the narrow projecting end of the subgenital plate or by two elongate projections from above dorsal surface

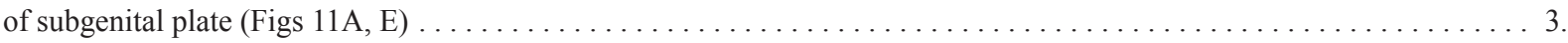
Subgenital plate with apical margin roundly or angularly incised in middle; without projection between bases of styli (Figs

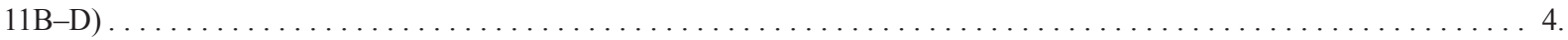

3. Subgenital plate deeply divided from base into a pair of semi-oval, strongly convex lateral halves connected at end by a short dorso-ventrally compressed apical area with straight hind margin (Fig. 11A). The hind margin is surpassed by a pair of laterally compressed elongate sheaths that are fused at bottom and form a shelter for the phallus with titillators when at rest (Figs 8B, 12A). Titillators forming simple, nearly U-curved sclerites with slightly narrowing, obtuse tip (Figs 12B-C) . H. tuta sp. nov. Subgenital plate roundly incised from base; lateral margins rounded, toward apical area elevated and at end forming a long, acute-triangular projection on dorsal side, while the ventral disc is rounded at end and only in midline extended behind into a long and narrow keel of the apical projection; the small styli are inserted at end of ventral disc on both sides of the ventral keel (Fig. 11E); the oblique dorso-apical end of that projection is provided with black transverse teeth of increasing size from tip to proximal area (Figs 12F, 14F). Titillators narrow throughout, faintly widened between compressed basal and little stouter distal area, the latter curved for more than $180^{\circ}$, tip truncate (Figs $12 \mathrm{G}-\mathrm{I}$ ) $\ldots \ldots \ldots \ldots \ldots \ldots \ldots \ldots$. $\ldots \ldots$ imitatrix Karny, 1912

4. Subapical internal projection of male cerci terminating into a pair of acute tips. $\ldots \ldots \ldots \ldots \ldots \ldots \ldots \ldots \ldots \ldots$. Subapical internal projection of male cerci terminating into a single acute tip; the posterior tip is reduced to a tubercle in basal half of hind margin (Figs 11D). Titillators with a strong bulge from ventro-proximal margin of distal area (Fig. 19F). . . . . .

H. curvata sp. nov.

5. Subgenital plate with lateral carinae little projecting beyond subtruncate hind margin that has a short triangular incision in middle which is shorter than the length of one stylus (Fig. 11B). Titillators with a weak bulge from ventro-proximal margin of

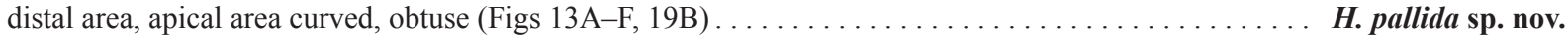
Hind margin of subgenital plate between bases of styli triangularly incised, with incision markedly longer than one stylus (Fig. 11C). Titillators nearly angularly bent in about mid-length, apical area narrow, only moderately curved, with dorso-distal margin constricted in middle, tips narrowed (Figs 12D-E) $\ldots \ldots \ldots \ldots \ldots \ldots \ldots \ldots \ldots \ldots \ldots \ldots \ldots \ldots \ldots \ldots$ pedala sp. nov.

6. Cercus behind mid-length bent angularly mediad, forming an anteriorly-posteriorly compressed process with convex distal and little concave proximal surface with wrinkles; the process carries along dorsal margin a cone-shaped process with small globular tip followed by a wavy lamella along dorsal margin (Figs 10A-C). Face with a pair of black lateral stripes (Fig. 4D). Titillators simply curved, in sub-basal area subfused; at tip compressed and provided with about 5 teeth (Figs $13 \mathrm{G}-\mathrm{H}) \ldots \ldots$. .

H. dentata sp. nov. Cercus at or around apical area with a laterally compressed wavy or simply rounded lamella along dorsal and/or apical margin, shape and size varying between species (Fig. 9) or without lamella; in both cases just before cercus end with a narrow, compressed, internal process that terminates into one or two short spinules. Face unicolorous pale or with a pair of black lateral

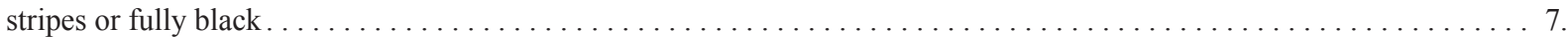

7. Subgenital plate in divided apical area strongly recurved, with apical area pointing dorso-anteriorly and thus not visible in strict ventral view (Figs 10E-F). Cerci narrow elongate and in apical area little curved; just before rounded tip with a strong and flattened projection with approaching lateral margins that at end is curved proximad and terminates into an acute tooth (Fig. $10 \mathrm{H})$. Titillators fused except at both ends, at end dividing into short proximal and short distal branches that support a white

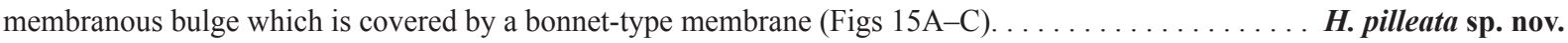
Subgenital plate in divided apical area only moderately upcurved, its end visible from below $\ldots \ldots \ldots \ldots \ldots . .$.

8. Face with a pair of black lateral stripes or fully black Figs $4 \mathrm{~A}-\mathrm{C}$ ). Tenth abdominal tergite with apical margin wide, roundly incised; resulting lobes at end compressed and bent posteriorly (Fig. 9A). Cercus in apical area around dorsal and apical margin with a large, laterally compressed lamella with wavy margin; apical-internal projection dorso-ventrally compressed with converging lateral margins and little curved in basal area, it divides before end into a short proximal cone with an acute spinule at tip and a longer, compressed and at base curved distal lobe with rounded tip that also carries an acute spinule (Figs 9A-C). Titillators very complex, with proximal and distal projections that are connected by semi-sclerotized membranes as in

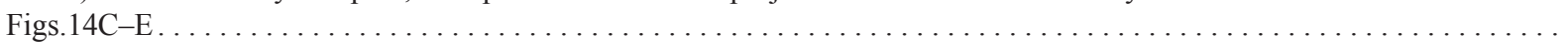

$\ldots \ldots \ldots \ldots \ldots \ldots \ldots \ldots \ldots \ldots \ldots \ldots \ldots \ldots \ldots \ldots \ldots \ldots \ldots \ldots \ldots \ldots \ldots \ldots$ bivittata sp. nov. Face unicolorous pale (Figs 4E-L). Cercus in apical area on dorsal and/or hind margin with a simply rounded dorsal or apical projection; compressed apical-internal projection with two spines or tubercles at end (Fig. 9D-H) $\ldots \ldots \ldots \ldots \ldots$.

9. Tenth abdominal tergite wide roundly incised with apical end of resulting lobes rounded. Cercus with subapical internal projection rather long, in basal area markedly curved proximad with approaching margins, afterward narrow with parallel margins and faintly re-curved, terminating into a pair of short apical teeth with acute tip of sub-equal size (Fig. 9G). Titillators very complex, with proximal and distal projections that are connected by semi-sclerotized membranes as in Figs $15 \mathrm{D}-\mathrm{H} \ldots \boldsymbol{H}$. wau sp. nov.

Cercus with subapical internal projection wider and shorter, with converging margins at least in basal half. $\ldots \ldots \ldots 10$.

10. Tenth abdominal tergite with hind margin only little concavely incised but in middle extended into a narrow, rounded incision. Cercus with apical dorsal lamella swollen; apical internal projection with converging margins in basal half, with subparallel margins in apical half, terminating into a pair of blunt teeth or tubercles at tip (Fig. 9F). Titillators with proximal projections subfused; distal projections entire, with two strong curvatures (Figs $16 \mathrm{~J}-\mathrm{L}) \ldots \ldots \ldots \ldots \ldots \ldots \ldots$ H. lalibu sp. nov. Cercus with apical dorsal crest more or less compressed, reaching or surpassing hind margin of cercus; apical internal projection with converging margins throughout, at tip with a pair of acute teeth standing nearly above each other $\ldots \ldots \ldots \ldots 1$. 
11. Tenth abdominal tergite strongly, triangularly incised from hind margin to nearly basal area, resulting lobes obtuse angularly rounded (Figs 9D). Cercus with apical dorsal crest running around and surpassing hind margin of cercus; internal process flattened, terminating into two acute teeth standing above each other (Figs 9D-E). Titillators with apical area of distal projection completely divided from basal area forming a separate arm (Figs $16 \mathrm{D}-\mathrm{I}) \ldots \ldots \ldots \ldots \ldots \ldots \ldots \ldots$ H. kondiu sp. nov. Tenth abdominal tergite with hind margin obliquely truncate, interrupted in middle by a short and narrow, rounded incision (Fig. 9H). Cercus with apical dorsal crest restricted to dorsal margin; apical-internal projections stout, little narrowing towards end and terminating into a pair of strong acute teeth of subequal size (Fig. 9H). Titillators with apical area of distal projection forming a hinge with basal area allowing articulation of both parts against each other (Figs $16 \mathrm{~A}-\mathrm{C}) \ldots \ldots$. . . simbai sp. nov.

\section{Taxonomic descriptions of species studied}

The species of Habetia are rather uniform in general habitus and coloration but differ markedly in sex specific characters. The general characters are already extensively described under genus. The description of the species is thus focused on male and female specific characters.

\section{Habetia spada (Brunner v. Wattenwyl, 1898)}

Figs 1A, 3G, 5A, Map 1(1).

Holotype (female): Papua New Guinea, Madang, Konstantinhafen [= Enke Port, the label reads "Konstantinshafen

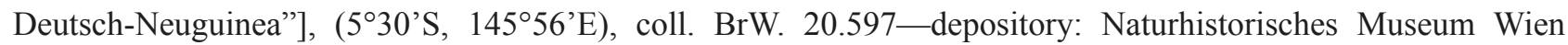
(NMW).

Diagnosis. $H$. spada differs from other species by the shape of the female subgenital plate that is flattened and has the lateral margins not markedly upcurved, the apical margin is wide-triangularly incised and the spines at apico-lateral angles are nearly rectangularly upcurved. The females from Toricelli Mountains that Karny identified as $H$. spada, however, differ significantly from the type of $H$. spada by the shape of the subgenital plate despite of the general similarity between both taxa as described below under $H$. pedala $\mathbf{s p . ~ n o v . , ~ w h i c h ~ h a s ~ a ~ d o m e d ~ s u b g e n i t a l ~}$ plate while in $H$. spada it is flattened.

Description. Index fastigium verticis : eye diameter $1.70: 1.96 \mathrm{~mm}$. Coloration of face of light general color; mandibles fully black; antennal scrobae and tip of fastigium frontis light brown (Fig. 3G). Femora with the following number of spines on ventral margins: Femur spines: (1) a 6 p 8; (2) a 7 p 3; (3) a 12-14 p 13-14.

Male unknown.

Female. Subgenital plate rather flat with converging lateral margins and with a medial furrow; at posterior-lateral angles with up-bent, acute cones; apical margin between cones wide, triangularly incised (Fig. 5A). Ovipositor about one and half time as long as body; behind basal constriction straight with dorsal valves in basal half only faintly convex (Fig. 1A).

Measurements ( 1 female).-Body w/o wings: 42; pronotum: 9.3; tegmen: 38; hind femur: 28.5; ovipositor length: $63 \mathrm{~mm}$.

\section{Habetia imitatrix Karny, 1912}

Figs 8A, 11E, 12F-I, 14F, 18D, Map 1(2).

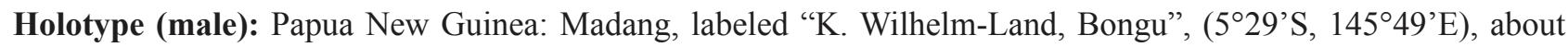
1910, collector and date not stated—depository: Senckenberg Museum für Tierkunde Dresden (SMTD).

Discussion. The only known specimen of H. imitatrix, the male holotype, is in general characters very similar to the type of $H$. spada, a female. Both taxa are known from a single specimen each. The type localities of both taxa are located very close to each other or are maybe identic: Konstantinhafen has been one of the old German settlements in New Guinea, while Bongu is not a locality but the name of a tribe living in the area about $30 \mathrm{~km}$ South of Madang (Hempenstall 2016), that is close to Enke Port. Karny (1912) might have been not aware of these facts when he described $H$. imitatrix. This raises the question if the female type of $H$. spada and the male type of H. imitatrix might belong to the same species. However, there are localities that house two different species of the genus Habetia. Moreover, both taxa are known from a single specimen, and these specimens are of the opposite sex. 
It is thus better to wait with any nomenclatural changes until more specimens of both taxa become available to solve this question, preferably male and female found together.

Diagnosis. The male of $H$. imitatrix is unique for the shape of the subgenital plate that has the central area prolonged behind and that area shaped like a hood that carries on apico-dorsal margin a row of teeth of decreasing size toward end, and the styli project laterally from the subgenital plate not from apical margin as in all other species (Figs 12F, 14F).

Description. General habitus of the genus. Coloration of face of general color; mandibles fully black; antennal scrobae with indistinctly darkened spot at ventro-internal angle. Femora with the following number of spines on ventral margins: (1) a 6 p 6; (2) a 7 p 3; (3) a 9-12 p ca $11(n=1)$.

Male. Stridulatory file on underside of left tegmen with a distinct step in distal area; file length $2.50 \mathrm{~mm}$ with 78 teeth, of which narrow curved basal area $0.25 \mathrm{~mm}$ with 8 teeth, central area $1.58 \mathrm{~mm}$ with 37 teeth, step $0.15 \mathrm{~mm}$ with 5 teeth, narrow apical area $0.54 \mathrm{~mm}$ with 28 teeth (Fig. 18D). Tenth abdominal tergite with convex surface; from hind margin with a long and narrow oval incision closed from behind by projecting acute angles from tip of resulting gap. Cerci moderately curved and little narrowing towards end; from little before mid-length with a dorso-ventrally compressed inner ridge that widens to a wide and compressed internal process, which divides towards end into two compressed, wide, and little curved lobes, the proximal branch little larger than the distal branch, both with a minute denticle at tip, the proximal branch also with a dorsal carina from base of process; inner surface of cercus between these projections and upper margin little concave and terminated dorsally by a narrow rim (Fig. 8A). Subgenital plate roughly semi-circular with a long and narrow medial projection; in ventral view deeply incised from base and membranous between resulting oblique anterior margins; sclerotized area with convex and later concave lateral margins forming a long and narrow apical projection with a fine medial carina and acute and laterally compressed tip; this rather high and towards ventral margin laterally compressed projection obviously results from a widened fusion of the dorsal lateral margins with the ventral, medial carina, it is in lateral view obliquely truncate at end and carries 3 larger transverse teeth in upper and a few minute denticles in lower area (Figs 11E, 12F, 14F). Titillators mostly black; at base little recurved and with narrowing margins, then straight and approaching each other; before performing a curvature slightly widened and diverging, then performing a more than $180^{\circ}$ curve, in apical area straight with parallel margins and truncate but with shortly recurved tip (Figs 12G-I); lateral sclerites elongate, of same color as titillators, with rounded ends and a small notch in about mid-length.

Female unknown.

Measurements (1 male).—Body w/o wings: 35; pronotum: 9.3; tegmen: 33.5; hind femur: $24.5 \mathrm{~mm}$.

\section{Habetia multispinulosa Griffini, 1908}

Figs 1E-F, 3H, 5B-C, 7K, Map 1(10).

Holotype (female): Papua New Guinea: Central, Dilo, 1.vi.-31.vii.1890, leg. Loria—depository: Museo Civico di Storia Naturale "Giacomo Doria", Genoa (MCSN).

Other specimen studied: Papua New Guinea: Rigo, Dorom, (942'S, 147²4'E), 1.-30.xi.1921, leg. R. Neill— 1 female (London NHM).

Note on type locality: The type locality of $H$. multispinulosa, Dilo, could not be traced on any map or online source. However, it is known that the collector, Loria, an Italian anthropologist who also collected insects, studied in an area which, at that time, was British New Guinea. According to the data in Dimpflmeier (2019) the area that Loria visited during June and July 1890 , should lie roughly between Maopa $\left(10^{\circ} 8^{\prime} \mathrm{S}, 148^{\circ} 1\right.$ 'E) in the SE, Dorom (see above) and Gabagaba ( $\left.9^{\circ} 48^{\prime} \mathrm{S}, 147^{\circ} 31^{\prime} \mathrm{E}\right)$ in the NW, thus, close to the locality of the second specimen studied.

Diagnosis. In general habitus H. multispinulosa resembles $H$. spada and the other four species known to have females with an extremely prolonged ovipositor. It differs from all in the shape of the subgenital plate although a basically rhombic shape with a pair of apical spines is common to all of them. In contrast to the subgenital plate of H. spada that has the lateral margins slightly thickened but not upcurved, the lateral margins in $H$. multispinulosa are moderately laterally upcurved but not as strongly as in $H$. pedala sp. nov., $H$. tuta sp. nov. and $H$. curvata $\mathbf{s p}$. nov., while the apical spines are strongly up-bent as in H. spada. It differs from all of them by the subgenital plate that has in basal area a medial furrow but in about mid-length an angular fold that separates a strongly sclerotized anterior area from a thinner, semi-membranous apical area, which is so far unique within the genus. 

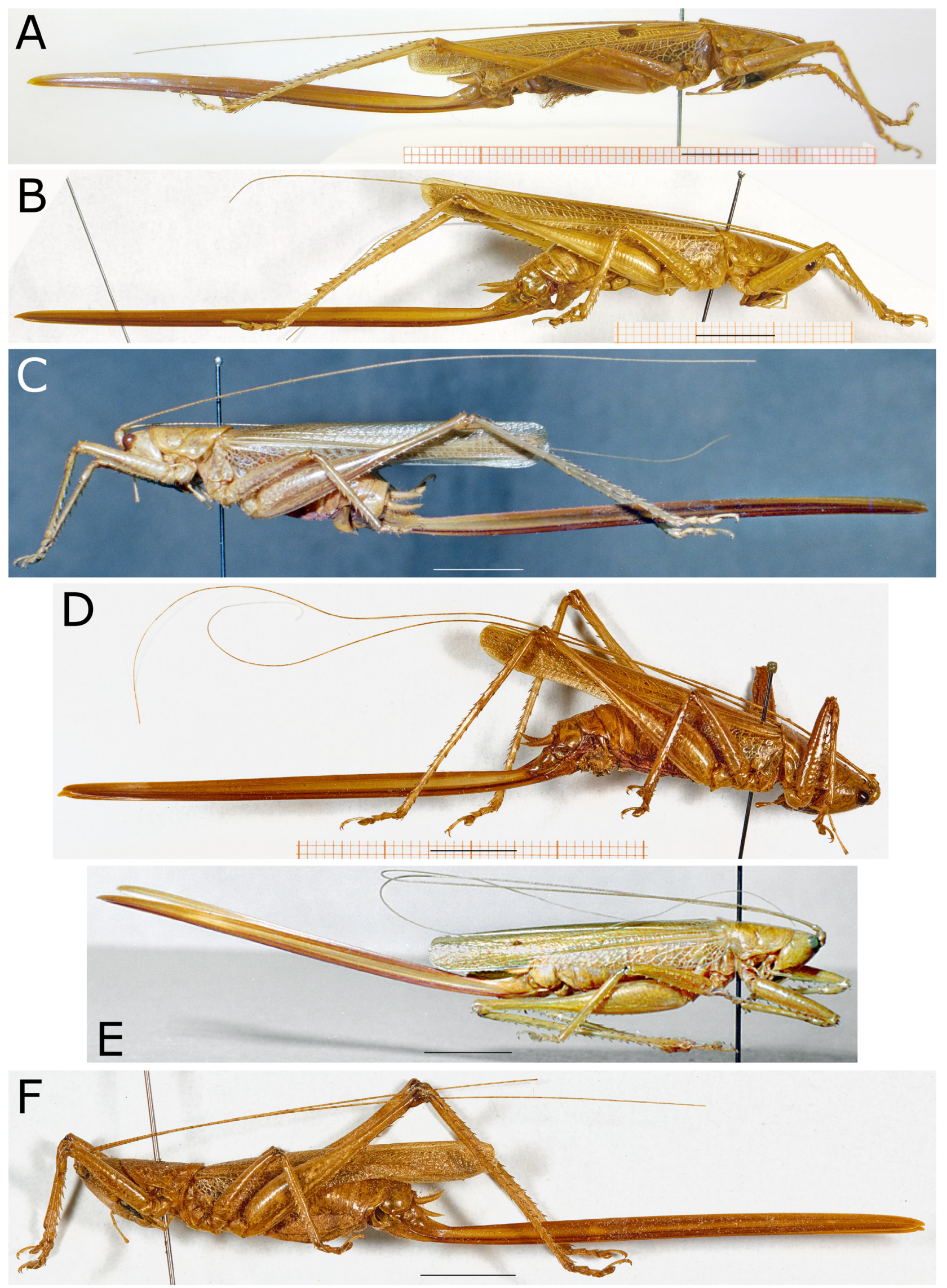

FIGURE 1. Habetia sp. females: habitus lateral view; species with very long ovipositor: A. H. spada (Brunner, 1898) holotype; B. H. tuta sp. nov. (Keram River); C. H. pedala sp. nov. (Toricelli Mts); D. H. pallida sp. nov. (Sentani); E-F. H. multispinulosa Griffini, 1908 (E holotype, F Rigo Dorom). Scales 10 mm. 
Description. Coloration of face uniformly pale, of general color; mandibles fully black; inner area of antennal scrobae partly brown. Femora with the following number of spines on ventral margins: (1) a 6-7, p 8; (2) a 6-7, p 4; (3) a 10-14, p 10-16 (n=2).

Male unknown.

Female. Subgenital plate about rhombic with concave anterior margin and little upcurved lateral margins, divided into two halves by a medial furrow; apico-lateral angles provided with acute upbent cones; apical margin of plate triangularly incised but that area filled by a less strong septum that connects the diverging margins unto the bases of the apical spines. Ovipositor about one and a half time as long as body; behind basal constriction straight with dorsal valves only faintly convex but not raised.

Measurements ( 2 females).-Body w/wings: 44; body w/o wings: 33-37; pronotum: 8.8-9.0; tegmen: 32-33; hind femur: 24.0-24.5; ovipositor length: 55-58; ovipositor height: $2.5 \mathrm{~mm}$.

\section{Habetia tuta sp. nov.}

Figs 1B, 3C, 5E-F, 8B, 11A, 12A-C, 18A, 20H, Map 1(3).

Holotype (male): Papua New Guinea: East Sepik, Lager am Rosensee [= Lake Chambri], $\left(4^{\circ} 18^{\prime} \mathrm{S}, 1^{\circ} 3^{\circ} 7^{\prime} \mathrm{E}\right)$, 16.ii.1913, leg. Bürgers (KAE 267)—depository: Museum für Naturkunde Berlin (ZMB).

Other specimens studied: Papua New Guinea: East Sepik, Lager am Töpferfluß [= Keram River], (42ㄱ'S,

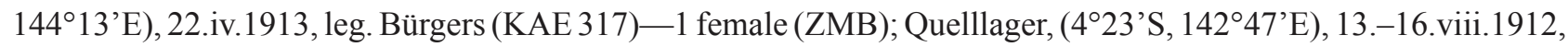
leg. Bürgers (KAE 128) - 1 male (paratype) (ZMB).

Diagnosis. The new species differs from its congeners by the titillators that form a pair of simple curved beams that are never markedly widened and have the apical area almost fully recurved (about $150-160^{\circ}$ ) against the truncate basal stem and are slightly narrowed but obtuse at tip; while in the other species with simple titillators the apical area is either less strongly recurved and has widened and/or narrowed sections in the apical area (H. pallida sp. nov., $H$. pedala sp. nov.) or the apical area is recurved against the basal area for little more than $180^{\circ}$ and has the tip broadly truncate $(H$. imitatrix), or the tip of the titillators is dentate ( $H$. dentata sp. nov.). The male cerci have the apico-internal process compressed and at tip divided into a spined dorsal and an obtuse ventral lobe in $H$. tuta sp. nov. while in H. pallida, that has the most similar cerci, the dorsal lobe is truncate, only half as long as the ventral lobe and not really separated from it, the ventral lobe terminates into an acute tip and the internal surface of the cercus is provided with a little wavy projecting ridge, in $H$. pedala the apical internal tooth is divided at end into a pair of stout acute teeth of equal length, in H. imitatrix the apical projection of the male cercus is dorso-ventrally compressed and widened and both apical lobes carry a minute spinule at tip, and in $H$. dentata the apical internal projection of the male cercus is prolonged and strongly modified.

Description. Coloration of face uniformly pale, of general color; lateral areas of face and genae little darker than central area of face, which might be due to conservation; antennal scrobae faintly darkened; mandibles black with few small yellow and dark red spots. Femora with the following number of spines on ventral margins of legs: (1) a 5-8, p 4-8; (2) a 7, p 2-4; (3) a 11-15, p 14-16 (n=3).

Male. Stridulatory file on underside of left tegmen with a distinct step in distal area, in holotype with 66 teeth, of which 7 narrow teeth at base, 36 in main part of file, 5 at a step, 13 clearly separated at end, and 6 of decreasing size at end (Fig. 18A), in paratype with 69 teeth, of which 8 narrow teeth at base, 35 in main part of file, 5 at a step, 13 clearly separated at end, and 6 of decreasing size at end. Mirror behind stridulatory file with straight anterior and posterior margins and convex lateral margins; slightly longer than wide, greatest width anteriorly. Tenth abdominal tergite transverse, in midline furrowed and at fore margin with an obtuse-angular incision filled by membrane, from hind margin with a narrow elongate triangular sub-membranous area; fully sclerotized areas with apical margin obtuse-angular but with rounded angle above bases of cerci (Fig. 8B). Cerci in about basal half roughly cylindrical, in apical half with an obtuse dorsal carina and strongly concave internal surface; at end of cercus, at dorsal margin from nearly tip, at ventral margin from beginning of apical third with a large internal projection with concave proximal surface that is before end divided into a short rounded dorsal process with narrowing margins that ends into an acute black spine, and into a small compressed ventral flap that is curved posteriorly, surpasses the dorsal spine, and carries a minute black spinule at tip (Fig. 12A). Subgenital plate with convex lateral margins that form in basal two thirds a wide, dorso-ventrally compressed rim that frame the strongly convex central area that is dived from 
base to nearly apical third into a pair of ovoid hemispheres; apical area short and narrow, flattened and with a faint median carina, with two short styli (Fig. 11A); above the subgenital plate there is a semi-tube-shaped sclerotized phallus sheath that holds the phallus when at rest, it has the dorsal margins faintly granular and terminates into a pair of separate rounded lobes (Fig. 8B). Its function is unknown. Titillators simple, laterally compressed, dark or red brown, forming a pair of simple, curved sclerites; at base faintly curved, then straight, followed by an about $150-160^{\circ}$ curve, in apical area faintly narrowed, tip rounded (Figs 12B-C). With a pair of spindle-shaped narrow elongate lateral sclerites.

Female. Subgenital plate rhombic with up curved lateral margins that are in basal area strongly prolonged dorsad; at apico-lateral angles with up-bent acute cones (Figs 5E-F). Ovipositor almost twice as long as body; behind basal constriction straight with dorsal valves in basal half faintly higher than in apical half; dorsal margin faintly convex but not raised (Fig. 1B).

Measurements ( 2 males, 1 female). - Body w wings: male 44-45, female 53; w/o wings: male 33-37, female 39; pronotum: male 9.2-9.5, female 10; tegmen: male 33-34, female 40; hind femur: male 23-24, female 29; ovipositor length: female 69 ; ovipositor height: female $2.7 \mathrm{~mm}$.

Etymology. The name of the new species refers to the cover encompassing the phallus when at rest; from the Latin adjective tutus, tuta $=$ protected.

\section{Habetia pedala sp. nov.}

Figs 1C, 3I, 5D, 8C-E, 11C, 12D-E, 18C, Map 1(15).

Habetia spada Karny (1912) misidentification

Holotype (male): Papua New Guinea: West Sepik, Toricelli Mountains, ( $\left.3^{\circ} 30^{\prime} \mathrm{S}, 142^{\circ}{ }^{\prime} \mathrm{E}\right), 1 .-31.1 .1910$, [original labels: "Kais. Wilhelmsland Toricelli Gebirge Dr. Schlaginhaufen" and "1910 1"]—depository: Senckenberg Museum für Tierkunde Dresden (SMTD).

Other specimens studied: same data as holotype -2 females, 1 male (paratypes) (SMTD).

Taxonomic note. When Karny studied the five specimens of Habetia in SMTD Dresden, he had just published the volume on Agraeciini in Genera Insectorum (Karny 1912a). At the time when he prepared the manuscript to that work, he could not have seen any true male of the genus Habetia, since he based the description of the male of that genus exclusively on the single male of "H. pictifrons Karny, 1911" and explicitly mentions in a footnote that "the description of the male end of abdomen refers only to H. pictifrons" (translated from German). That species is moved below to the genus Parahabetia gen. nov. The species introduced here as $H$. pedala sp. nov. had been reported by Karny (1912b) as Habetia spada (Brunner, 1898). The SMTD holds five specimens of Habetia, two males and two females from the Toricelli Mountains and a single male labeled Bongu. The male from Bongu was described as H. imitatrix Karny, 1912, although its locality lies close to the type locality of $H$. spada, while the pair from the Toricelli Mountains had been identified as H. spada by Karny (1912b). However, the females from the Toricelli Mountains show distinct differences in the shape of the subgenital plate compared to that of the holotype of H. spada, and the males do not show the striking modifications of the subgenital plate found in the male from Bongu but is closer to H. pallida sp. nov. Thus, the Habetia specimens from the Torricelli Mountains represent a formerly undescribed species.

Diagnosis. The new species has a dorsal (inner) crest at the end of the male subgenital plate (Fig. 8D), a character that it shares with $H$. pallida sp. nov. However, in $H$. pedala sp. nov. that crest is higher, roughly twice as high as the diameter of the rounded ends of the subgenital plate and only faintly incised in middle, while in $H$. pallida it is only as high as one diameter of the rounded ends of the subgenital plate and more distinctly incised. Moreover, the incised apical area of the subgenital plate is markedly longer than in $H$. pallida. Further differences are the longer male cerci of $H$. pedala, that have the internal projection inserted little more proximad instead of at end and the acute apical teeth of that process are longer and of different shape. The titillators are similar to those of H. pallida and H. curvata sp. nov. but have the apical area narrow, not widened as in those species, and the dorsodistal margin is markedly constricted in sub-apical area. From the latter species, $H$. pedala also differs by the small and narrow styli and by the bi-spinose tip of the internal process of the cerci. The female subgenital plate of the new species is similar to that of $H$. pallida but has the apical margin more strongly upcurved between the apical spine-like projections which thus appear stouter at base and shorter than in the latter species. From $H$. spada that 
looks otherwise similar, H. pedala sp. nov. differs by the female subgenital plate that is markedly convex with a pair of stout, at tip spinose projections while in H. spada the subgenital plate is flattened and the apical projections are narrow.

Description. Coloration of face uniformly pale, of general color; mandibles fully black. Femora with the following number of spines on ventral margins: (1) a 7, p 9; (2) a 6-8, p 3-4; (3) a 12-14, p about 14 (n=2).

Male. Stridulatory file on underside of left tegmen $2.55 \mathrm{~mm}$ long with 74 teeth and with a distinct step in distal area: curved narrow basal area ca $0.37 \mathrm{~mm}$ (broken) with 12 teeth, central area $1,55 \mathrm{~mm}$ with 35 teeth, step $0,17 \mathrm{~mm}$ with 6 teeth, narrow apical area $0,51 \mathrm{~mm}$ with 23 teeth of which 11 clearly separated and 12 of decreasing size at end (Fig. 18C). Tenth abdominal tergite nearly parallel-sided with down-curved lateral areas, with medial furrow and a narrow apical incision in middle, internal margin of that area down-curved and strongly setose (Fig. 8C). Epiproct little widening toward sub-truncate apical margin and with a fine medial furrow. Cerci narrow elongate, markedly curved in apical half, behind basal area with an internal carina that delimits an excavation of the internal surface on dorsal side; that area with a wide compressed internal projection that divides in apical area into two branches that are little curved proximad, the ventro-proximal branch little longer than the dorso-apical branch; both terminate into an acute spine (Figs 8C-D). Subgenital plate with roundly incised basal margin, with lateral rims along dorsal margins; ventral disc with convex lateral margins, that become at end slightly diverging; from apex deep and widely incised; styli rather short and thin (Fig. 11C); at dorsal side of subgenital plate, just before the incision of the apical margin, with a rather high lamellar elevation with slightly bilobate dorsal margin (Fig. 8D). Titillators at base little widened and curved ventro-distad, in central area nearly parallel-sided, straight, at transition to apical area, the dorso-proximal margin is bent posteriorly with nearly straight dorso-distal and concave ventro-proximal margin, about in mid-length the dorsal margin is constricted and afterward convex, at end titillators curved mediad and narrowed into obtuse tip (Figs 12D-E).

Female. Subgenital plate with a fine membranous medial furrow and with strongly up-bent lateral and apical margins; at up-bent apico-lateral angles terminating into a pair of stout cones with acute tips (Fig. 5D). Ovipositor about twice as long as body; behind basal constriction straight with dorsal valves faintly convex but not raised (Fig. 1C).

Measurements ( 2 males, 2 females). - Body w/o wings: male 34-35, female 30-32; pronotum: male 9.0-9.6, female 9.6-9.8; tegmen: male 32.0-32.5, female 36.5-38.0; hind femur: male 22.5-24.0, female 26.5; ovipositor length: female 67-68; ovipositor height: female $2.5-2.8 \mathrm{~mm}$.

Etymology. Named for the large size and long ovipositor; from Latin pedalis $=$ one foot long.

\section{Habetia pallida sp. nov.}

Figs 1D, 3B, 5H-L, 8F-H, 11B, 13A-F, 17A-C, 18B, Map 1(4).

Holotype (male): Indonesia: Papua, Bernhard Camp, elev. 50 m (3²9'S, 139¹3'E), 1-31.x.1938, leg. J. Olthofdepository: Museum Zoologicum Bogoriense, Cibinong (MBBJ).

Other specimens studied: Indonesia: Papua: same data as holotype - 1 male paratype (MBBJ); same locality as holotype, 1-31.vii.1938, leg. J. Olthof -1 male paratype (MBBJ); Jayawijaya [= Central] Mountains, mountain

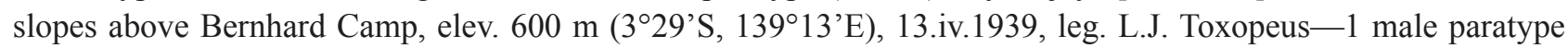
(MBBJ); Hollandia [Jayapura], (2²9’S, 140²1' E), 14.xii.1957, leg. R.T. Simon Thomas-1 female (NBC); Jayapura

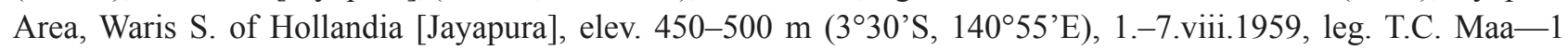
male (BPBM); Cyclop Mountains, Ifar, elev. 300-500 m (2³3’S, 140 $30^{\circ}$ 'E), 23-25.vi.1962, leg. J. Sedlacek-1 female (BPBM); same locality, 23.vi.1962, leg. J. Sedlacek-1 male (BPBM); same locality, 26-28.vi.1962, leg. J.L. Gressitt-1 female (BPBM); same locality, 28-30.vi.1962, leg. J.L. Gressitt-1 female (BPBM); W. Sentani, elev. 150-250 m (2³6'S, 140³8'E), 16.vi.1959, leg. T.C. Maa-1 female (BPBM); Irian Jaya [= Papua], Tobati District, Jutefa Bay. Pim., elev. 0-30 m (2³6’S, 140²''), 1-28.ii.1936, leg. L.E. Cheesman-1 female (NHM); Humboldt Bay District, Bewani Mountains, elev. 400 m ( $\left.3^{\circ} 0^{\prime} \mathrm{S}, 141^{\circ} 0^{\prime} \mathrm{E}\right)$, 1.iv.-31.viii.1937, leg. W. Stüber-1 female (NHM); New Guinea, without locality label, 1.i.-31.xii.1911-1 male (NBC).

Diagnosis. The new species belongs to the larger species of the genus that have the female ovipositor strongly prolonged, and the male stridulatory file on the underside of the left tegmen is provided with a distinct step in the distal area. It is most similar to $H$. curvata sp. nov. that lives at the Mamberamo River. H. pallida sp. nov. differs 
from the latter by the shape of the male cerci that have the apical area on internal side excavated and merging at end into a compressed but wide internal process that terminates into two acute tips while in H. curvata the male cerci have a compressed triangular internal process from sub-apical area that terminates into a single acute tip. The male titillators are similar in both species but in H. pallida they have the apical area narrow oval and the narrow, curved end longer, while in $H$. curvata the apical area at ventral margin is semi-circularly projecting and the narrowly curved end shorter. The female subgenital plate of $H$. pallida has the lateral margins strongly upcurved and the apical margin truncate with a pair of up-bent acute spine-like projections. This resembles the situation in $H$. pedala sp. nov. However, in the latter species, the apical margin is also upcurved and the apical spine-like projections are markedly stouter and shorter. There is some variation in the shape of the female subgenital plate, documented in Figs $5 \mathrm{H}-\mathrm{L}$.

Description. Coloration of face uniformly pale, of general color; mandibles black, in some specimens with little distinct light spots in baso-external and apical areas. Femora with the following number of spines on ventral margins: (1) a 4-8, p 7-8; (2) a 6-8, p 3-4; (3) a 11-16, p 14-19 (n=9).

Male. Stridulatory file of holotype on underside of left tegmen $2.33 \mathrm{~mm}$ long, with a distinct step in distal area; with 72 teeth, of which 8 narrow teeth at base, 38 in main part of file, 6 at step, 12 clearly separated at end, and 8 of decreasing size at end (Fig. 17C). Stridulatory file (4 other specimens): $2.35-2.57 \mathrm{~mm}$ long with $67-79$ teeth (mean 74 teeth), of which in curved narrow basal area 9-11 teeth at $0.31-0.35 \mathrm{~mm}$, in middle of file with 32-34 large teeth at $1.40-1.51 \mathrm{~mm}$, at step with 4-7 teeth at $0.13-0.19 \mathrm{~mm}$, and in narrow apical area with $21-28$ teeth at $0.39-0.64 \mathrm{~mm}$ (Fig. 18B). Tenth abdominal tergite transverse, in midline furrowed, from apical margin with a narrow and deep incision with setose margins, lateral margins roughly parallel (Fig. 17A). Supra-anal plate narrow, elongate, little widening toward subtruncate or slightly concave apical margin, which carries at both apical angles a small tubercle. Cerci in about basal half roughly cylindrical with slightly flattened internal surface; afterward with an obtuse dorsal carina that outlines the strongly excavated internal surface and is curved onto proximal margin of the wide apical internal process; the process divides in apical area into a proximal, narrow cylindrical and a distal, at base flattened branch, both with an acute spine at tip; the end of the cercus stem forms a short obtuse bump that hardly projects behind apical margin of the internal process (Figs 8F). Subgenital plate at base with a roughly triangular membranous area; in about basal two thirds wide with convex dorsal lateral margins that are approaching posteriorly into the nearly parallel-sided apical area; apical margin little triangularly incised followed by a short narrow slit in middle, lateral margins in apical area forming obtuse rounded carinae which are at end little project behind disc (Fig. 11B); on dorsal side of subgenital plate with a small disc shaped elevation around the projecting area of the rounded carinae; styli short (Fig. 8G-H). Titillators moderately widened at base and shortly curved ventro-apicad, afterward ascending and simply band-shaped, in little more than apical half curved ventro-apicad and in roughly apical third widened to a long-oval plate that is at end little narrowed and in-curved, with obtuse tip; phallus also with a pair of elongate lateral sclerites and a pair of small rounded sclerites on top of the titillators (Figs 13A-F, 17B).

Female. Subgenital plate wide at base with converging lateral margins and elevated disc; disc in basal half provided with a narrow medial carina in midline; surface of disc in dried specimens slightly concave; apical margin of disc truncate, straight, and provided at both lateral angles with a rather long, obliquely up-bent spine-like process with subacute tip (Figs $5 \mathrm{H}-\mathrm{L}$ ). Ovipositor about one and a half time as long as body; behind basal constriction straight with dorsal valves in basal half faintly convex (Fig. 1D).

Measurements ( 3 males, 7 females).-Body w/wings: male 42-47, female 48-53; body w/o wings: male 30-37, female 39-43; pronotum: male 8.8-9.5, female 9-10; tegmen: male 31.5-34, female 36-39; hind femur: male 22.525.0, female 25-28; antenna: male 90-110, female 95-130; ovipositor length: female 57-67; ovipositor height: female $2.5-2.7 \mathrm{~mm}$.

Etymology. The new species is named for its uniform pale coloration, from Latin pallidus, pallida $=$ pale.

\section{Habetia curvata sp. nov.}

Figs 3D-F, 5G, 11D, 17D-F, Map 1(5).

Holotype (male): Indonesia: Papua, North New Guinea, Mamberamo, Albatros Bivak, (2॰17'S, $\left.138^{\circ} 1^{\prime} \mathrm{E}\right)$, 1.31.v.1926, leg. W. Docters v. Leeuwen, North New Guinea Exped.—depository: Museum Zoologicum Bogoriense, Cibinong (MBBJ). 


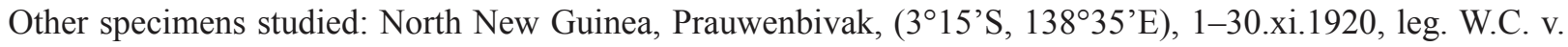
Heurn-1 female (MBBJ).

Remark. The female is assigned conditionally to this species since it had been found nearly half-way between the type localities of H. curvata and H. pallida. Only for the latter species there is one locality in which both, male and female had been collected, although not at the type locality. Since the female from Prauwenbivak does not agree with those of $H$. pallida, it is likely that it belongs to $H$. curvata, but the occurrence of additional species of the genus in that area cannot be excluded.

Diagnosis. H. curvata sp. nov. is similar to H. pallida sp. nov. It differs by the shape of the male cerci that have the compressed internal projections subapical instead of apical, of triangular shape instead of band-shaped, and terminating into a single apical spine instead of two apical spines as in most other species of Habetia; a remnant of the second spine is however still visible as a minute tubercle at the posterior margin of the internal projection. The narrow, compressed ridge at the internal side of the cercus of $H$. curvata is roundly projecting in about mid-length of cercus while straight throughout in H. pallida. The titillators are very similar to those of H. pallida but have the apical area more strongly widened with markedly bulging proximal margin. In H. curvata, the male subgenital plate has the central disc with narrowing but straight lateral margins, the apical margin less strongly incised but at tip swollen around bases of the long and stout styli while in H. pallida the lateral margins of the subgenital plate are concave in apical area, the apical margin is triangularly incised followed by a short narrow slit in middle and the styli thin and connected on dorsal side of subgenital plate by an elevated crest.

Description. Coloration of face uniformly pale, of general color; mandibles black, only a small area at base light (Fig. 3D-E). Femora with the following number of spines on ventral margins: (1) a 6-7, p 6-8; (2) a 7, p 3; (3) $\mathrm{a}>10, \mathrm{p}>14(\mathrm{n}=1)$.

Male. Stridulatory file on underside of left tegmen with a distinct step in distal area; with 79 teeth, of which 7 narrow teeth at base, 41 in main part of file, 5 at a step, 15 clearly separated at end, and 11 of decreasing size at end (Fig. 17F). Tenth abdominal tergite transverse, nearly parallel-sided; at base wide roundly incised in middle; surface with a medial furrow and with a long narrow apical incision from hind margin through which the epiproct is visible; at both sides of apical incision hind margin faintly slanting mediad. Cerci narrow elongate, faintly curved, behind basal area with an internal carina that forms a small projecting lobe before mid-length of cercus; internal surface, especially behind mid-length excavated with the ventral margin prolonged into a curved-triangular internal process that terminates into one acute spine, the hind margin of that process carries a minute tubercle at about end of basal third; the cercus stem ends into a short cone behind the internal process (Figs 11D, 17D). Subgenital plate strongly incised from base to almost mid-length; lateral margin convex in basal, straight in apical area, dorsal-lateral margin partly with laterally expanded rim; apical margin in middle roundly incised; with a pair of rather long styli (Fig. 11D). Titillators moderately widened at base that is curved ventro-apicad, then simply band-shaped, from around mid-length apical area curved ventro-apicad and widened to an oval extension that has the proximal margin markedly widened in middle; apical area narrowed and recurved, with obtuse tip. Phallus also provided with a pair of small circular sclerites at top of titillators and with a pair of elongate lateral sclerites (Fig. 17E).

Female. Subgenital plate with lateral margins upcurved and approaching each other posteriorly and with a shallow furrow along midline, at end terminating into a pair of narrow spine-like projections, apical margin between bases of projections subtruncate, very faintly projecting in middle; above apical margin and between bases of apical projections with a compressed, upright lamella with faintly bilobate margin (Fig. 5G).

Measurements ( 1 male, 1 female).—Body w/o wings: male 30, female 35; pronotum: male 8.7, female 9.5; tegmen: male 30, female 36; hind femur: male 27, female 27; ovipositor length: female $62 \mathrm{~mm}$.

Etymology. The new species is named for the strongly curved titillators, from Latin curvus, curva $=$ curved.

\section{Habetia dentata sp. nov.}

Figs 2B, 4D, 6F, 10A-C, 11F, 13G-H, 18E, 20C, Map 1(13).

Holotype (male): Papua New Guinea: Madang, Finisterre Mts., Saidor: Kiambavi Village, (53'ㅅ, $\left.146^{\circ} 30^{\prime} E\right)$, 22-29.vii.1958, leg. W.W. Brandt—depository: Bernice B. Bishop Museum, Honolulu (BPBM).

Other specimens studied: Same data as holotype -1 female (paratype, BPBM).

Diagnosis. The new species is characterized by the shapes of the male cerci and titillators. The cercus is rectangularly curved mediad behind mid-length forming a compressed process with convex distal and concave proximal surface and modified dorsal margin. The titillators form rather simple, $\mathrm{U}$-shaped sclerites that are fused in 
sub-basal area, have the sub-apical area inflated but at apical margin compressed and provided with a row of acute teeth. The disc of the female subgenital plate has the anterior and the lateral margins rectangularly bent dorsad not gradually curved as in the other species of the genus, and additionally, the anterior margin is also angularly bent anteriorly thus forming a step as is a staircase. H. dentata is also one of the few species with two vertical black bands on the face.

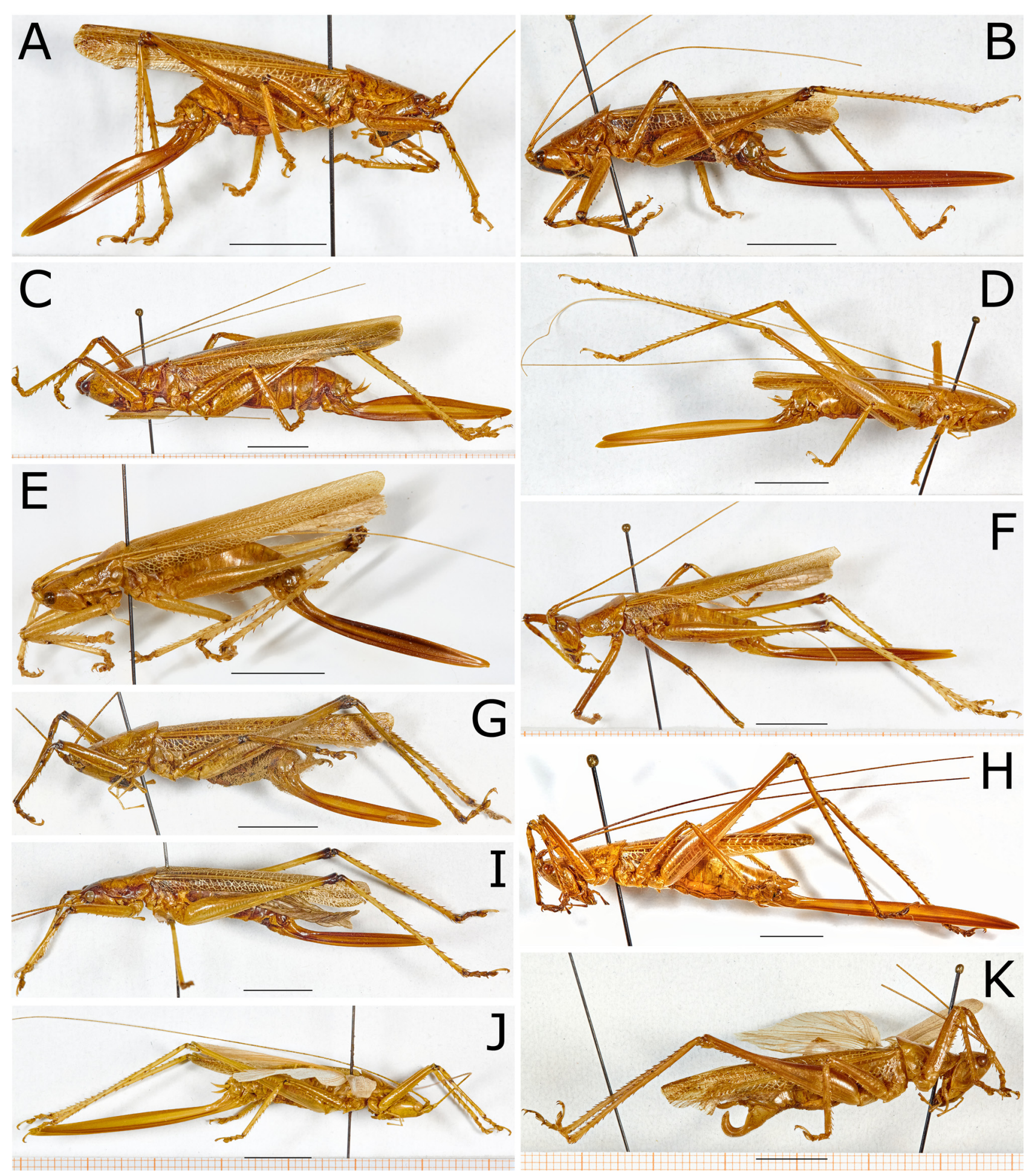

FIGURE 2. Habitus of Habetia species with moderately long ovipositor (A-J, females; K, male): A, H. bivittata sp. nov. (Chimbu Valley); B, H. dentata sp. nov. (Saidor); C, H. elevata sp. nov. (Salamaua); D, H. pinnigera sp. nov. (Madang); E, H.

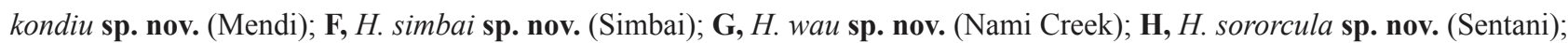
I, H. nigricauda sp. nov. (Popondetta); J, H. quatrispina sp. nov. (Pionierlager); K, H. pilleata sp. nov. holotype (Wau 1200m). All scales $10 \mathrm{~mm}$. 

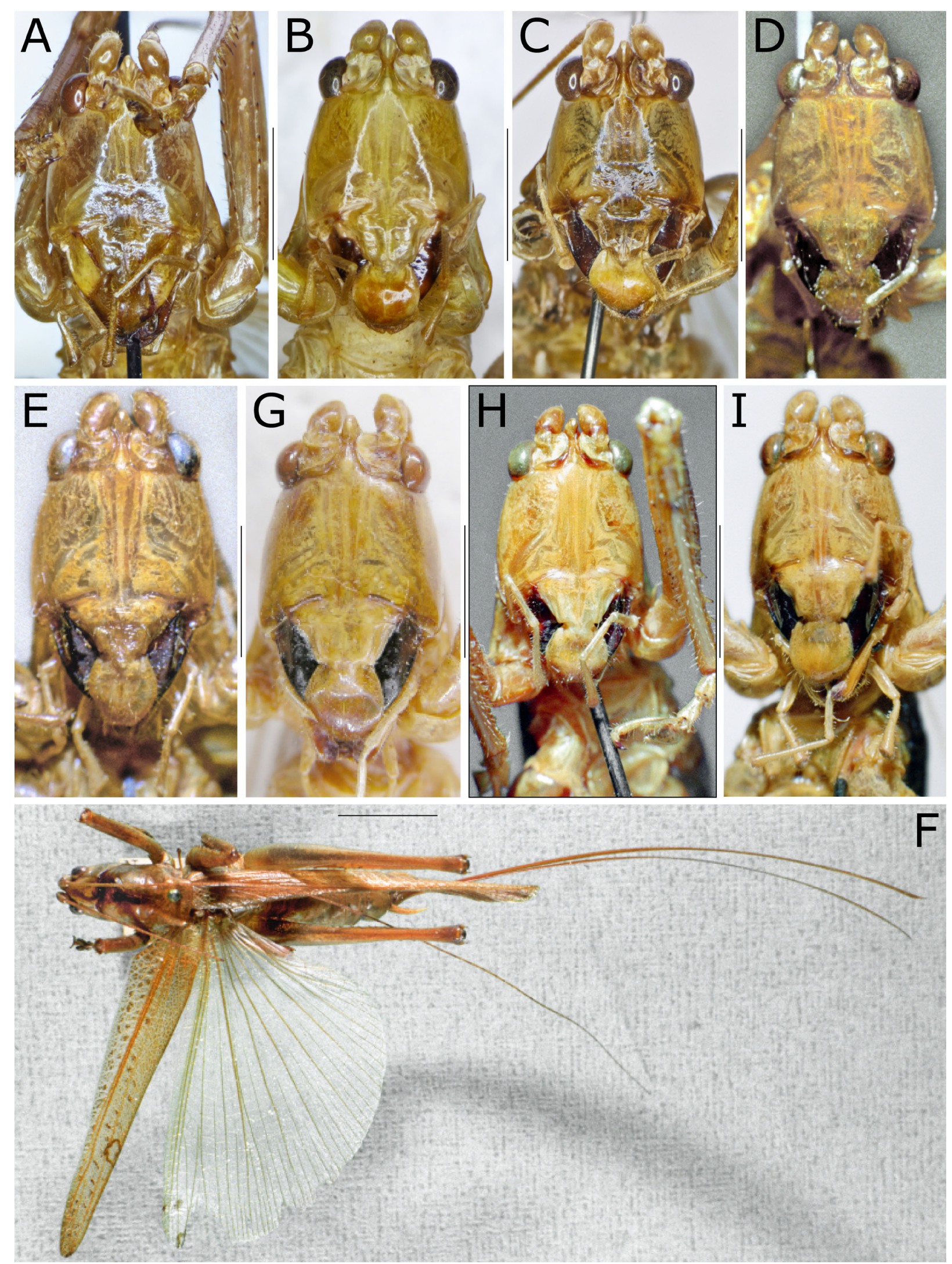

FIGURE 3. A, Habetia pilleata sp. nov. male (Wau 1200m); B, H. pallida sp. nov. female (Hollandia); C, H. tuta $\mathbf{s p . ~ n o v . ~}$ male (Quelllager); D-F, H. curvata sp. nov. (D, male Albatros Bivak, E-F, female Prauwenbivak); G, H. spada (Brunner, 1898) female holotype (Konstantinhafen); H, H. multispinulosa Griffini, 1908 female holotype (Dilo); I, H. pedala sp. nov. female (Toricelli Mountains).-Frons (A-E, G-I), female dorsal view (F). Scales 5 mm (A-E, G-I), 10 mm (F). 

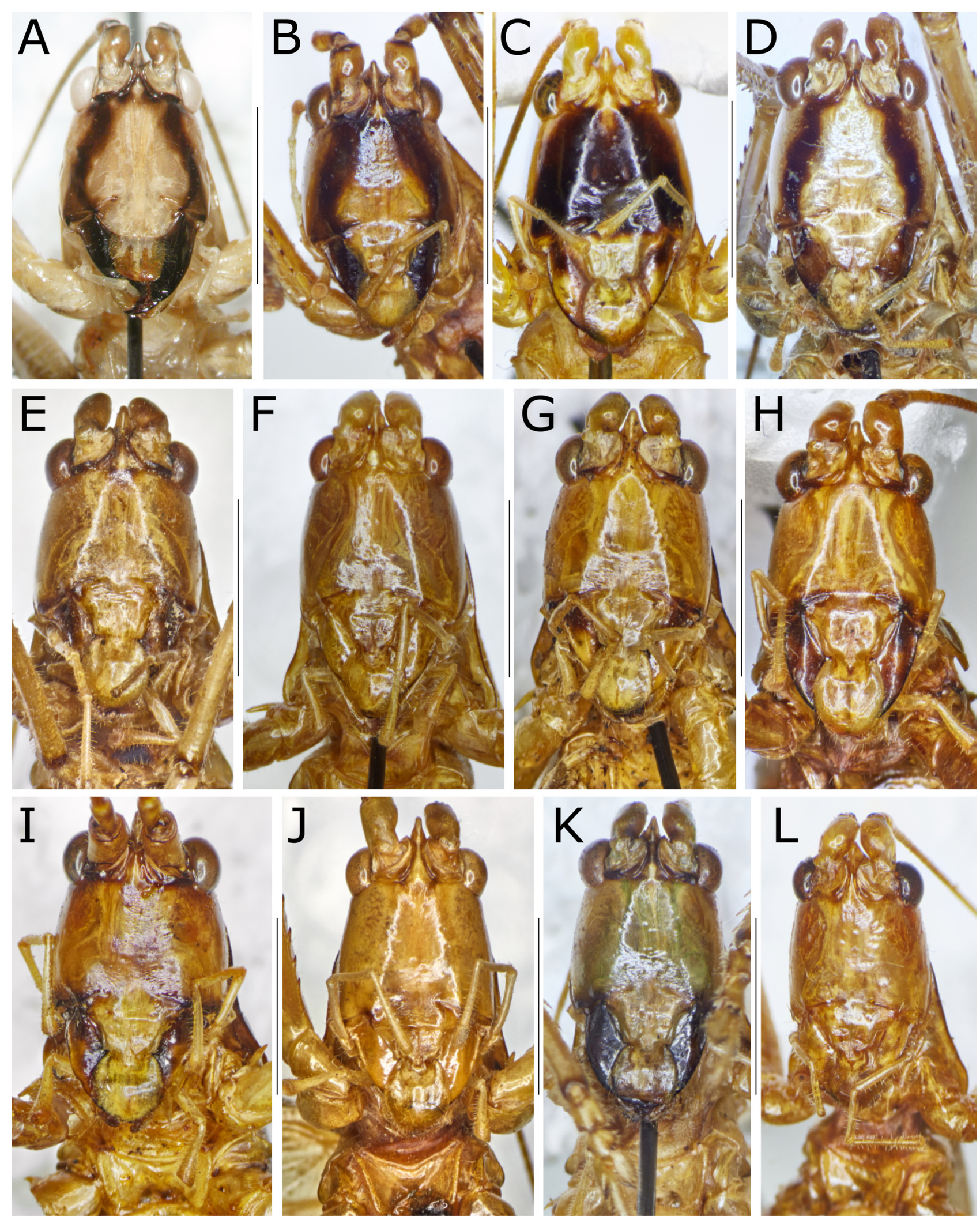

FIGURE 4. Frons of Habetia species: A-C, H. bivittata sp. nov., variation of the black marks (A Goroka male, B Mt. Wilhelm male, C Keltiga female); D, H. dentata sp. nov. female (Saidor); E, H. kondiu sp. nov. female (Kubor Range); F, H. pinnigera sp. nov. female (Madang); G, H. lalibu sp. nov. male (Lalibu); H, H. simbai sp. nov. female (Simbai Valley); I, H. nigricauda sp. nov. female (Popondetta); J, H. quatrispina sp. nov. female (Pionierlager); K, H. wau sp. nov. male (Nami Creek); L, $H$. sororcula sp. nov. female (Ifar). Scales $5 \mathrm{~mm}$. 

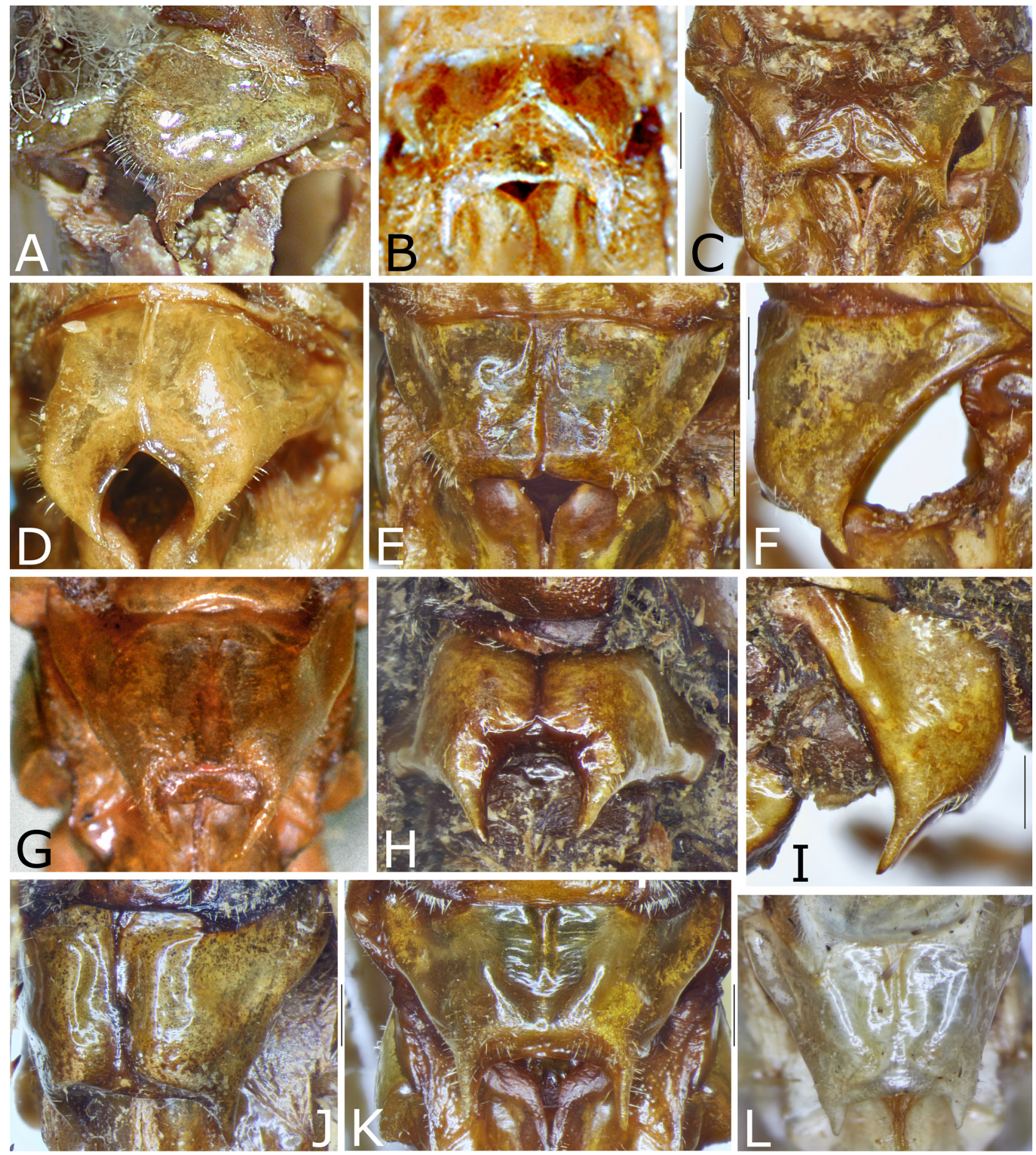

FIGURE 5. Female subgenital plate of Habetia species in oblique ventral (A, J), ventral (C, E, G, L), apico-ventral (B, D, G, K), apical (H), and lateral (F, I) view.-A, H. spada holotype; B-C, H. multispinulosa (B holotype, C from Dorom), D, H. pedala sp. nov. (Toricelli Mts); E-F, H. tuta sp. nov. (Keram river); G, H. curvata sp. nov. (Prauwenbivak); H-L, H. pallida sp. nov. (H-I Jutefa Bay, J Bewani, K Ifar, L Hollandia).- Scales $1 \mathrm{~mm}$; A, D, G not to scale.

Description. Coloration of face pale with a pair of dark reddish brown to black lateral bands; mandibles of same color as lateral bands; antennal scrobae with brown and black areas, tip of fastigium frontis black (Fig. 4D). Femora with the following number of spines on ventral margins: (1) a 6-7, p 7-8; (2) a 6, p 3; (3) a 11-12, p 10-12 (n=2).

Male. Stridulatory file on underside of left tegmen $2.36 \mathrm{~mm}$ long, in subapical area faintly sinuously curved but without distinct step, with 110 teeth, of which 21 narrow teeth in curved basal area at $0.56 \mathrm{~mm}, 44$ teeth in central area at $1,18 \mathrm{~mm}$, and 45 narrow teeth in apical area at $0.5 \mathrm{~mm}$. Teeth in about second quarter from base widest and 
largest, then becoming gradually narrower and very small in white, curved apical area (Fig. 18E). Tenth abdominal tergite wider than long, in central area little longer than in lateral areas, lateral margins in about mid-length and at end very faintly projecting; apical margin oblique, in middle interrupted by a wide and deep incision that is little longer than half the length of the tergite, inner margins of that incision curved ventrad and with sub-parallel margins and rounded bottom that is on ventral side extended by a membranous septum; at both sides of apical incision hind margin of tergite little projecting and elevated with sub-straight hind margin, laterally with convex hind margin (Fig. 10A). Cerci rather short and little conical, at end prolonged into a large, incurved and laterally compressed process that has the proximal side concave and the distal side convex and carries the following modifications: at base and somewhat at the inner side of the process there is a conical projection that sits on a widened socket and carries at tip a short, rounded, oval extension that is separated from the cone by a distinct constriction; the large cone is followed on the proximal side by a small simple cone and on the distal side by an elongate elevation along the dorsal margin of the process that forms three dorsal bows of decreasing size along its dorsal margin and a minute cone at tip (Figs $10 \mathrm{~A}-\mathrm{C})$. There is another short cone before the incurved end of the process. Subgenital plate in basal area wide with strongly convex lateral margin, in central area rather narrow with parallel lateral margins and flattened surface, then deeply incised from behind and lateral areas continued as narrow parallel stripes that are upcurved at end and carry at tip small styli; anterior margin concave; parallel to the lateral margins with a pair of thickened ridges (Fig. 11F). Titillators compressed, strongly curved, only in about mid-length with a sub-straight area; at base widened and free then subfused to about end of basal third; at end compressed with rounded margin that carries six teeth: four large and two small teeth (Figs 13G-H).

Female. Subgenital plate with central area in ventral view about rhombic with flattened surface but little concave apical area; anterior and lateral margins nearly rectangularly bent dorsad, anterior area bent in a $90^{\circ}$-angle with little swollen lateral margins and in front curved again anteriorly into a narrow transverse strip with anterior margin convex on both sides, concave in middle; lateral areas with concave surface; apical margin of central area concave on both sides and with a convex lobe in middle; lateral angles extended, curved dorsad into lateral surfaces and give rise to internal septa that seem to form a pair of pockets together with the ventral surface of the plate (Fig. 6F). Ovipositor about as long as body length from head to tip of wings; laterally compressed, dorsal margin only faintly convex behind basal constriction (Fig. 2B).

Measurements (1 male, 1 female).-Body w/wings: male 35, female 35; body w/o wings: male 27, female 27; pronotum: male 9.5, female 7.5; tegmen: male 13.5, female 26; hind femur: male 18.2, female 19.5; tegmen width: male 4.5; antenna: male 60; ovipositor length: female 31.5; ovipositor height: female $1.9 \mathrm{~mm}$.

Etymology. The new species is named for the dentate tip of the male titillators, a unique character within the genus; from Latin dentatus, dentata $=$ provided with teeth.

\section{Habetia bivittata sp. nov.}

Figs 2A, 4A-C, 6A-B, 7A-B, 9A-C, 11G, 14A-E, 19A-D, 20A, Map 1(7).

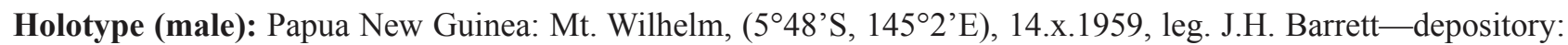
Naturalis Biodiversity Center, Leiden (NBC).

Other specimens studied: Papua New Guinea: same data as holotype- 1 female, 1 male, paratypes, 1 female

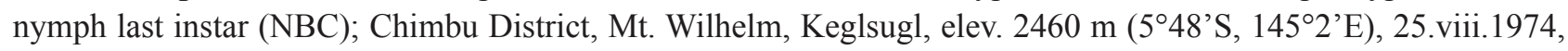

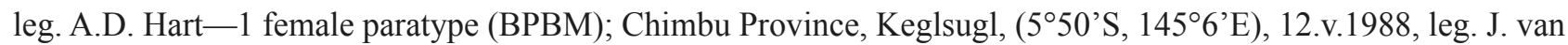
Stalle (St. 026, I.G. no. 27363) -3 females, 1 male, paratypes (ISNB); Eastern Highlands, Aiyura, ex bush, $\left(6^{\circ} 20^{\prime} \mathrm{S}\right.$

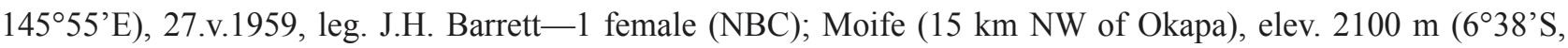
$145^{\circ} 33^{\prime}$ E), 7.-14.x.1959, leg. T.C. Maa-15 females, 13 males, 1 nymph male (BPBM); Purosa (20-26 km SE of

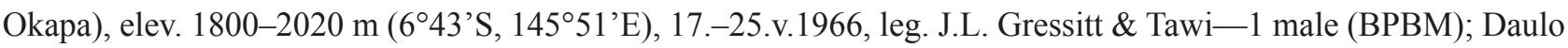

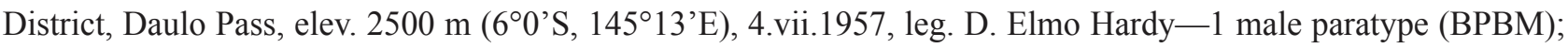
New Guinea (NE), Chimbu Valley, elev. 1800 m (6²’S, 14457’E), 16.v.1963, leg. J. Sedlacek-1 female (BPBM); New Guinea NE, Sinofi, 30 km south of Kainantu, elev. 1590 m (6 $6^{\circ} 2^{\prime}$ S, $145^{\circ} 58^{\prime}$ E), 4.x.1959, leg. T.E. Maa-1

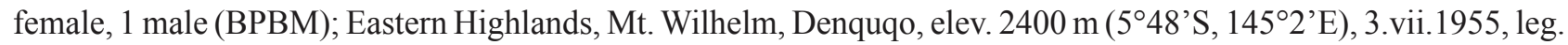
J.L. Gressitt—3 males (BPBM); Western Highlands, Keltiga, Mt. Hagen Valley, elev. 1700 m (5'52'S, 144¹3”'E), 1-31.x.1961, leg. W.W. Brandt-1 female, 1 male (NBC); New Guinea (NE), Ahl Valley, Nondugl, elev. 1750 
m (552'S, 14446'E), 8.vii.1955, leg. J.L. Gressitt-1 male topotypic specimen (BPBM); New Guinea: Kenoa, 29.iii.1960 — 1 female (NBC); Papua, 1972, leg. Ströder — 1 female, 2 males, paratypes (NMW), note on locality: Although the labels of specimens collected by Karl Wilhelm Ströder read only "Neuguinea 73 Papua, Ströder leg.", it is likely that the specimens had been collected in the environs of Goroka in 1973 where K.W. Ströder, a vendor of artefacts, did his ethnographic studies (Carlotta 2021, The British Museum 2021).

Diagnosis. $H$. bivittata sp. nov. is characterized by the pair of black lateral bands on the frons. A character that it shares only with $H$. dentata sp. nov., from which the new species can be easily separated by the shapes of the male cerci and the female subgenital plate. All other species studied have uniformly light faces except for the mandibles that can be black in several species. Other unique characters are the extended and lamellar, dorsal expansions and the shape of the internal projection of the male cerci. Highly characteristic is the complex modification of the male titillators in which the proximal and distal branches are connected by sub-membranous septa, which is found in a similar way only in $H$. wau sp. nov. Females also differ from most other species of the genus by the strong expansion of the dorsal ovipositor valves. A character that $H$. bivittata only shares with $H$. elevata sp. nov., from which it differs, apart from a shorter ovipositor (20-25 mm against $32 \mathrm{~mm}$ ), by the strikingly different shape of the female subgenital plate that is elongate with very high but short baso-lateral expansions and the disc ends into long spine-like projections in $\mathrm{H}$. bivittata, while in $\mathrm{H}$. elevata it is nearly semi-circular in ventral view and elongate without expansion at base in lateral view (compare Figs $6 \mathrm{~A}-\mathrm{B}$ with $6 \mathrm{~J}$ ) and by the coloration of the striped face in H. bivittata that is of uniform color in H. elevata.

Description. Coloration of face pale with a pair of black lateral bands of variable width, rarely extended over the whole face (Figs 4A-C); antennal scrobae and fastigium frontis also black, median ocellus pale; mandibles often fully black. Femora with the following number of spines on ventral margins: (1) a 4-8, p 4-10; (2) a 4-8, p 2-5; (3) a 7-13, p 4-14 (n=38).

Male. Stridulatory file on underside of left tegmen 1.6-1.9 mm long (mean $1.7 \mathrm{~mm}$ ) with 56-74 teeth (mean 65) that are at both ends very small, in central area rather wide: with 12-18 narrow basal (mean 14) teeth and 16-24 narrow apical (mean 19) teeth; in central $1 \mathrm{~mm}$ of file with 29-34 (mean 32) teeth [n =12] (Figs 19A-D). Tenth abdominal tergite nearly domed but toward hind margin less strongly sloping than laterally, ventro-lateral margins concave; downcurved apical area deeply, roundly incised to almost dorsal surface and in ventral area slightly curved laterally and often little curved posteriorly above bases of cerci; the deep apical incision provides room for the large, triangular epiproct that has a deep furrow in midline (Figs 9A-B). Cerci moderately long, faintly curved mediad, and of subequal width to rounded tip; in apical area with a large, laterally compressed expansion with wavy margin that runs from top of cercus and there parallel to cercus axis and then curves ventrad and runs down along subapical internal surface of cercus to almost ventral margin; just below that expansion arises a long, dorso-ventrally compressed and in basal area little curved projection with converging lateral margins that divides before end into a short proximal cone with an acute spinule at tip and a longer, compressed and at base curved distal lobe with rounded tip that also carries an acute spinule at tip. Subgenital plate with basal margin strongly concave; basal area otherwise with upcurved and in ventral view bulging lateral margin; in central area with concave lateral margins and with a wide, obtuse medial furrow; in apical area divided into a pair of long, narrow, but in lateral view little elevated, lateral lobes that are more than half as long as the entire subgenital plate (13:20) and carry at tip short styli (Fig. 11G). In lateral view, subgenital plate regularly curved throughout behind basal widening; dorsal margin in basal area with an angle and parallel to dorsal margin with a deep furrow. Titillators very complex; in situ, as can be seen through the genital opening, they appear as a pair of rather soft dorso-ventral structures with furrowed central areas that carry two pairs of compressed apical projections from dorsal and from ventral margins: dorsal lobes with rounded apical margin and granular surface, also along margin, and ventral lobes with dentate margin (Figs 14A-B). In preparations the titillators appear as follows: in basal area, they are compressed and widened and run parallel to each other but are not fused; reaching the top, they are divided into proximal (anterior) and distal (posterior) branches; the proximal branches are short, dorso-ventrally compressed and moderately curved, the distal branches are elongate and little ascending posteriorly and end into a curved, obtuse tip, which re-curves and then runs ventrad where it ends into a short lobe at a level little above the level of the base of the titillators. The basal, dorsal and distal branches are connected by sub-membranous septa. In lateral view this structure thus appears as an irregular square with projections at all four angles. This square has an outer and an inner surface, is closed at bottom and probably filled with muscles in the alive insect. There is also a pair of large, elongate lateral sclerites with three flattened expansions from a little wavy central spindle; the membranes covering the titillators dorsally are provided with a pair of small rounded and convex semi-sclerotized caps (Figs 14C-E). 
Female. Subgenital plate with ventral disc near base with diverging, afterward with converging lateral margins and terminating into a pair of elongate, spine-like, apical projections separated by a deep apical incision with rounded bottom; very basal area of disc on both sides merging into narrow dorso-lateral projections of about same length as disc including apical projections; they are separated from disc by a wide oblique furrow and afterward bulging with rounded tip (Figs 6A-B, 7A-B). Ovipositor only little longer than body, laterally compressed; behind basal constriction dorsal margin strongly elevated, highest in central third of its length, afterward gradually narrowing with dorsal margin straight or very faintly concave to rounded tip (Fig. 2A).
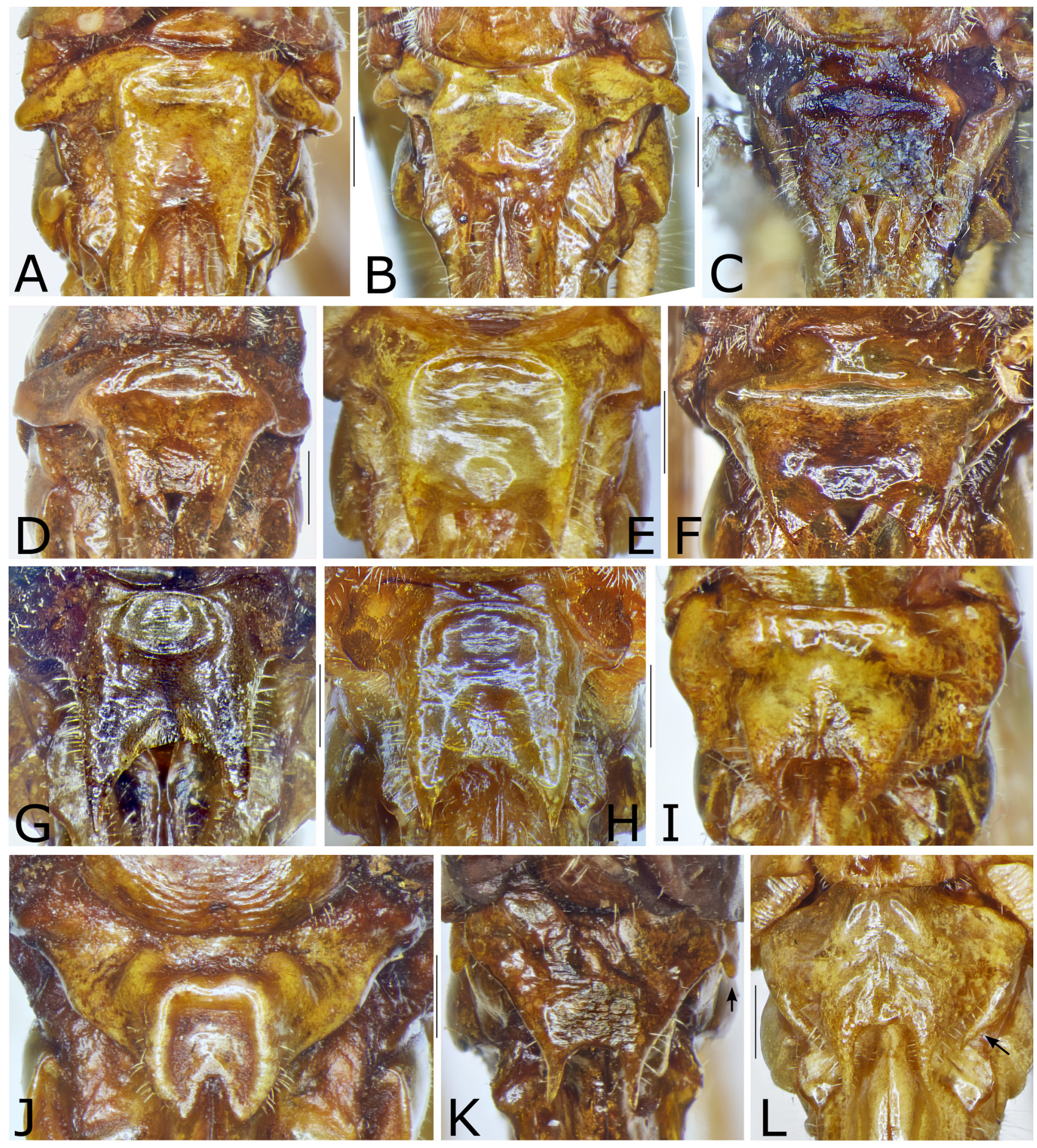

FIGURE 6. Female subgenital plate of Habetia species in about ventral view: A-B, H. bivittata sp. nov. (A Chimbu Valley, B Moife); C, H. nigricauda sp. nov. (Popondetta); D, H. wau sp. nov. (Upper Watut); E, H. simbai sp. nov. (Simbai Valley); F, $H$. dentata sp. nov. (Saidor); G-H, H. kondiu (G Mt Hagen, H Mendi); I, H. pinnigera sp. nov. (Madang); J, H. elevata sp. nov. (Salamaua); K, H. sororcula sp. nov. (Ifar); L, H. quatrispina sp. nov. (Pionierlager), the arrow points at the lateral spine-like projection. Scales $1 \mathrm{~mm}$. 


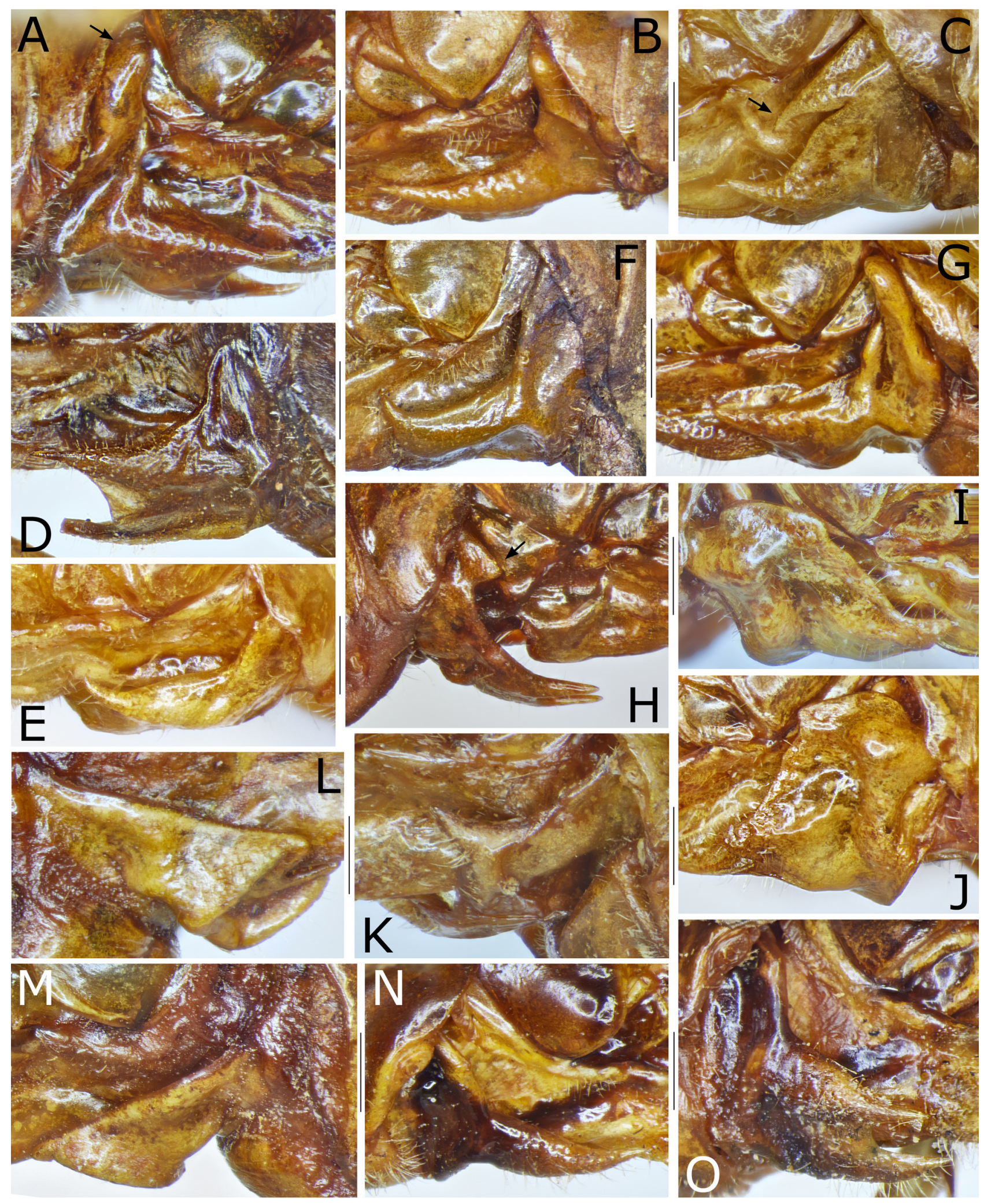

FIGURE 7. Female subgenital plate of Habetia species in lateral (B-C, E-I, M-N) and oblique lateral (A, D, J-L, O) view: A-B, H. bivittata sp. nov. (A Aiyura, B Mt Wilhelm); C, H. quatrispina sp. nov. (Pionierlager); D, H. kondiu sp. nov. (Kubor Range); E, H. simbai sp. nov. (Simbai Valley); F-G, H. wau sp. nov. (F Nami Creak, G Wau); H, H. sororcula sp. nov. (Ifar); I-J, H. pinnigera sp. nov. (Madang); K, H. multispinulosa Griffini, 1908 (Rigo Dorom); L-M, H. elevata sp. nov. (Salamaua); $\mathbf{N}-\mathbf{O}$, H. nigricauda sp. nov. (Popondetta). The arrows in A, C and $\mathrm{H}$ point at the tip of the dorso-lateral lobes. Scales $1 \mathrm{~mm}$. 

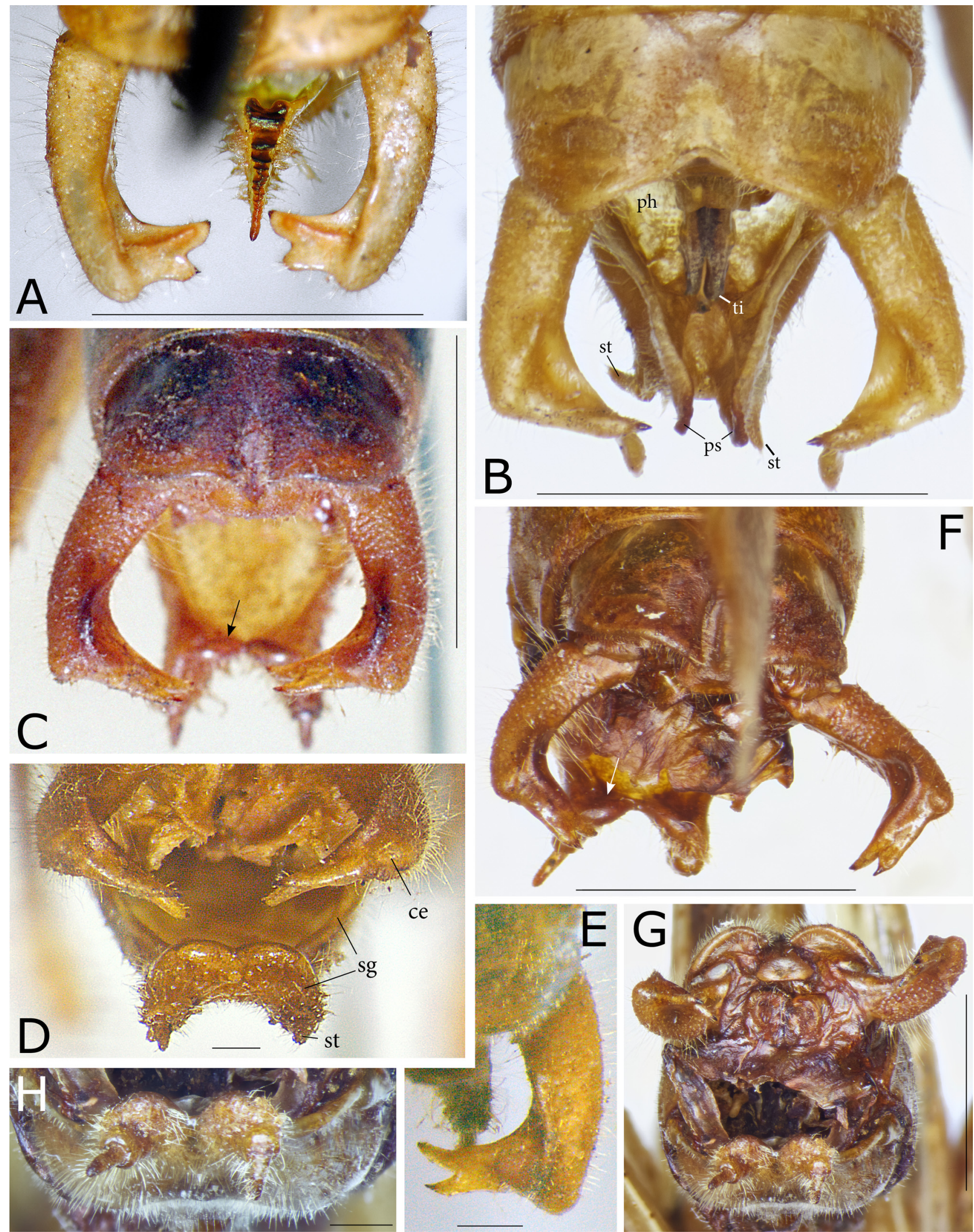

FIGURE 8. Male abdominal apex with cerci in dorsal view (A-B, F) dorso-apical view (C) and apical view (D, G); male cercus in roughly dorsal view (E); apical view of subgenital plate with styli (H).-A, Habetia imitatrix Karny, 1912 (Bongu); B, Habetia tuta sp. nov. (Quelllager); C-E, Habetia pedala sp. nov. (Toricelli Mts); F-H, Habetia pallida sp. nov. (Ifar).- The arrows aim at dorsal modifications of the subgential plate. Abbreviations: ce cercus, ph phallus, ps phallus sheath, sg subgenital plate, st stylus, ti titillator. Scales $5 \mathrm{~mm}(\mathrm{~A}-\mathrm{C}, \mathrm{F}-\mathrm{G}), 1 \mathrm{~mm}$ (D-E, H). Phallus removed in D, F-G. 

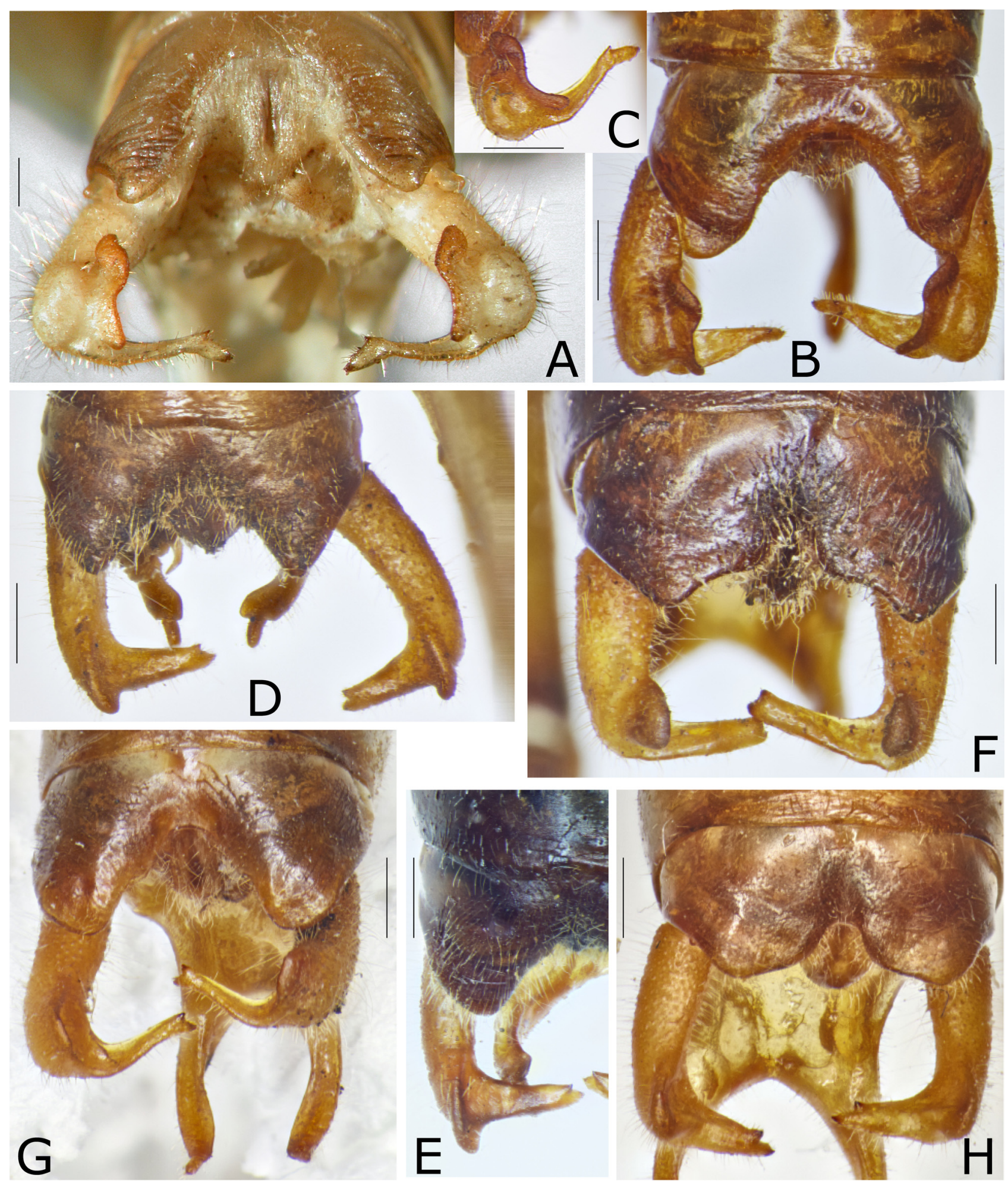

FIGURE 9. Male abdominal apex in apical (A), dorsal (B, D-E), and apico-dorsal view (F-H); left cercus (C).-A-C, Habetia bivittata sp. nov. (A Goroka, B Daulo Pass, C Mt Wilhelm); D-E, Habetia kondiu sp. nov. (D Kubor Range, E Wabag); F, Habetia lalibu sp. nov. (Lalibu); G, Habetia wau sp. nov. (Nami Creek); H, Habetia simbai sp. nov. (Simbai Valley).--Scales $1 \mathrm{~mm}$.

Measurements (25 males, 23 females).-Body w/wings: male 31-36, female 35-41; body w/o wings: male 22-29, female 20-29; pronotum: male 6.5-8.5, female 6.3-8.0; tegmen: male 21.5-30.0, female 26-30; hind femur: male 15.5-19.0, female 17.5-20.0; antenna: male 60-70, female 70-85; ovipositor length: female 20-25; ovipositor height: female $2.5-3.0 \mathrm{~mm}$. 

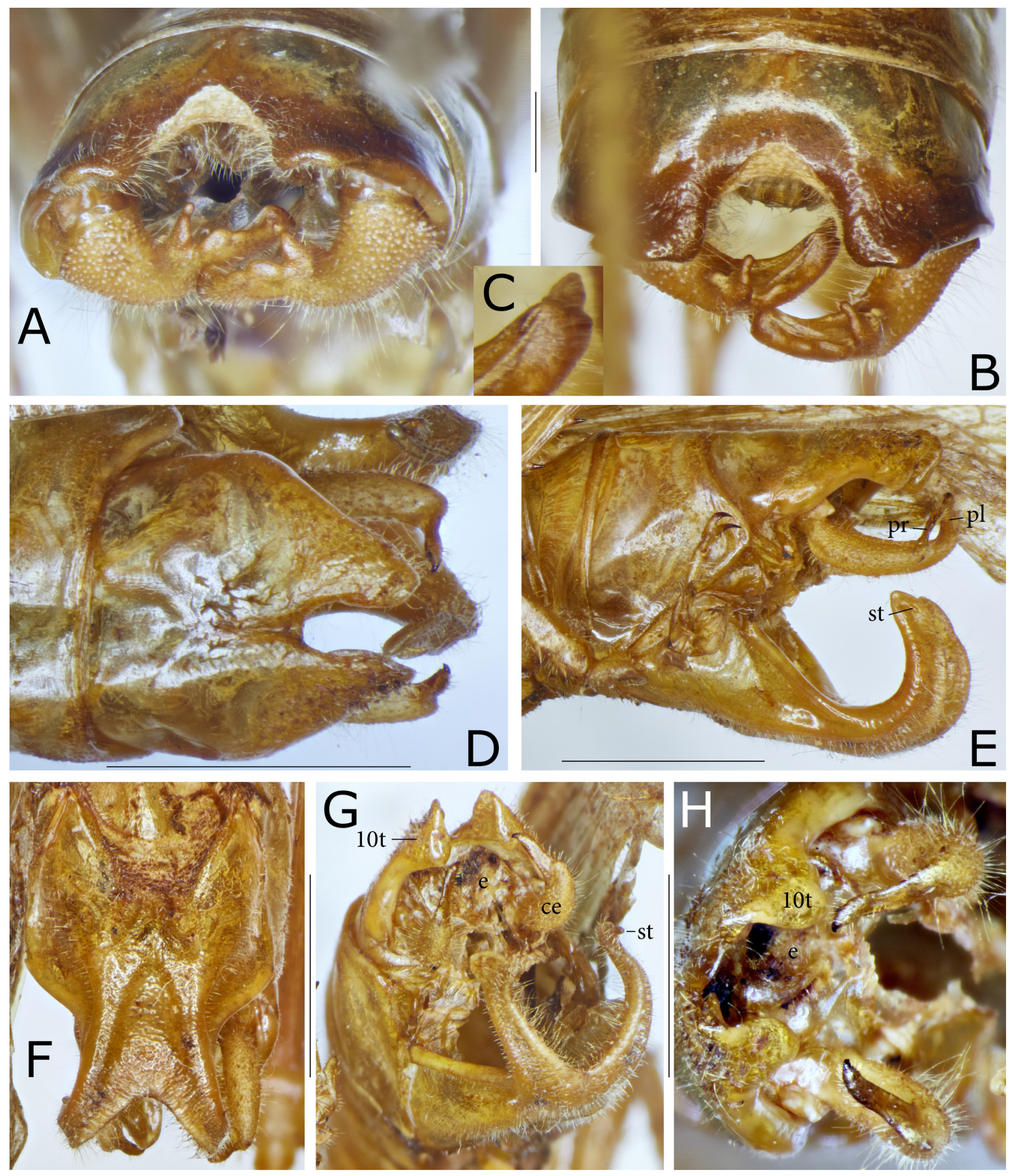

FIGURE 10. A-C, Habetia dentata sp. nov. (holotype), male abdominal apex with tenth tergite and cerci in apical (A) and dorsal view (B), tip of cercus twice enlarged (C); D-H, Habetia pilleata sp. nov. (holotype), tenth abdominal tergite and cerci in dorsal view (D), abdominal apex with subgenital plate and cerci in lateral view (E), subgenital plate in ventral view (F), end of abdomen in oblique apical view $(\mathrm{G})$, end of cerci and tenth abdominal tergite in strict apical view ( $\mathrm{H}$, top side is left).Abbreviations: 10t end of tenth tergite, ce cercus, e epiproct, pl projection of left cercus, pr projection of right cercus, st stylus. Scales A-B $1 \mathrm{~mm}$ (C as B twice enlarged); D-H $5 \mathrm{~mm}$. 

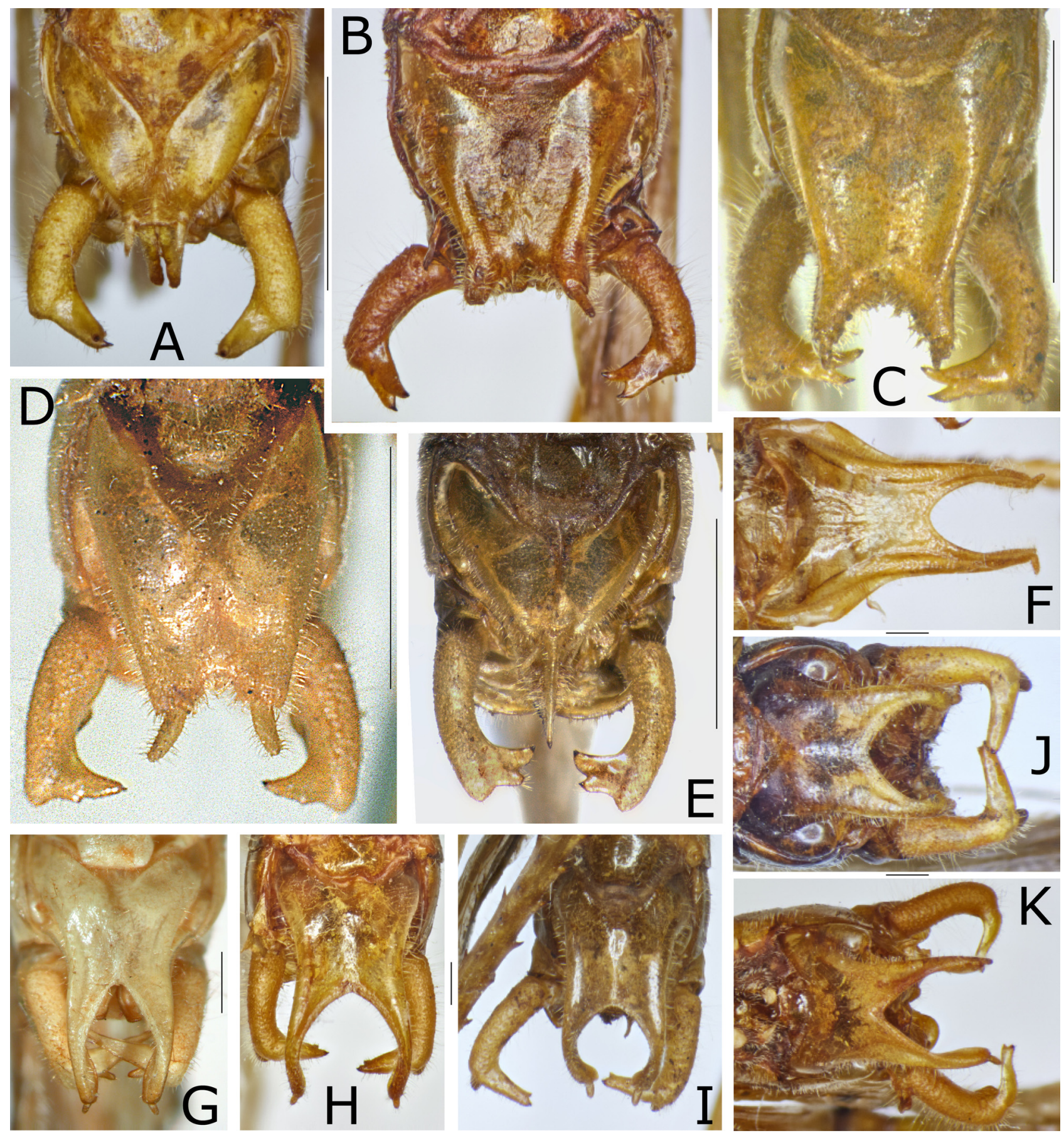

FIGURE 11. Male subgenital plate and cerci of Habetia species in ventral view ( $\mathrm{J}$ in ventro-apical view).-A, $H$. tuta $\mathbf{\text { sp. nov. }}$ (Rosensee); B, H. pallida sp. nov. (Ifar); C, H. pedala sp. nov. (Toricelli Mts); D, H. curvata sp. nov. (Albatros Bivak); E, $H$. imitatrix Karny, 1912 holotype (Bongu); F, H. dentata sp. nov. (Saidor); G, H. bivittata sp. nov. (Goroka); H, H. simbai sp. nov. (Simbai Valley); I, H. kondiu sp. nov. (Kondiu); J, H. lalibu sp. nov. (Lalibu); K, H. wau sp. nov. (Nami Creek). Scales 5 $\mathrm{mm}(\mathrm{A}-\mathrm{E}), 1 \mathrm{~mm}(\mathrm{~F}-\mathrm{K})$.

\section{Habetia wau sp. nov.}

Figs 2G, 4K, 6D, 7F-G, 9G, 11K, 15D-H, 18G-H, 20G, Map 1(9).

Holotype (male): Papua New Guinea: Morobe, Wau, Nami Creek, (7¹9’, 146²42'), 8.viii.1968, leg. J. Sedlacekdepository: Bernice B. Bishop Museum, Honolulu (BPBM).

Paratypes: Papua New Guinea: same data as holotype - 3 females, 2 males (paratypes, BPBM); same locality 
as holotype, 15.i.1969, leg. J. Sedlacek-1 male (BPBM); Morobe, Edie Creek, $11.2 \mathrm{~km}$ west of Wau, elev. 1700 m ( $7^{\circ} 22^{\prime}$ S, $146^{\circ} 40^{\prime}$ E), 16.vii.1971, leg. J. \& M. Sedlacek-1 female (BPBM); NE Wau, elev. 1600-1700 m (7¹7'S, 14644'E), 28.xii.1961, leg. J., J.H. \& M. Sedlacek-1 female (BPBM); Wau, elev. 1150-1500 m (7²0’S, 146.45’E), 31.vii.1964, leg. J. Sedlacek-1 female, 3 males (BPBM); same locality, 25.iii.1966, leg. J.L. Gressitt—1 female (BPBM); Wau, Mt. Missim, elev. 1400 m (7¹0’S, 14654’E), 24.ix.1964, leg. M. Sedlacek-1 nymph female (BPBM); New Guinea (NE), Morobe district, Wau, Kunai Creek, elev. $1500 \mathrm{~m}\left(7^{\circ} 20^{\prime} \mathrm{S}, 146^{\circ} 41^{\prime} \mathrm{E}\right)$, 28.-30.v.1963, leg. P. Sganshan -1 male (BPBM); New Guinea NE, Upper Watut, (657’S, $146^{\circ} 21^{\prime}$ 'E), 3.v.1968, leg. J.L. Gressitt-1 female (BPBM).

Diagnosis. Regarding the shapes of the male titillators, $H$. wau sp. nov. and $H$. bivittata sp. nov. are closely related species that differ however by the shapes of the male abdominal appendages, details of the titillators, the female ovipositor and subgenital plate and by the absence $(H$. wau $)$ or presence $(H$. bivittata) of a pair of black bands on the face. The male tenth abdominal tergite ends into a pair of lobes with simply rounded tip in $H$. wau while in $\mathrm{H}$. bivittata the apical lobes are narrowed at end and curved distad; the dorsal projection of the male cercus is simply rounded in $H$. wau but prolonged and with wavy margin in $H$. bivittata, the internal process of the male cerci is little curved in both species but in $\mathrm{H}$. wau it ends into a pair of about equal apical spines while in H. bivittata into a smaller subapical spine and short apical lobe with a spinule at tip. The basically U-curved male titillators of the genus Habetia are modified by voluminous sub-membranous septa in both species as illustrated in Figs 15D-H for $H$. wau and Figs 14A-E for $H$. bivittata. The female subgenital plate of $H$. wau has the baso-lateral extensions simply rounded and oriented in the same direction as the disc, they are however in some dried specimens shrunk and rolled-up, and the spine-like apical projections of the subgenital plate are shorter and separated by a wider interspace in H. wau (Fig. 6D), while in H. bivittata the baso-lateral extensions are twisted against the central disc and the apical spine-like projections are stouter and longer and separated by a narrower interspace (Fig. 6A-B). The females of both species can be easily separated by the shape of the ovipositor, which has the dorsal margin strongly elevated around mid-length in $H$. bivittata, but hardly convex, nearly straight in $H$ wau.

Description. Coloration of face uniformly pale, of general color, few specimens with remnants of green, thus face might be green when alive; mandibles black or black with brownish spots; antennal scrobae and fastigium frontis partly or fully black or of general color; median ocellus light (Fig. 4K). Femora with the following number of spines on ventral margins: (1) a 4-8, p 5-9; (2) a 3-7, p 2-6; (3) a 7-11, p 5-16 (n=15).

Male. Stridulatory file on underside of left tegmen 2.0-2.1 mm long (mean 2.07) with 78-86 teeth (mean 82) that are at both ends very small and difficult to separate from each other, with 17-22 narrow basal teeth (mean 20) and 27-34 narrow apical teeth (mean 31); counted over the whole file length with 38-43 teeth per $1 \mathrm{~mm}$ (mean 39.5 ); in central $1 \mathrm{~mm}$ of file with 29-33 (mean 32) teeth; in central $0.5 \mathrm{~mm}$ with $14-15$ teeth [n $=5$ ] (Fig. 18G-H). Tenth abdominal tergite almost twice as wide as long (1.7-1.8 times) with lateral margins curved ventrad in basal area; from apical margin deeply incised in middle resulting in a pair of roughly triangular lobes with widely rounded tips. Epiproct with medial furrow and obtuse tip (Fig. 9G). Cerci narrow elongate and in apical area little curved; just before tip with a simple, compressed dorsal projection with nearly rounded, substraight or faintly angular dorsal margin; with an elongate, laterally compressed, and little wavy internal process from internal end of cercus, the process terminates into a pair of short apical teeth of sub-equal size (Fig. 9G). Subgenital plate with basal margin concavely incised; lateral margins convex, basal area strongly projecting dorsad on both sides, upcurved dorsal margin descending to about mid-length and afterward forming a narrow compressed dorsal lamella; ventral disc in entire basal half with concave surface and convex lateral margins that become concave in, and little widening again behind mid-length; in nearly apical half deeply incised from hind margin, leaving only the strengthened lateral margins with a compressed dorsal lamella; at tip with a pair of small styli (Fig. 11K). Titillators compressed throughout; at free base rather wide and little projecting distad; otherwise running dorsad, narrowing and subfused in about mid-length and then separating again; in dorsal area dividing into proximal and distal branches; proximal branches curved ventrad and fused at end to form in proximal view a U-shaped structure with wide margins and a medial furrow; apical branches strongly widened dorso-ventrally and with dorsal margin curved laterad; in ventral view it can be seen that the widened and sclerotized apical branches are connected to the corresponding basal branches in nearly full length to form a large wall; in lateral view with dorsal margin concave and at end little roundly projecting, afterward running ventrad to about same level as bases of titillators; at ventral margin curved distad, forming a narrowing apical projection and end into a rounded tip with serrulate margin and granular surface (Figs 15D-H). Two large lateral sclerites with three-fold lamellae are also present. 

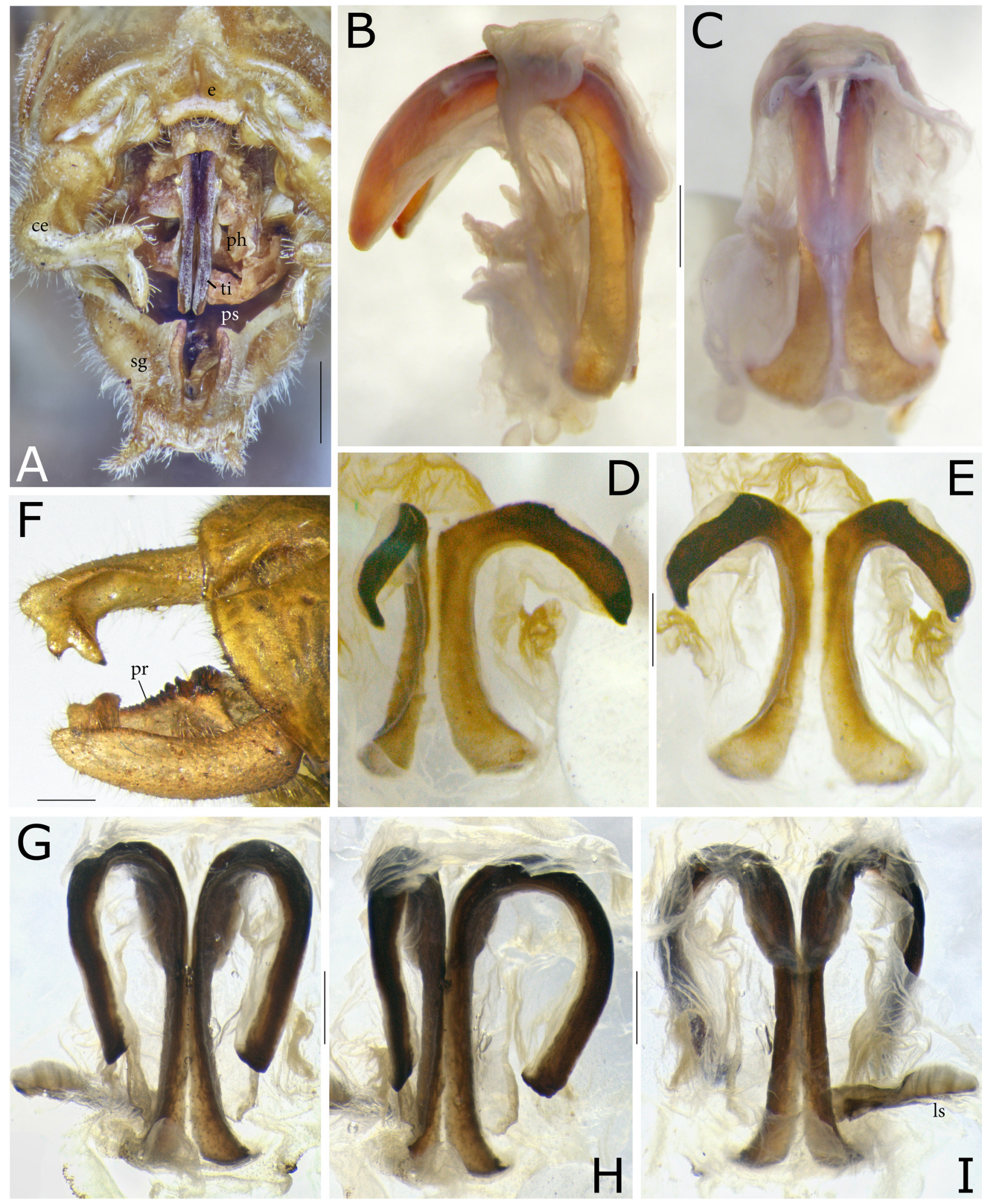

FIGURE 12. Male titillators and other abdominal appendages of Habetia species: A-C, H. tuta sp. nov. (A Quelllager, B-C Töpferfluß); D-E, H. pedala sp. nov. (Toricelli Mts); F-I, H. imitatrix Karny, 1912 holotype.-Abdominal apex with titillators in situ (A); titillators in lateral (B), dorso-proximal (C, I), oblique ventro-apical (D, H), and strict ventro-apical views (E, G); abdominal apex with dorsal projection of subgenital plate in lateral view (F).- Abbreviations: ls lateral sclerite, ph phallus, pr apical projection of subgenital plate, ps phallus sheath, sg subgenital plate. All scales $1 \mathrm{~mm}$. 

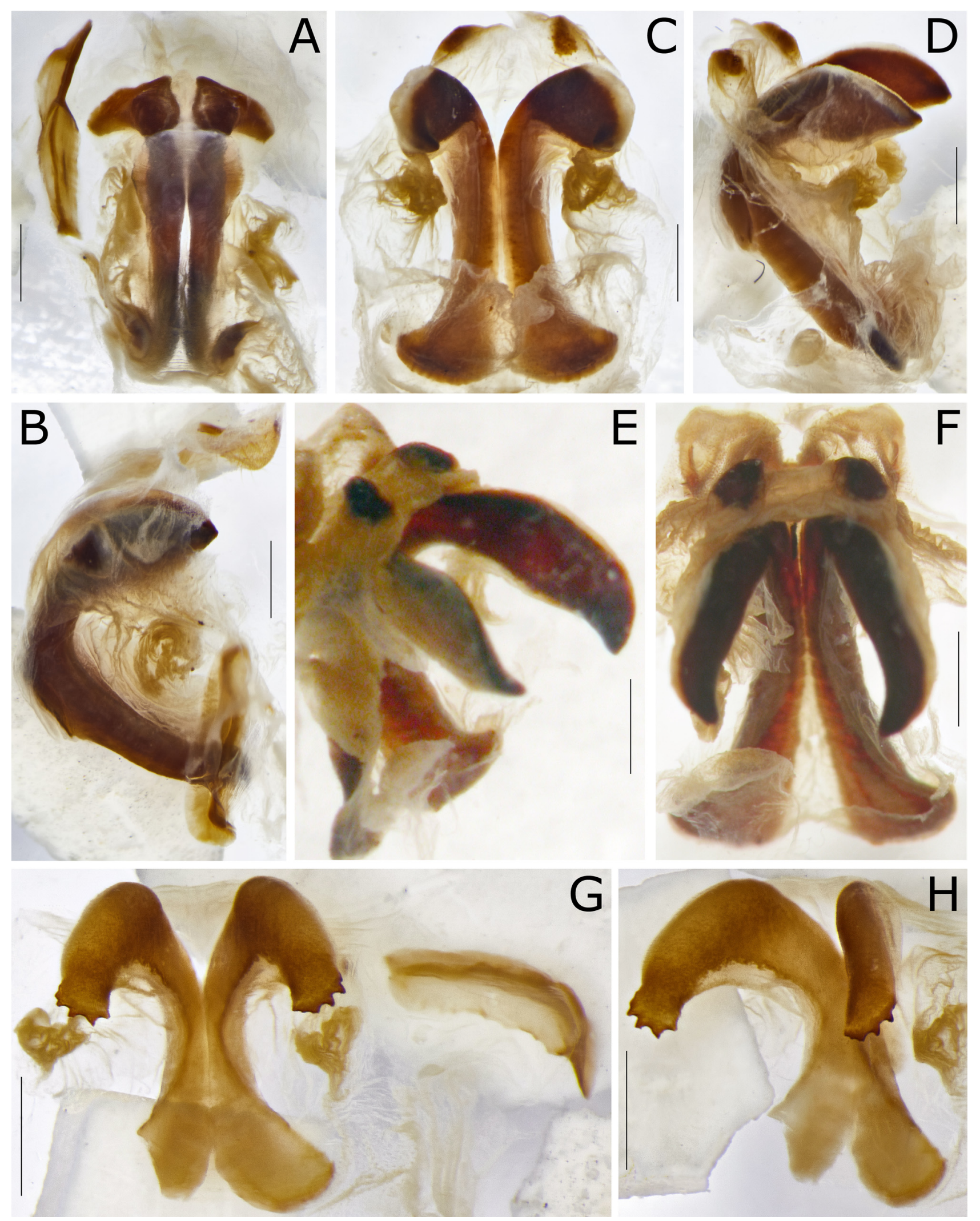

FIGURE 13. Male titillators of Habetia species in ventro-apical view (A, C, G), lateral view (B, D), oblique lateral view (E), oblique view on top (F), oblique vento-apical view (H).-A-F, H. pallida sp. nov. (A-B Waris, C-D Ifar, E-F Ned.N.G.); G-H, H. dentata sp. nov. (Saidor).-Scales $1 \mathrm{~mm}$. 


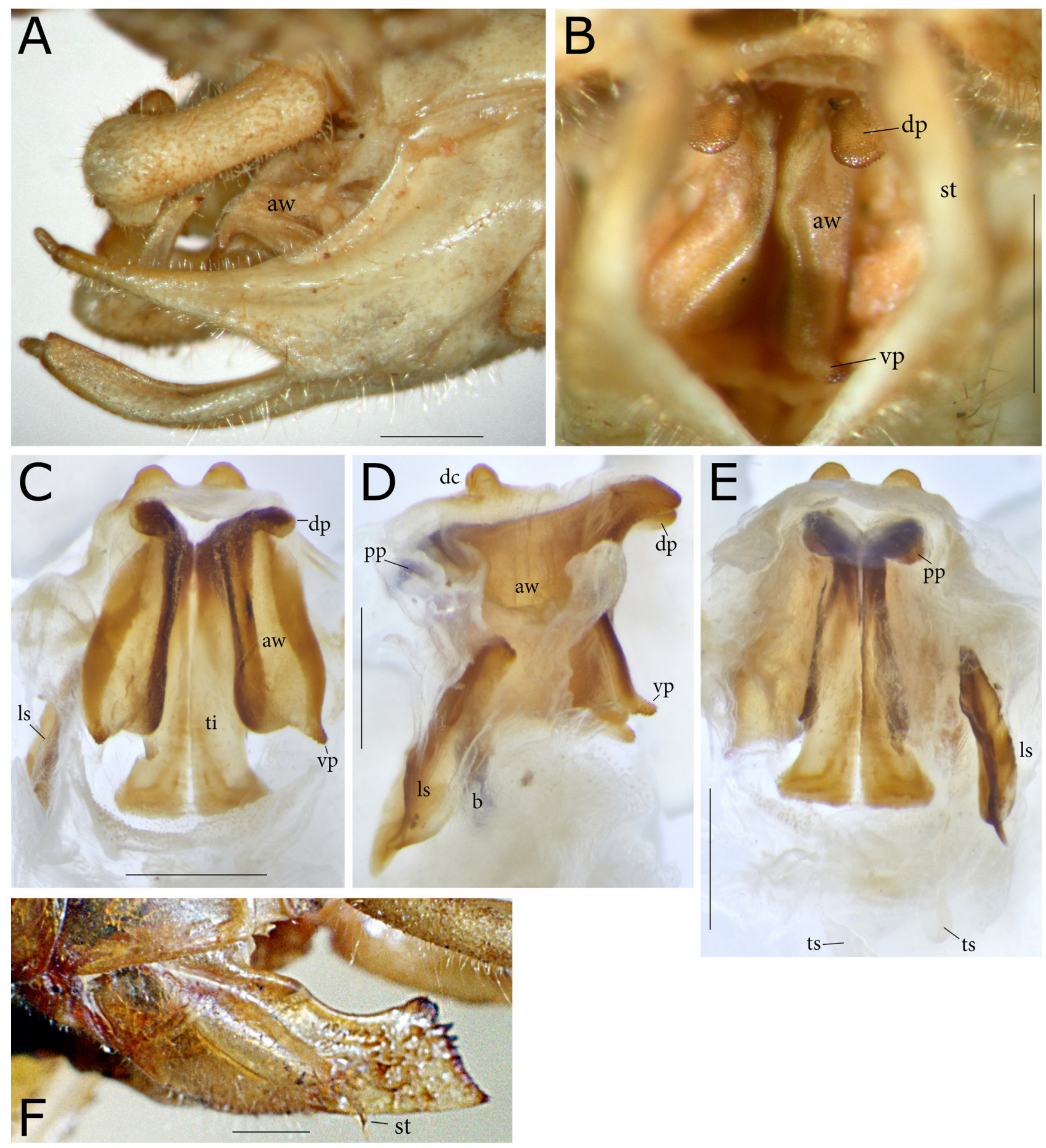

FIGURE 14. A-E: Titillators of Habetia bivittata sp. nov. (A-B in situ, male from Goroka, C-E dissected, male from Moife).A, abdominal apex in lateral view; B, view through the gap of the subgenital plate on the apical widenings of the titillators; C-E, titillators of male phallus in ventro-apical (C), lateral (D), and dorso-proximal (E) views.-F: Habetia imitatrix Karny, 1912 male subgenital plate with apical projection in lateral view.-Abbreviations: aw apical widening, b base of titillator, dc dorsal cap, dp dorso-apical projection, ls lateral sclerite, pp proximal projection, ti titillator stem, ts testes, vp ventral projection; st stylus of subgenital plate. Scales $1 \mathrm{~mm}$. 

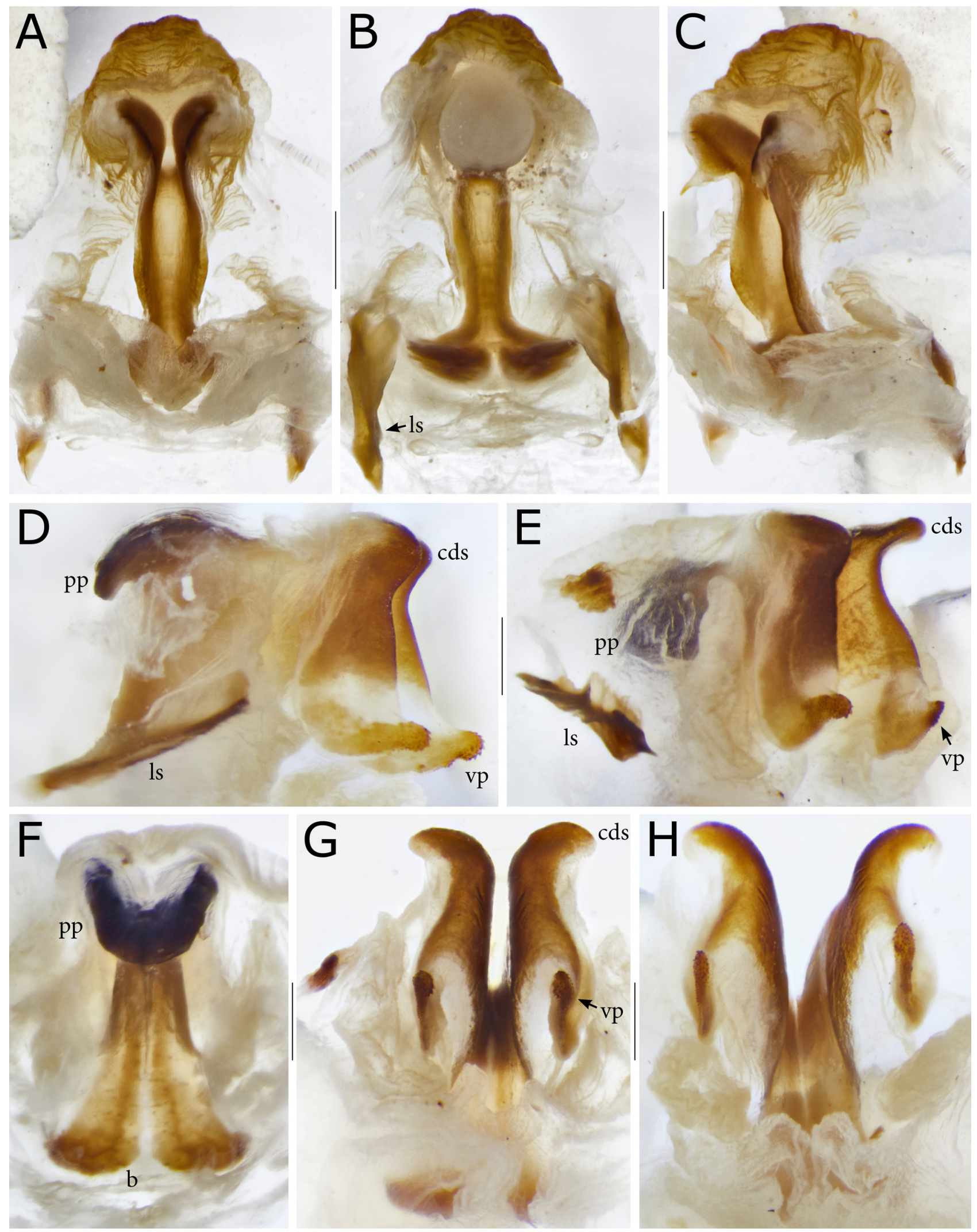

FIGURE 15. A-C, Habetia pilleata sp. nov. (Wau 1200 m); D-H, Habetia wau sp. nov. (Wau 1100-1500 m). - Titillators in proximal view (A), distal view (B), oblique proximo-lateral view (C), lateral view (D), oblique lateral view (E), proximal view (F), distal view $(\mathrm{G})$, ventro-distal view $(\mathrm{H})$.- -Abbreviations: b base, cds out curved dorsal surface, ls separate lateral sclerite, pp proximal projection, vp ventro-apical projection. Scales $1 \mathrm{~mm}$. 

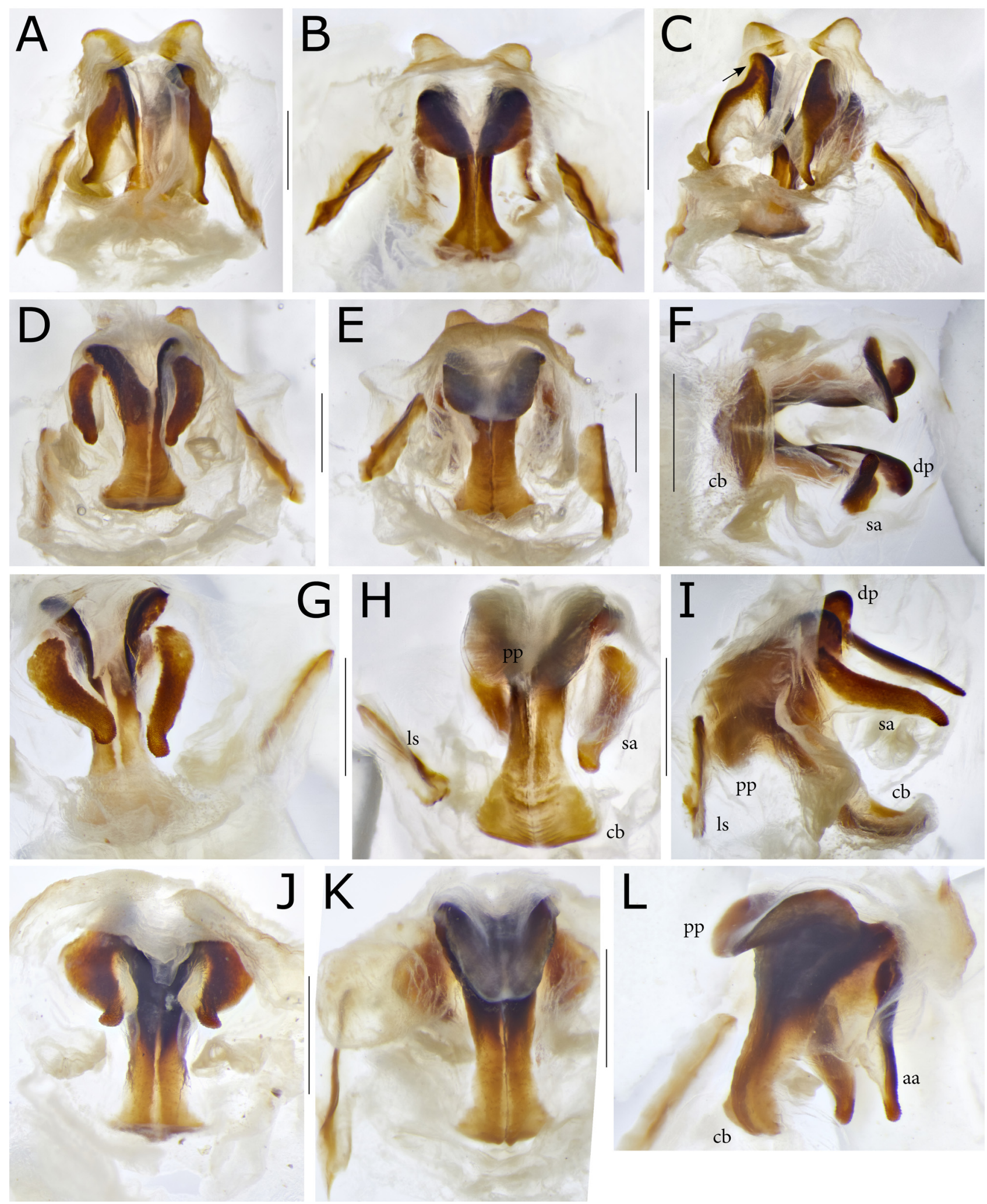

FIGURE 16. A-C, Habetia simbai sp. nov. (Simbai Valley); D-I, Habetia kondiu sp. nov. (D-E Kubor Range, F-I Wabag); J-L, Habetia lalibu sp. nov. (Lalibu). - Male titillators in distal view (A, D, G, J), in proximal view (B, E, H, K), in oblique distal view (C), in ventral view (F), and in oblique lateral view (I, L).-Abbreviations: aa apical arm, cb curved base, dp dorsal projection, ls lateral sclerite, pp proximal projection, sa separate apical arm. The arrow points at the hinge between the central and apical area of the titillator. Scales $1 \mathrm{~mm}$. 

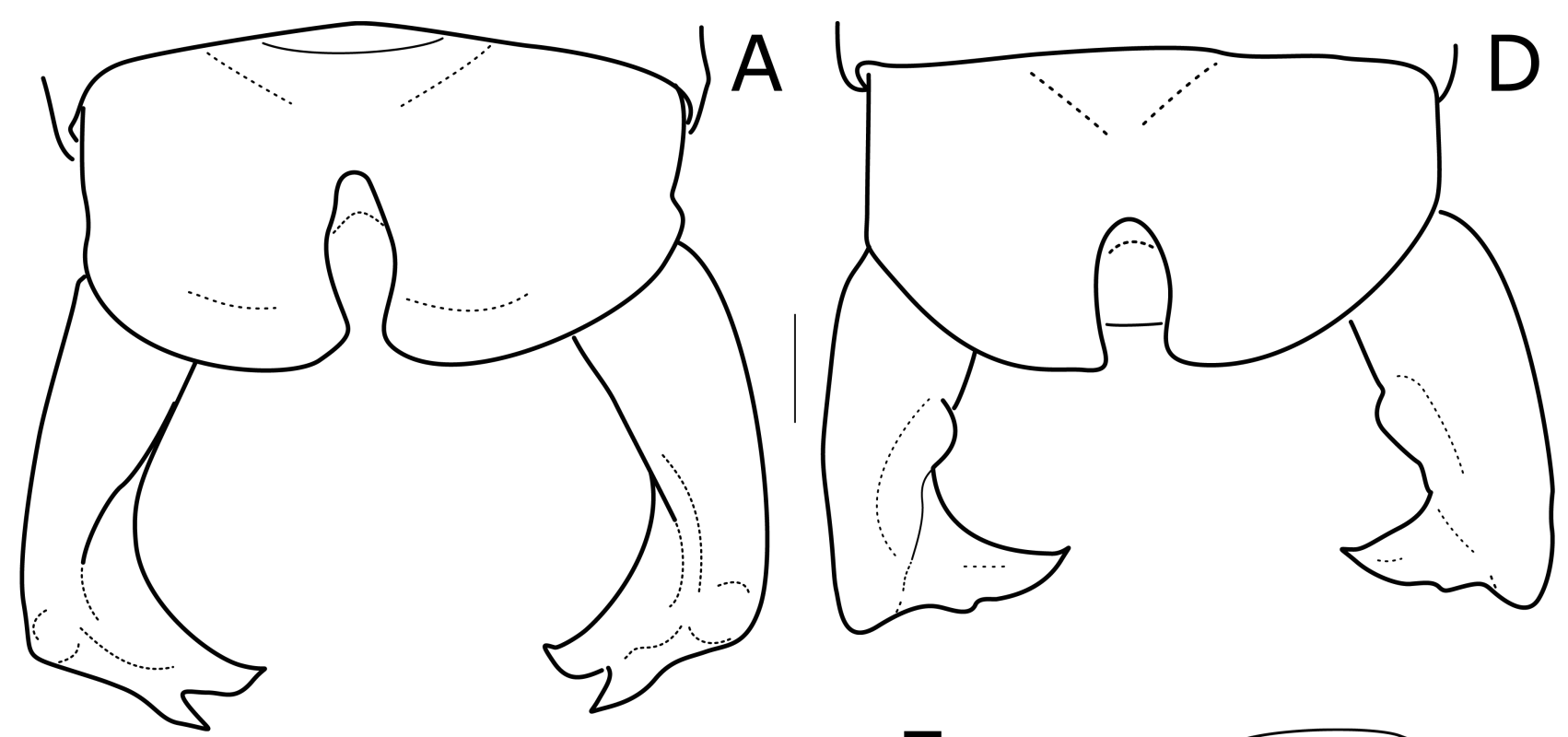

$\mathrm{B}$
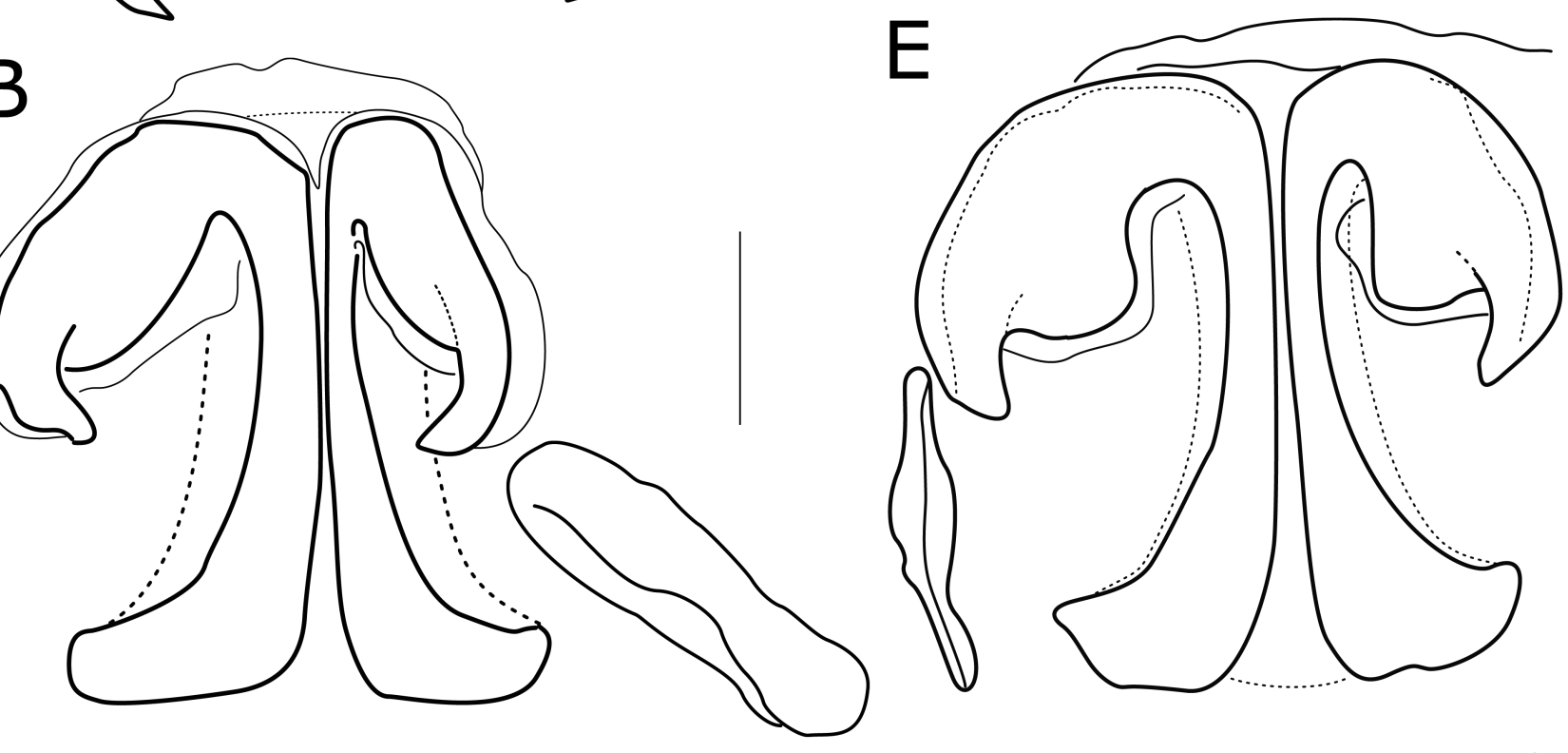

C

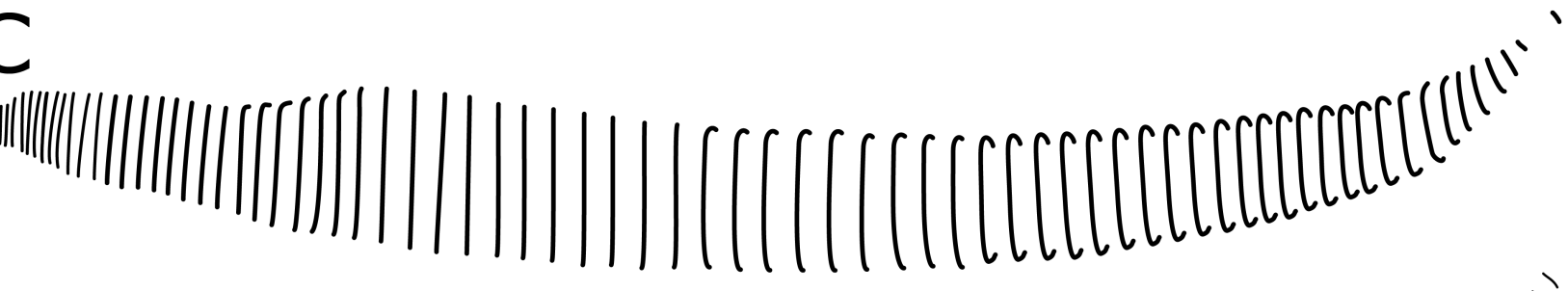

$\mathrm{F}$

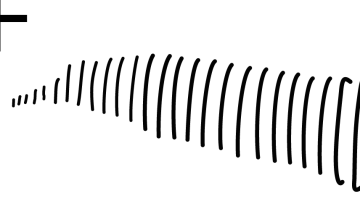

FIGURE 17.A-C, Habetia pallida sp. nov. holotype (Bernhard Camp); D-F, Habetia curvata sp. nov. holotype (Mamberamo).Male tenth abdominal tergite and cerci in dorsal view (A, D); titillators of male phallus in apical view, the lateral sclerites are drawn only at one side each (B, E); stridulatory file on underside of left tegmen (C, F). All scales $1 \mathrm{~mm}$. 

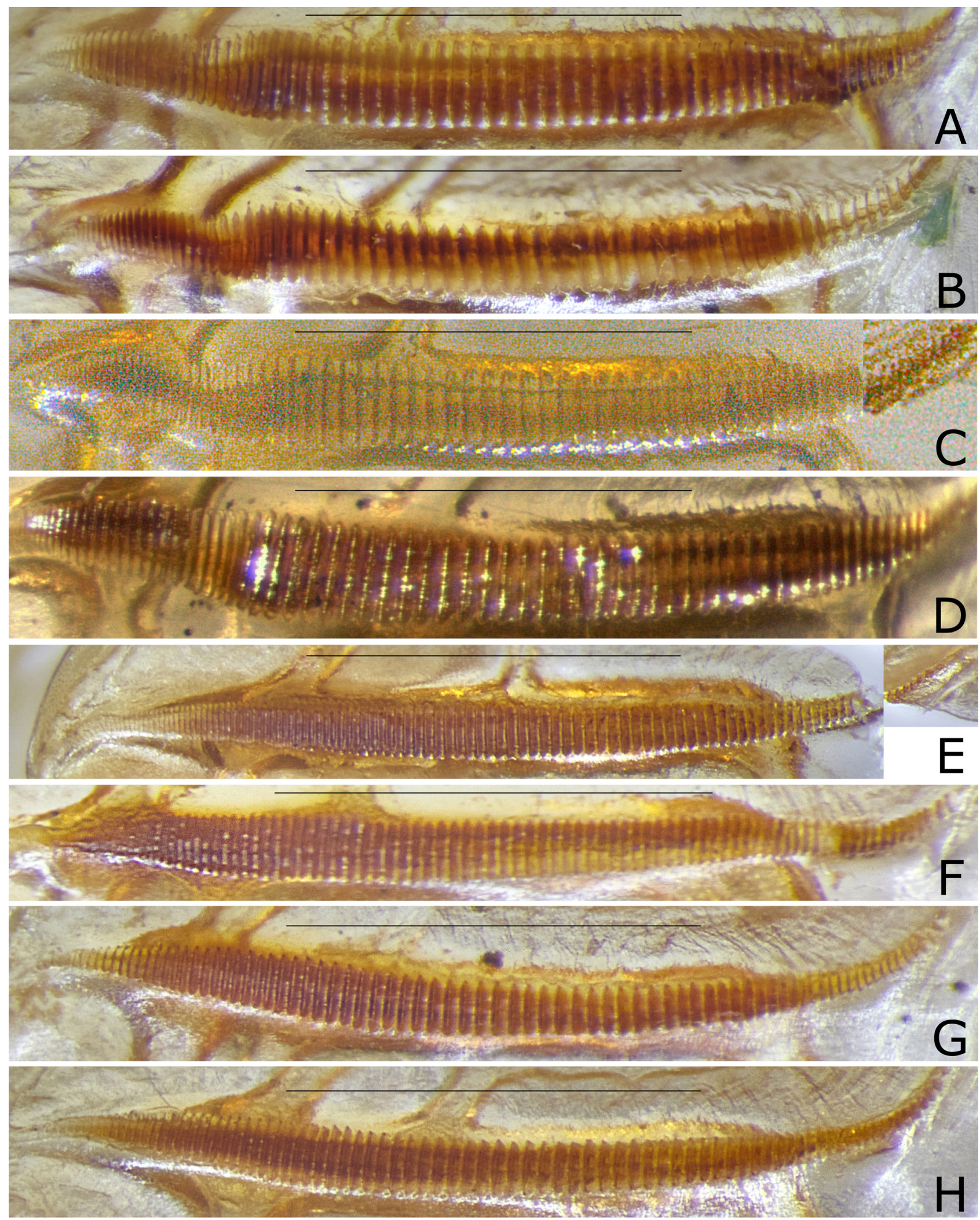

FIGURE 18. Stridulatory files on underside of left tegmen of males of Habetia species: A, H. tuta sp. nov. (Lake Chambri); B, H. pallida sp. nov. (Waris); C, H. pedala sp. nov. (Toricelli Mts); D, H. imitatrix Karny, 1912 (Bongu); E, H. dentata sp. nov. (Saidor); F, H. pilleata sp. nov. (Wau 1200 m); G-H, H. wau sp. nov. (G Nami Creek; H Wau).-Scales 1 mm. 

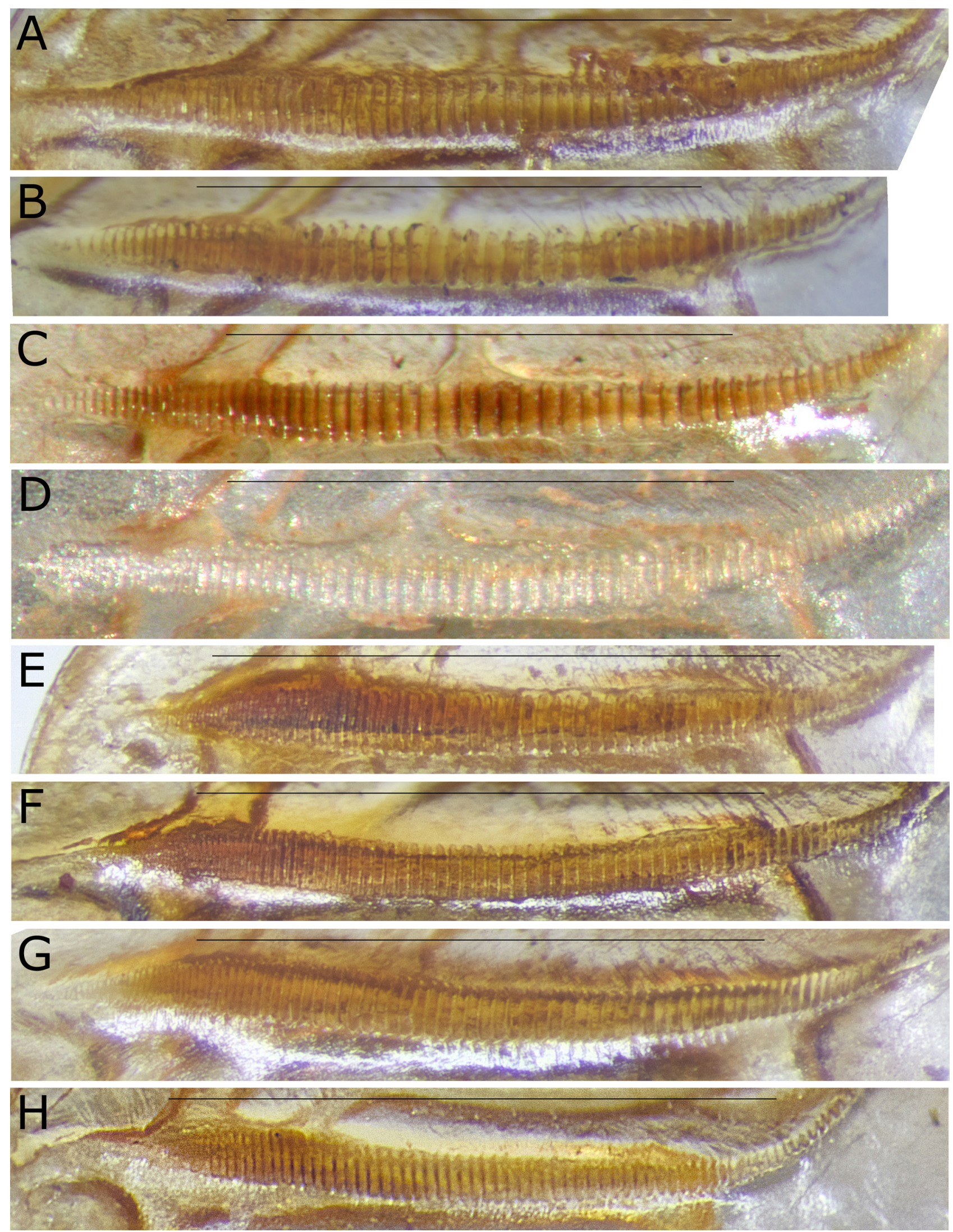

FIGURE 19. Stridulatory files on underside of left tegmen of males of Habetia species: A-D, H. bivittata sp. nov. (A Sinofi, B Daulo Pass, C-D Goroka); E-F, H. kondiu sp. nov. (E Kubor Range, F Wabag); G, H. lalibu sp. nov. (Lalibu); H, H. simbai sp. nov. (Simbai Valley). Scales $1 \mathrm{~mm}$. 
Female. Subgenital plate at base in central area slightly elevated and with long and upcurved lateral lobes with obtuse tip and nearly flat surface but separated from central plate by a deep and wide furrow; ventral disc with transverse furrow in subbasal area afterward curved anterior-posteriorly with converging lateral margins that terminate into a pair of upcurved cones; apical margin faintly concave between lateral cones (Figs 6D, 7F-G). Ovipositor about as long as body; behind basal constriction straight (Fig. 2G).

Measurements ( 8 males, 8 females).-Body w/wings: male 35.0-36.5, female 36-41; body w/o wings: male 23-28, female 21-29; pronotum: male 7-8, female 7.0-8.5; tegmen: male 25-27, female 26-31; hind femur: male 18-20, female 18-22; antenna: male 85 ; ovipositor length: female 19.0-23.5; ovipositor height: female 2.0-2.3 $\mathrm{mm}$.

\section{Habetia nigricauda sp. nov.}

Figs 2I, 4I, 6C, 7N-O, Map 1(19).

Holotype (female): Papua New Guinea: Northern, Popondetta, elev. 60 m ( $8^{\circ} 46^{\prime}$ S, 148 14 'E), 1.vi.-31.vii.1970, leg. R. Straatman - depository: Naturalis Biodiversity Center, Leiden (NBC).

Other specimens studied: same data as holotype -1 female (paratype, NBC).

Diagnosis. The new species is striking for the dark tegmen with light veins and veinlets and the dark brown to black subgenital plate. Apart from the dark coloration, H. nigricauda sp. nov. is similar to $H$. wau sp. nov. but differs in details of subgenital plate and ovipositor. The female subgenital plate has the transverse subbasal furrow markedly delimited by a rather deeply impressed and narrow furrow instead of becoming gradually flattened toward fore and hind margins in $\mathrm{H}$. wau, this is more strongly expressed by bulging elevations along anterior and lateral margins in $H$. nigricauda that are absent in $H$. wau. The ovipositor is rather short for the genus in both species. In $H$. nigricauda it is in the mean little longer than in $H$. wau, 24.3 against $20.9 \mathrm{~mm}$, and $H$. nigricauda is generally little larger. The black coloration of the hind knees is distinct and more extended in H. nigricauda, little expressed in $H$. wau.

Description. Coloration of face pale, of general color; ventral and lateral areas of antennal scrobae and ventrolateral margin of frons and ventral margin of genae black; mandibles in basal area black, brownish thereafter (Fig. 4I). Tegmen dark brown in anterior area, gradually changing to medium brown posteriorly; veins and veinlets pale yellowish. Hind knees black. Subgenital plate black, lighter toward end and at lateral margins. Ovipositor brown. Femora with the following number of spines on ventral margins: (1) a 5-7, p 7-8; (2) a 6, p 2-3; (3) a 9-12, p 10-12 $(\mathrm{n}=2)$.

Male unknown.

Female. Subgenital plate with anterior margin raised; baso-lateral areas expanded dorsad, with parallel margins and convex dorsal end, furrowed along mid-length; disc of subgenital plate in sub-basal area with a transverse groove, which is bordered along proximal and lateral margins by a convex, bulging carina, the furrow widened in middle and narrowing towards both sides; area behind furrow little elevated and with flat surface; lateral margins of disc behind baso-lateral expansions with, in ventral view converging, and in lateral view bulging lateral margins that terminate into a pair of lateral, spine-like projections, apical margin between these projections straight (Figs 6C, $7 \mathrm{~N}-\mathrm{O}$ ). Coloration of subgenital plate black in anterior area including lateral expansions and changes to dark and medium brown in apical area; dorsal margin of baso-lateral expansions and lateral angles of transverse bulge yellow brown; apical area of bulging lateral margins and tip of apical spine-like projections pale yellowish. Ovipositor elongate but shorter than body, with faintly convex margins around mid-length; tip obtuse (Fig. 2I).

Measurements ( 2 females). - Body w/wings: 43-45; body w/o wings: 30-32; pronotum: 8.1-8.4; tegmen: 32.5; hind femur: 24; ovipositor length: 23.5-25.0; ovipositor height: female $2.0 \mathrm{~mm}$.

Etymology. The name of the new species refers to the color of the female subgenital plate, which is largely black; from Latin niger, nigra, nigrum $=$ black and $c a u d a=$ tail or end piece.

\section{Habetia lalibu sp. nov.}

Figs 4G, 9F, 11J, 16J-L, 19G, 20D, Map 1(11).

Holotype (male): Papua New Guinea: New Guinea NE, Lalibu, elev. 2300 m (6¹6’S, 14359’E), 8-14.iv.1968, leg. J.L. Gressitt \& Mea—depository: Bernice B. Bishop Museum, Honolulu (BPBM). 
Other specimens studied: same data as holotype 1 male (paratype, BPBM).

Diagnosis. $H$. lalibu sp. nov. belongs to a group of species that have the male cerci with a simple, rounded projection on the dorsal margin just before the cercus is curved mediad into the compressed apical internal process instead of a prolonged, wavy projection as in H. bivittata sp. nov. It differs from the other three species with similar basic structure of the cerci (H. kondiu sp. nov., H. simbai sp. nov., and H. wau sp. nov.) by the dorsal projection that is swollen instead of flattened and the internal projection is almost parallel sided with a pair of tubercles of equal size at tip instead of with distinctly converging margins and with a pair of acute teeth or with a curved process as in $H$. wau. The male tenth abdominal tergite has a narrow and short apical incision as in $H$. simbai but different from the long and wide apical incision as in $H$. kondiu and $H$. wau; however, the tenth tergite of $H$. lalibu has the apical margin concave on both sides of the incision and with a short obtuse projection on both sides, while in $H$. simbai the apical margin on both sides of the apical incision is obliquely truncate. The male titillators of $H$. lalibu have the proximal projections subfused and with upcurved lateral margins, forming together a wide furrow, and the distal projections are widened and strongly curved, while in the two species with similar titillators, $H$. simbai and $H$. kondiu, the proximal projections are separate, and the distal projections forming moveable arms or are separated from the titillator stem.

Description. Coloration of face of general color; mandibles darkened at base, otherwise of general color; in one male part of antennal scrobae in external half of ventral margin black (Fig. 4G). Femora with the following number of spines on ventral margins: (1) a 6, p 6-9; (2) a 5-6, p 3; (3) a 9-11, p 10-11 (n=2).

Male. Stridulatory file on underside of left tegmen $1.6 \mathrm{~mm}$ long, with $87-88$ teeth that are at both ends very narrow with 15-16 basal and 23-28 apical teeth, in central $1 \mathrm{~mm}$ of file with 48-49 teeth, of which are 21-22 largest teeth in central $0.5 \mathrm{~mm}, \mathrm{n}=2$ (Fig. 19G). Tenth abdominal tergite in about basal half with sub-parallel but little wavy, down-curved lateral areas, afterward with approaching lateral margins, forming a pair of obtuse triangular lobes, in middle of concave hind margin between both triangular lobes roundly incised (Fig. 9F). Epiproct with medial furrow and apical margin rounded. Cerci elongate, rounded with slightly approaching lateral margins; at end suddenly bent in a roughly $90^{\circ}$-angle mediad into compressed internal projections that end into a pair of very short, obtuse tubercles; cercus stem just before apical curvature with a semi-circular but little swollen dorsal crest; internal surface of cercus little excavated around curvature (Fig. 9F). Subgenital plate in lateral view curved throughout; in basal area elevated and provided with a large oval swelling that is in situ probably hidden by the ninth tergite, afterward with dorsal rim and a lateral furrow in about mid-length of plate; ventral surface from base with a large triangular and membranous incision, lateral margins little swollen; in about apical third subgenital plate deep roundly, in middle little angularly incised and up-curved, in apical area consisting only of the stiffened lateral margins that are faintly approaching towards tip; styli short, inserted at underside of the narrow apical extensions of the subgenital plate (Fig. 11J). Titillators at base slightly widened and faintly curved, basal branches subfused, separated by a fine membranous suture; in upper area divided into proximal and distal branches; proximal branches stick together, curved proximo-ventrad, have lateral areas upcurved, and tip shortly bi-lobate; distal branches around dividing point fully fused and black, after a short distance divided from each other and running more dorsad and laterad; afterward they are strongly curved ventrad and little approaching each other while becoming markedly wider and reddish brown, at end they are compressed, becoming roughly circular plates with granular surface and margin and are slightly projecting distad (Figs 16J-L). There is also a pair of large elongate lateral sclerites with three flattened expansions from a little wavy central spindle, and the membranes covering the titillators dorsally are provided with a pair of small, rounded caps.

Measurements (2 males). - Body w/wings: $39-41$; body w/o wings: $32-33$; pronotum: $8.2-8.5$; tegmen: $28.5-$ 29.5; hind femur: 20.0-21.5; tegmen width: 4.5-5.0 mm.

Etymology. The new species is named after the type locality, noun in apposition.

\section{Habetia kondiu sp. nov.}

Figs 2E, 4E, 6G-H, 7D, 9D-E, 11I, 16D-I, 19E-F, 20B, Map 1(8).

Holotype (male): Papua New Guinea: Jiwaka province, Kondiu, Kubor Range, (555’S, 14452’'E), 1.ii.-31.iii.1964, leg. P.C. Voss - depository: Zoologische Staatssammlung München (ZSM).

Other specimens studied: Papua New Guinea: same data as holotype - 1 female (paratype, ZSM); Southern 
Highlands, Mendi, (6 $\left.{ }^{\circ}{ }^{\prime} \mathrm{S}, 143^{\circ} 39^{\prime} \mathrm{E}\right), 7 . \mathrm{x} .1958-1$ female (ZSM); New Guinea (NE), $11 \mathrm{~km}$ south of Mt. Hagen

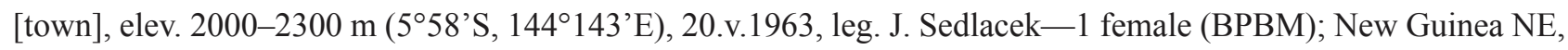

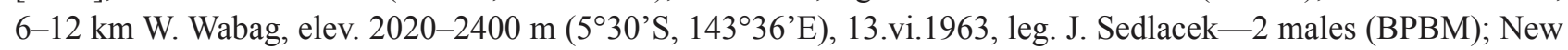
Guinea NE, Madang district, Simbai Valley, elev. 1750 m (5'16'S, 144³3'), 26.v.1965, leg. J.L. Gressitt—1 female (BPBM).

Diagnosis. The shape of the tenth abdominal tergite of $H$. kondiu sp. nov. being divided into two long apical lobes with obtuse tip resembles the situation in $H$. wau sp. nov. and differs from that of $H$. simbai sp. nov., while the shape of the male cerci is similar to those in H. simbai but markedly different from those in $H$. wau. It differs from both by the shape of the cerci that have the disc shaped projection running around the tip of the cercus while in $H$. wau and in $H$. simbai it projects only from the dorsal surface. The internal process of the male cerci is similar in $H$. kondiu and H. simbai, but in $H$. kondiu the short acute apical lobes are shorter than in $H$. simbai. The titillators of $H$. kondiu also resemble more those in $H$. simbai than the strongly modified shape in $H$. wau. The titillators of $H$. kondiu and H. simbai are of similar basic shape, but in $H$. kondiu the apical area of the distal branches is completely separated from the more basal area while in $H$. simbai it is still connected to but moveable against that area. The female of $H$. kondiu has the subgenital plate of similar general outline as in $H$. simbai; it differs by the margins of the subgenital plate being angular and the stout basal and lateral areas being thicker and wider and the compressed and thin central area narrower than in H. simbai.

Description. Coloration of face uniformly pale, of general color or laterally indistinctly darkened; antennal scrobae partly black or of same color as face; mandibles pale, only the in situ hidden tips black (Fig. 4E). Tegmen yellowish semi-transparent with dark cells especially in anterior area; radius in more than basal half brown (Fig. 20B). Coloration of abdominal tergites varies between specimens from light yellowish brown to dark brown or almost black. Femora with the following number of spines on ventral margins: (1) a 5-8, p 5-8; (2) a 5-8, p 2-4; (3) a $10-13, \mathrm{p} 10-14(\mathrm{n}=5)$.

Male. Stridulatory file on underside of left tegmen diagonal length $1.35-1.56 \mathrm{~mm}$, with $82-93$ teeth that are at both ends very narrow (19-30 apical, 9-14 basal teeth); in central $1 \mathrm{~mm}$ of file with 49-52 teeth, of which largest 21.5-22.0 teeth in central 0,5 mm (Figs 19E-F). Tenth abdominal tergite in less than basal half with sub-parallel, down-curved lateral areas, afterward with approaching lateral margins and deeply incised from apical margin forming a pair of triangular lobes with obtuse tips; bottom of apical incision obtusely rounded (Figs 9D-E). Epiproct roughly triangular with medial furrow and rounded angles. Cercus rounded elongate, in apical area curved mediad into a process with flattened dorsal surface and slightly approaching margins; the process terminates into two short cones with acute tips, ventro-apical cone little longer than dorso-proximal cone; at end of cercus stem with a semidisc-shaped projection around dorsal and apical margins with slightly concave internal and convex external surface (Figs 9D-E). Subgenital plate in lateral view curved throughout; in basal area elevated and provided with an oval swelling that in situ can be hidden from ninth tergite, afterward with dorsal rim and a lateral furrow in little more than basal half; ventral surface from base with a large triangular and membranous incision; lateral margins little swollen and with a shallow medial furrow; in about apical third deep roundly incised and upcurved, lateral margins little approaching towards tip; styli short, inserted at underside of the narrow apical branches of the subgenital plate (Fig. 11I). Titillators at very base shortly curved distad, otherwise in basal area subfused and parallel, at end becoming darker and divide into proximal and distal branches; proximal branches curved proximad and ventrad and end into rounded tips that are covered by a common hyaline membrane; distal branches curved dorso-distad and end into obtuse tips; on ventro-apical side of these obtuse tips with a pair of broad, flattened and markedly curved dark sclerites that are connected to the titillator stem only by membrane and end into a compressed, nearly disc shaped apex with serrulate margin (Fig. 16D-I). A pair of large, elongate, three-edged lateral sclerites with wavy margins is also present.

Female. Subgenital plate at base with long dorso-lateral projections with wide obtuse end; hind margin of these projections from about mid-length widened into an oblique connection with the lateral rims of ventral surface; ventral surface with basal margin little concave, followed behind by an indistinctly outlined, transverse oval groove; stiffened lateral margins long, running parallel to each other and are narrowed toward subacute tips; about half of the area between the stout margins connected by a thin and little caved-in membranous surface (Figs 6G-H, 7D). Ovipositor little shorter than body; behind basal constriction dorsal margin convex, markedly but not very strongly elevated in middle and narrowing again towards sub-obtuse tip. (Figs 2E). 

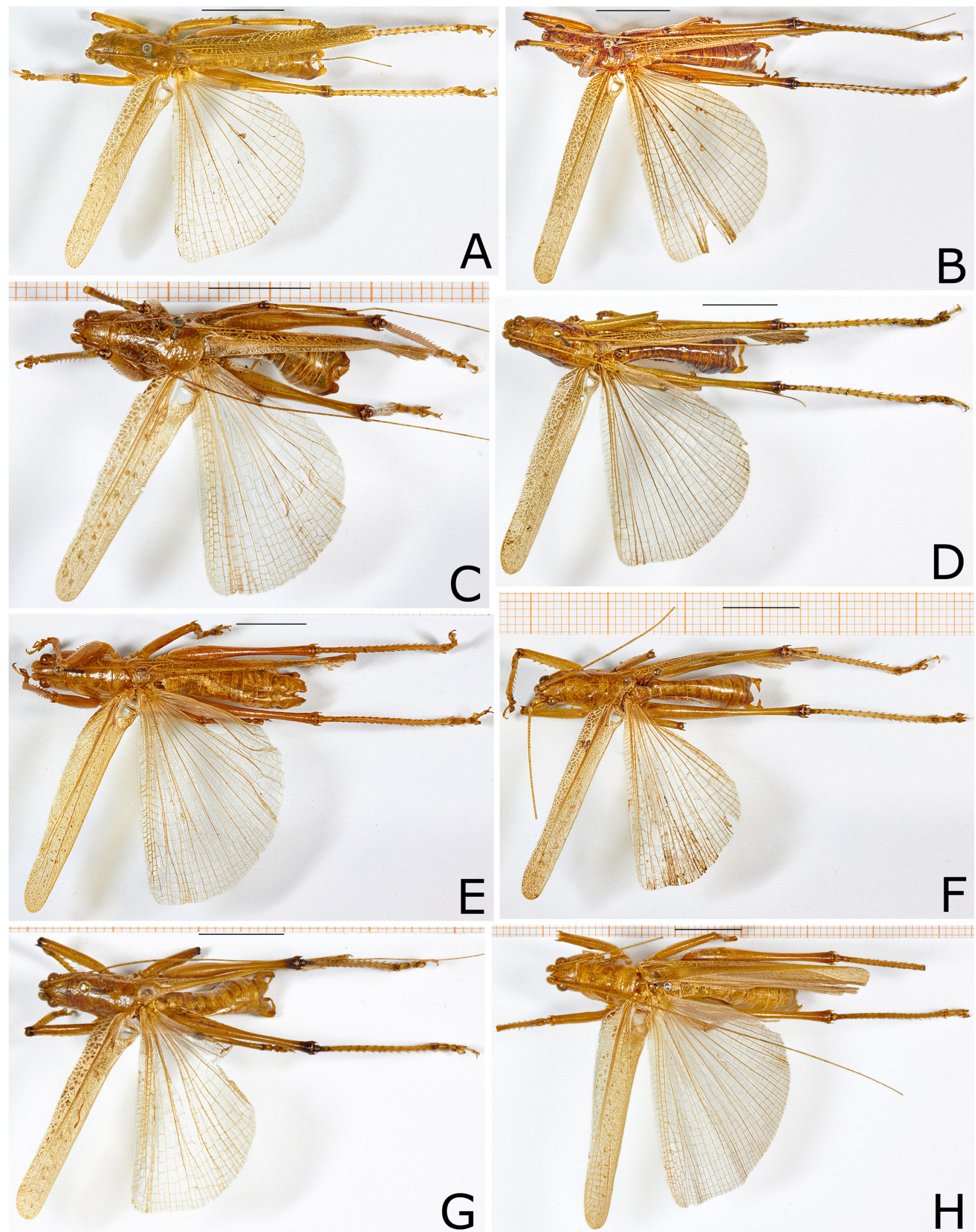

FIGURE 20. Habetia sp. males: Habitus in dorsal view with left wings spread.-A, H. bivittata sp. nov. (Moife); B, H. kondiu sp. nov. (Wabag); C, H. dentata sp. nov. (Saidor); D, H. lalibu sp. nov. (Lalibu); E, H. pilleata sp. nov. (Wau); F, H. simbai sp. nov. (Simbai Valley); G, H. wau sp. nov. (Wau); H, H. tuta sp. nov. (Lake Chambri).—All scales $10 \mathrm{~mm}$. 
Measurements (3 males, 4 females). - Body w/wings: male 36-39, female 39-41; body w/o wings: male 28-32, female 27-31; pronotum: male 7.0-8.2, female 7.5-8.0; tegmen: male 27-30, female 30-31; hind femur: male 20-21, female 21.0-24.5; antenna: female 75; ovipositor length: female 24-26; ovipositor height: female $2 \mathrm{~mm}$.

Etymology. The new species is named after the type locality, noun in apposition.

\section{Habetia simbai sp. nov.}

Figs 2F, 4H, 6E, 7E, 9H, 11H, 16A-C, 19H, 20F, Map 1(12).

Holotype (male): Papua New Guinea: New Guinea NE, Madang district, Simbai Valley, elev. $1750 \mathrm{~m}\left(5^{\circ} 16^{\prime} 7^{\prime}\right.$ 'S, 14432’35.46”E), 26.v.1965, leg. J.L. Gressitt—depository: Bernice B. Bishop Museum, Honolulu (BPBM).

Other specimens studied (paratypes): same data as holotype -2 males, 1 female (BPBM).

Diagnosis. Males of $H$. simbai sp. nov. are similar to those of $H$. lalibu sp. nov. The new species differs by the tenth abdominal tergite that has the apical margin on both sides of the medial incision straight not concave nor with projecting lateral angles; the male cerci have the dorsal apical projections compressed not bulging and the apical internal process is anterior-posteriorly compressed and terminates into a pair of spines while in H. lalibu it is dorso-ventrally compressed and terminates into a pair of tubercles. The shape of the internal process resembles the situation in H. kondiu sp. nov. which has however the dorsal projection running around the apical margin of the cercus, not restricted to the dorsal margin as in $H$. simbai and the shapes of the tenth abdominal tergite of both species are quite different. The titillators of $H$. simbai are similar to those in H. lalibu and $H$. kondiu but differ in having the apical area of the titillators separated by a short sub-membranous area from the central area, which might allow a separate movement of the apical arm (Fig. 16A-C), while the apical arm is either completely separated in $H$. kondiu or continuous with the central area in H. lalibu. The female subgenital plate of H. simbai is similar to that of $H$. kondiu but wider and has the anterior lateral angles less strongly extended dorsad, the lateral margins less strongly bulging and the flattened central area hardly instead of markedly depressed; in lateral view the central area appears straight, only upcurved at tip, while in both other species it is gradually curved onto tip.

Description. A slender species with narrow tegmina that only slightly surpass the hind knees (Fig. 2F). Coloration of face uniformly pale, of general color, mandibles in more basal and in apical areas black, in between of various shades of medium to dark brown, ventral rim of genae and lateral areas of clypeo-frontal suture of same color; rim of antennal scrobae in lateral and external areas darkened (Fig. 4H). Femora with the following number of spines on ventral margins: (1) a 5-6, p 4-7; (2) a 5-7, p 2-3; (3) a 7-11, p 6-12 (n=4).

Male. Stridulatory file on underside of left tegmen $1.54 \mathrm{~mm}$ long, with 75 teeth that are at both ends very narrow (12 apical and 16 basal teeth); in middle of file with 47 teeth at $1 \mathrm{~mm}$, or in central $0.5 \mathrm{~mm}$ with 22 teeth, $\mathrm{n}=1$ (Fig. 19H). Tenth abdominal tergite wider than long; in basal half with down-curved lateral areas, then with approaching and slightly concave lateral margins, apical margin sub-truncate but little oblique toward middle where it is interrupted by a rounded notch; surface in front of that notch furrowed in midline (Fig. 9H). Epiproct with medial furrow and rounded tip. Cerci moderately long and narrow, towards apical area with flattened of faintly concave internal margin and curved nearly rectangularly mediad into an internal process; curved area with a compressed, roughly semi-circular crest on top; process laterally compressed and with approaching dorsal and ventral margins; at end divided into two short rounded projections; dorsal projection little longer than ventral projection; both with a short acute and faintly downcurved spine at tip (Fig. 9H). Subgenital plate curved along longitudinal axis; base widely incised but faintly projecting in middle; lateral margins little stiffened throughout, approaching from base to about mid-length and then widening again toward strongly incised apical area; styli short, inserted at underside of the narrow apical branches of the subgenital plate (Fig. 11H). Titillators at very base subfused and shortly curved distad with rounded basal margins, afterward compressed, nearly band-shaped and fixed to each other by a narrow transparent septum; at dorsal end on proximal side with rather large, roughly oval compressed projections curved laterad; on distal side with elongate and nearly black, moderately widened and compressed projections with dorsal margin little curved; from the concave ventro-distal surface of these proximal projections and connected to them by a very short membranous area with elongate secondary projections that in internal view appear narrow band-shaped and curved several times, in apico-lateral view widened, ventrally expanded in basal half, afterward narrow and curved twice; that distal pair of projections terminate into rounded, serrulate tips; space between basal and apical posterior projections filled by a transparent, hyaline membrane, leaving only the serrulate tip free (Fig. 16A-C). 
Female. Subgenital plate consisting of a central plate with posteriorly converging lateral margins and rather simple, moderately up-bent baso-lateral expansions that have the apical area at proximal side little grooved, at distal side slightly swollen; central part with posteriorly approaching lateral margins only little upcurved; ventral surface wide and except for margins shallowly grooved, at end concavely incised and on both sides prolonged into a rather short, little upcurved, and acute spine-like process (Figs 6E, 7E). Ovipositor about as long as body, little longer than hind femur; behind basal constriction dorsal margin convex, but only faintly elevated around mid-length, tip subobtuse (Fig. 2F).

Measurements (3 males, 1 female).-Body w/wings: male 35.5-37.0, female 42.0; body w/o wings: male 28.0 28.5, female 30.0; pronotum: male 7.2-7.5, female 7.5; tegmen: male 26-28, female 31; hind femur: male 22-23, female 24; tegmen width: male 3.5; ovipositor length: female 32.5; ovipositor height: female $2.2 \mathrm{~mm}$.

Etymology. The new species is named after the type locality, noun in apposition.

\section{Habetia elevata sp. nov.}

Figs 2C, 6J, 7L-M, Map 1(18).

Holotype (female): Papua New Guinea: Morobe, $25 \mathrm{~km}$ South of Salamaua, elev. 1-80 m ( $\left.7^{\circ} 13^{\prime} \mathrm{S}, 1^{\circ} 7^{\circ} 7^{\prime} \mathrm{E}\right)$, 25-26.i.1969, leg. J. Sedlacek—depository: Bernice B. Bishop Museum, Honolulu (BPBM).

Diagnosis. A rather stout and compact species compared to the other species of the genus. Wings surpassing hind knees. The species is unique for the shape of the female subgenital plate that has the dorso-lateral projections strongly prolonged on basal side and the apical area is, in lateral view, hidden between the projecting lateral surfaces. In strict lateral view it thus appears that the subgenital plate is becoming wider toward tip (Fig. 7M) while in the other species it is becoming narrower and terminates into a pair of narrow projections. In ventro-apical view the plate has a rectangular frame in center with bi-triangular apical margin, while the lateral areas are strongly stretching dorso-laterad. H. elevata sp. nov. is also striking for the large excavation of the eight abdominal tergite from the ventro-posterior angle, leaving only a narrow, sclerotized band along the anterior margin while the dorsal area of the tergite is normal; the rim of the tergite around the excavation is strengthened and little projecting; that space provides room for articulation of the baso-lateral extensions of the subgenital plate and the base of the ventral ovipositor valves.

Description. Coloration of face uniformly pale, of general color, mandibles black. Femora with the following number of spines on ventral margins: (1) a 6, p 7-8; (2) a 6-7, p 3; (3) a 15-16, p 16.

Male unknown.

Female. Eighth abdominal tergite with a large membranous convexity at latero-posterior angle providing room for base of subgenital plate and ventral ovipositor valves. The narrow lateral expansions of the subgenital plate appear in lateral view to be squeezed between the long and narrow membranous area at base of the ventral ovipositor valve and the eight abdominal sternite; the ventral margin with a small sub-basal convexity otherwise reflect the modifications of the ventral surface (Fig. 7M). Subgenital plate in ventral view sub-triangular with concave basal margin and strongly converging lateral margins, concave near base, convex thereafter; behind about basal third in middle of plate with elevated ridges forming a rectangular elevation with straight basal and lateral margins that embrace a depression; that structure surpasses the converging lateral margins of the plate and terminates into a pair of triangular extensions with less elevated rims; baso-laterally of that structure there is a pair of short and stout curved ridges (Fig. 6J). In lateral view, the dorsal margin of the subgenital plate appears nearly straight. The apical area is hidden between the projecting apical margins of the rectangular elevation, while the ventral margin reflects the sculptured ventral surface of the plate (Figs 7L-M). Ovipositor little shorter than body in the single female at hand; behind basal constriction dorsal margin convex, strongly elevated to about mid-length, then narrowing again towards sub-obtuse tip (Fig. 2C).

Measurements ( 1 female).—Body w/wings: 56 ; body w/o wings: 47; pronotum: 10; tegmen: 40; hind femur: 27; ovipositor length: 32; ovipositor greatest height: $4.5 \mathrm{~mm}$.

Etymology. The name of the new species refers to the shape of the ovipositor that is markedly elevated around mid-length, from Latin elevata $=$ to elevate, elevated. 
Habetia pinnigera sp. nov.

Figs 2D, 4F, 6I, 7I-J, Map 1(14).

Holotype (female): Papua New Guinea: Madang, Madang, elev. 5 m ( $5^{\circ} 15^{\prime}$ 'S, 145 $50^{\prime}$ E), 22.x.1958 on pandanus, leg. J.L. Gressitt—depository: Bernice B. Bishop Museum, Honolulu (BPBM).

Diagnosis. The new species differs from all other species of the genus so far known by the strongly elevated central area of the female subgenital plate from which a bulging basal area is, in lateral view, obliquely ascending from base to nearly mid-length of the plate, the lateral areas are otherwise compressed and running as a broad lateral band along both sides of the elevated central area leaving only the acute apical projections without rim. This shape is somewhat similar to that in H. quatrispina sp. nov., in which however the transverse basal bulge and the lateral rims are less strongly expressed, and the rims end into distinct spines while in $H$. pinnigera sp. nov. they appear in ventral view as wing-like expansions.

Description. Coloration of face uniformly pale, of general color including mandibles and antennal scrobae, only narrow lateral rims of genae and of mandibles darkened (Fig. 4F). Femora with the following number of spines on ventral margins: (1) a 7, p 7-9; (2) a 7-8, p 2-3; (3) a 15-16, p 1-21 (n=1).

Male unknown.

Female. Subgenital plate in basal area with a transverse bulge that is narrowed in middle, swollen on both sides with the swollen area continued onto dorso-lateral areas; oblique proximal surface of subgenital plate encircled by the bulge membranous (Fig. 7J); on distal side of bulge, ventral surface in central area strongly convex and terminating into a pair of little incurved but strongly upcurved projections with apical margin between these projections truncate (Fig. 6I); laterally, convex central area bordered by wide, compressed dorso-lateral expansions which, in lateral view, are flattened behind basal bulge and largely extended but obliquely narrowed into the apical cones (Fig. 7I-J). Ovipositor about as long as body; behind basal constriction dorsal margin convex, markedly but not very strongly elevated in middle and narrowing again towards sub-obtuse tip (Fig. 2D).

Measurements ( 1 female).—Body w/wings: 35 ; body w/o wings: 30; pronotum: 8.5 ; tegmen: 25 ; hind femur: 22.5; antenna: 90; ovipositor length: 31; ovipositor height: $2.1 \mathrm{~mm}$.

Etymology. from Latin pinniger, pinnigera = winged. The name of the new species refers to the long and wide, flattened lateral expansions that run along the lateral margins of the subgenital plate.

\section{Habetia pilleata sp. nov.}

Figs 2K, 10D-H, 15A-C, 18F, 20E, Map 1(6).

Holotype (male): Papua New Guinea: Morobe, Wau, elev. 1200 m (7²0’S, 146²5'E), 1.-3.x.1963, leg. J. Sedlacek — depository: Bernice B. Bishop Museum, Honolulu (BPBM).

Diagnosis. $H$. pilleata sp. nov. differs from all other species of the genus by the prolonged male subgenital plate that has the apical area divided into two narrow branches that are strongly recurved with the tips pointing dorsocraniad and carry at the upcurved underside minute styli. The apical internal process of the male cerci terminates into a single acute tooth instead of being for a short distance divided at end and terminating into two teeth as in most other species of the genus. Moreover, the male titillators are not strongly curved in about mid-length as in most other species of the genus but fused over almost the whole length except at base and at end; at end they divide into short proximal and distal branches that together form the base for a large, white, and membranous, balloon-like structure. H. pilleata is slightly larger and stouter than other species from the mountain areas, e.g., H. wau sp. nov., that occurs in the same area.

Description. Coloration of face uniformly pale, marbled with light brown and yellowish; mandibles yellow, at base little darker, in apical area brown; labrum and lower area of maxillae brown. Femora with the following number of spines on ventral margins: (1) a 6 , p 8; (2) a 7, p 3-4; (3) a 14-16, p 14-15.

Male. Stridulatory file on underside of left tegmen $2.07 \mathrm{~mm}$ long with 89 teeth that are in sinuously curved basal area of file still rather large and preceded toward base by a row of tiny, indistinct dots, while at distal end, teeth becoming very dense and indistinct; over total file length with 43 teeth per $\mathrm{mm}$; in central $1 \mathrm{~mm}$ of file with 37 teeth (Fig. 18F). Tenth abdominal tergite in basal half with dorsal surface faintly convex and with deeply sloping lateral margins, at base with three depressions, one in center and two laterally; apical half of tergite in dorsal view 
triangular with approaching lateral margins and with a moderately wide incision from apical margin for two thirds of the apical area; anteriorly of the incision is a short and narrow furrow; resulting lobes of tergite at end angularly rounded in dorsal view, but on underside forming an apical hood that is ventrally covered by membrane, has the internal surface flattened and the distal margin produced into a slight, rounded apical lobe (Figs 10D, 10G). Epiproct wider than long with obtusely rounded tip. Cerci narrow elongate and in apical area little curved; just before rounded tip with a strong and flattened projection with approaching lateral margins that at end is curved proximad and terminates into an acute tooth (Figs 10G-H). Subgenital plate with little more than apical third re-curved with tip pointing dorso-proximad; in ventral view, subgenital plate wide in basal area and deeply incised from basal margin with the incision bordered by strong carinae that are fused to become a flattened plate behind basal incision which divides shortly after into a pair of deviating carinae that, when the plate curves dorsad, are fused with the strengthened dorsal rim of the subgenital plate, thereafter the plate divides into a pair of narrow, deviating, apical lobes that are curved dorso-proximad and terminate into rounded-angular tips; the small styli insert little before end of upcurved underside of apical lobes (Figs 10E-G). Titillators fused, forming a ventro-posteriorly rounded duct or channel that is strongly curved around mid-length and open on dorso-proximal side; only very bases are free, roughly triangular with obtuse tips projecting disto-laterad; at apical end, the free dorso-proximal margins are oval, projecting proximad and diverging from each other, while the fused ventro-distal margin is projecting distad; both ends together form a plateau for a strong hyaline protuberance (in preparation with white content) that in apical view is oval, in lateral view becoming tubular and hyaline and terminates on both sides above the proximal ends of the sclerites into a hyaline spine (Figs 15A-C). There is also a pair of three-lamellar lateral sclerites.

Female unknown.

Measurements (1 male).—Body w/wings: 46; body w/o wings: 40; pronotum: 9.5; tegmen: 33.5; hind femur: 24; anterior femur: $5.5 \mathrm{~mm}$.

Etymology. The new species is named for the convex membranous cap at top of the titillators; from Latin pilleatus, pilleata $=$ adorned by a cap.

\section{Habetia quatrispina sp. nov.}

Figs 2J, 4J, 6L, 7C, Map 1(16).

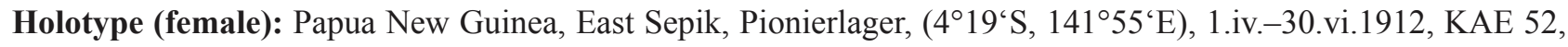
leg. Bürgers - depository: Museum für Naturkunde, Berlin (ZMB).

Diagnosis. The new species is unique for the possession of four spine-like projections of the female subgenital plate: one pair from the end of the upcurved baso-lateral areas, and the other pair from the end of the central disc. Moreover, the dorsal ovipositor valves have the dorsal margin markedly convex but not strongly widened.

Description. Coloration of face uniformly pale, of general color; mandibles of same color, only at, in situ hidden, tip black; antennal scrobae light to medium brown (Fig. 4J). Femora with the following number of spines on ventral margins: (1) a 6, p 7-8; (2) a 7-8, p 5; (3) a 13, p 13-15 (n=1).

Male unknown.

Female. Subgenital plate with convex ventral surface but in lateral areas curved more strongly dorsad; lateral margins convex behind basal area, the marginal lateral areas divide from the disc and form a pair of stout, rounded projections with approaching margins and acute tip; in the further curse the lateral margins then run in a bow to the somewhat elevated central area; the central area divides at end into a pair of apical, spine-like projections that are separated by a wide and straight interspace with subtruncate bottom (Figs 6L, 7C). Ovipositor only little longer than body but for one third longer than the hind femur, laterally compressed; behind basal constriction with dorsal margin convex and moderately elevated around mid-length, in apical area straight and narrow (Fig. 2J).

Measurements (1 female).-Body w/o wings: 30; pronotum: 8; tegmen: 27; hind femur: 22; antenna: 90; ovipositor length: 33; ovipositor height: $2.4 \mathrm{~mm}$.

Etymology. The new species is named for the presence of four spine-like projections of the female subgenital plate, from the Latin words quaternio, quattuor $=$ four and spina $=$ spine. 


\section{Habetia sororcula sp. nov.}

Figs 2H, 4L, 6K, 7H, Map 1(17).

Holotype (female): Indonesia: Papua, Cyclop Mountains, Ifar, elev. 300-500 m (2³3’S, 140³1’'E), 23-25.vi.1962, leg. J. Sedlacek - depository: Bernice B. Bishop Museum, Honolulu (BPBM).

Other specimens studied: Indonesia: same locality as holotype, 24.ix.1958, leg. J.L. Gressitt-1 female paratype (BPBM); West of Sentani, elev. 200-1000 m (2³6’S, 140³7’E), 16-18.vi.1959, leg. J.L. Gressitt-1 female (BPBM); Ned. New Guinea Expedition 1911, leg. Dr. P.N. van Kampen-1 female (NBC).

Diagnosis. A slender, medium-sized species with narrow tegmen that hardly reach the hind knees. In the two localities, in which $H$. sororcula sp. nov. had been found, also lived $H$. pallida sp. nov., from which $H$. sororcula differs by smaller size, narrower appearance, much shorter ovipositor (28-31 against $57-67 \mathrm{~mm}$ ), narrow tegmen with dark spots instead of uniformly colored tegmen, and by the shape of the female subgenital plate that is characterized by a transverse furrow in sub-basal area, triangular projections at upper end of the baso-lateral expansions, and longer apical spine-like projections. In general appearance the new species is most similar to H. quatrispina sp. nov., it differs by the more strongly expressed dark spots on the tegmen and by the shape of the female subgenital plate that in ventral view has the lateral margins approaching and straight and the dorso-lateral expansions end into a small triangular lobe in $H$. sororcula, while in H. quatrispina the disc of the subgenital plate appears semi-circular and the lateral expansions terminate into a long spine.

Description. Elongate and slender species; wings barely reaching hind knees. Coloration of face uniformly pale, of general color; mandibles with black tips only; antennal scrobae with indistinct dark spots (Fig. 4L). Tegmen pale with distinct dark spots in cells. Femora with the following number of spines on ventral margins: (1) a 7-10, $p$ $7-9$; (2) a 6-8, p 3-5; (3) a 9-15, p 10-16 (n=4).

Male unknown.

Female. Subgenital plate with concave anterior margin, in subbasal area with a wide transverse furrow; proximal area laterally expanded on both sides, strongly upcurved and narrowing, before end with a longitudinal furrow followed by a triangular projection at dorso-lateral ends (Fig. 7H); disc of subgenital plate in ventral view behind transverse furrow with converging lateral margins that terminate into a pair of elongate, little diverging and up-bent, spine-like projections; apical margin between these projections concave and moderately wide (Fig. 6K). Ovipositor about as long as body; behind basal constriction dorsal margin convex, but only little elevated around mid-length (Fig. $2 \mathrm{H}$ ); ventral valves at very base with a distinct oval indentation that is bordered on ventral side by a curved bulge (Fig. $7 \mathrm{H}$ ).

Measurements (4 females).-Body w/wings: 30-31; body w/o wings: 25-29; pronotum: $6.5-7.7$; tegmen: 20.5-22.0; hind femur: 20-21; antenna: 65-100; ovipositor length: 28-31; ovipositor height: 2.0-2.2 mm.

Etymology. The name of the new species is adopted from the Latin word sororcula $=$ little sister. It is chosen as in two localities the species was found occurring together with a larger species of the same genus, $H$. pallida sp. nov., from which it differs by shorter body length, very narrow and rather short tegmina, the subgenital plate, and shorter ovipositor relative to the body length.

\section{Parahabetia gen. nov.}

Typus generis: Habetia pictifrons Karny, 1911, here designated

Diagnosis. In general habitus the new genus resembles Habetia: The pronotum has the posterior area not prolonged but leaves the stridulatory apparatus in male largely uncovered; the lateral lobes are not deep, and the ventral margin is little descending posteriorly; the hind margin of the lateral lobes is rather strongly ascending and substraight or faintly concave, with a humeral sinus only faintly indicated or missing, and the hind margin of the disc is substraight to faintly convex in both genera, Parahabetia gen. nov. and Habetia. Also, the rather narrow fore wings that have the fore margin rather suddenly, obliquely narrowed into the narrow apical area is similar in both genera. However, Parahabetia differs from Habetia by the shapes of the male cerci and titillators and by the female ovipositor and subgenital plate. The male cerci are only little curved or nearly straight and provided in Habetia with an apical or subapical internal process that basically divides at end into two acute tips while in Parahabetia the cerci are 
markedly curved and provided with two or three internal projections and have the apex widened. The titillators are basically U-shaped sclerites with various modifications in Habetia, while basically straight in Parahabetia. The titillators in Parahabetia have the base widened, the central area narrow and the apical area little widened again and at end they are strongly sclerotized and carrying a curved lamellar crest at tip. The female ovipositor is straight and long or very long and with obtuse or subobtuse tip in Habetia, but rather short, curved, at end slightly recurved, and with acute tip in Parahabetia. The shape of the rather simple male titillators with an apical crest in the new genus resembles that in Philmontis Willemse, 1966. Parahabetia differs from Philmontis by the absence of the black lateral bands on pronotum and tegmen and by the pronotum with subtruncate instead of rounded hind margin that in the type species Philmontis nigrofasciatus Willemse, 1966 covers the stridulatory area of the tegmen. There are however also species with a shorter pronotum, e.g. Philmontis lobatus Naskrecki \& Rentz, 2010. The rather short female ovipositor in Parahabetia is upcurved as in Philmontis but has the end re-curved instead of running straight into the tip as in the latter genus. Moreover, the female subgenital plate in Parahabetia is provided with a medial furrow and with large, oval, lateral swellings, which is quite different from the shape in P. nigrofasciatus that has a narrow transverse swelling in basal area, and more than apical half divided into a pair of narrow lateral lobes. From both, Habetia and Philmontis, Parahabetia gen. nov. also differs by the high number of stridulatory teeth on the rather short stridulatory file on underside of male tegmen which carries high numbers of densely packed stridulatory teeth.

Description. Rather small to medium sized species with wings that reach about the hind knees and little surpass the abdomen. Head with fastigium verticis narrow conical, moderately projecting anteriorly and separated by a transverse furrow from fastigium frontis; face long conical. Pronotum longer than wide with disc roundly merging into paranota; anterior margin subtruncate to faintly concave, posterior margin little convex or nearly truncate, with two little suspicious transverse furrows; apical area of disc little elevated with sub-rugose surface and sub-angular lateral margins; paranota rather low, swollen above auditory spiracle, ventral margin very faintly concave, anterior angle rounded, posterior angle nearly rectangular but with rounded tip, humeral sinus only slightly indicated. Prosternal spines short but distinct; mesosternal lobes triangular with a tubercle at tip or with obtuse tip; metasternal lobes with sub-truncate, oblique apical margin. Fore coxa with a long, mid coxa with a short spine at anterior margin. Femora of all legs with spines on both ventral margins; hind knee lobes bi-spinose. Tibial tympana conchate on both sides. Anterior tibiae with anterior surface convex and with indistinct rounded angles that are indicated by rows of few minute spinules. Wings little surpassing abdomen, in female hardly so; tegmen markedly narrowing from base toward subapical area; tip rounded.

Male. Tenth abdominal tergite vaulted with posterior area curved distad, flattened and divided into a pair of triangular lobes. Cerci rather long and narrow, curved and provided with two or three internal projections and modified tip. Male subgenital plate at end provided with a pair of short styli and with or without a pair of narrow apical projections that are longer than the styli. Titillators separate from each other, with basal area curved laterad, distal area long-oval or band-shaped, with a compressed crest at external side of swollen apical area.

Female. Subgenital plate with a medial furrow and lateral swellings. Ovipositor curved, but in apical area slightly re-curved, with acute tip.

Coloration in the preserved specimens almost uniformly light yellowish, ochre, or brownish, but might be discolored and a mainly green when alive. Face green. Antennal scapus and abdominal tergites in one male from Bulolo Gorge also green. In that male head and pronotum ochre with a greenish shine, and tibia with remnants of green flecks. Tegmen with light veins and darkened cells, especially in anterior area.

Etymology. The name of the new genus is built from the genus name Habetia adding the prefix para which is used to change the meaning of a word.

\section{Key to the species and subspecies of Parahabetia gen. nov. (males only)}

1. Male cercus with three projections and a swollen, globular or oval tip (Figs 21C, 21F, 21H). Male subgenital plate apart from the styli with a pair of narrow apical projections (Figs 21D, 21G, 21I). Male paraproctes not strongly enlarged, rather inconspicuous. Stridulatory file on underside of left tegmen even in central area with teeth very densely packed (Figs 22H-I)

Male cercus with two projections and a compressed apical lobe (Figs 22D-F). Male subgenital plate at end without apical projections, with styli only (Fig. 22C-E). Male paraprocts strongly enlarged (Fig. 22F). Stridulatory file on underside of left tegmen with teeth in central area clearly separated from each other (Fig. $22 \mathrm{G}) \ldots \ldots \ldots \ldots \ldots \ldots$. bispinosa sp. nov. 
2. Male tenth abdominal tergite roundly incised from apical margin with incision and resulting apical lobes rather short, pointing oblique apico-mediad (Fig. 21H). Male subgenital plate more elongate, with elevated disc and with flattened lateral areas that do not reach the bases of the styli; apical margin markedly incised before bases of styli and then prolonged into long, narrow projections that are markedly longer than the styli; styli inserted latero-ventrally (Fig. 21I). Cerci less strongly curved, basal projection inserted somewhat away from base and with club-shaped, long-oval end; end of cercus globular (Fig. 21H) . . . . .

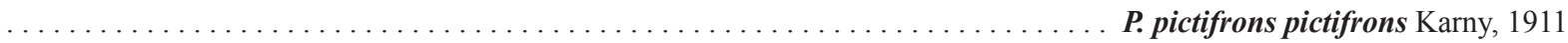

Male tenth abdominal tergite long and narrowly incised and terminating into a pair of long, dorso-ventrally compressed projections with acute or obtuse tips. Male subgenital plate more semi-circular with compressed lateral areas reaching bases of styli or nearly so; apical margin before bases of styli only slightly incised with curved or with widened tips. Cerci with basal projection inserted closer to base; basal projections at end suddenly widened, with apical area either globular but little compressed or disc-shaped, in both cases with a spinule at tip; end of cercus globular or oval . . . . . . . . . . . . . .

3. Apical lobes of tenth abdominal tergite with acute tip and separated by a narrow interspace from each other (Fig. 21A). Male cercus with second and third internal projection inserted closely together, apical widening of cercus somewhat compressed and roughly oval (Fig. 21C). Apical projections of subgenital plate at tip compressed and roundly widened (Figs 21B, D). Male titillators only little curved in about mid-length, apical area narrower and apical cap less extended (Fig. 23D) ...........

P. pictifrons acuta ssp. nov.

Apical lobes of tenth abdominal tergite with obtuse tip and separated by a wider interspace (Fig. 21E). Male cercus with second and third internal projections inserted more away from each other; apical widening of cercus globular (Fig. 20F). Apical projections of subgenital plate at tip twisted and narrow (Fig. 21G). Male titillators curved in about mid-length, apical area wider and apical cap more extended (Fig. 23E-G) $\ldots \ldots \ldots \ldots \ldots \ldots \ldots \ldots \ldots \ldots \ldots \ldots \ldots$ P. pictifrons obtusa ssp. nov.

\section{Parahabetia pictifrons (Karny, 1911) comb. nov.}

\section{Parahabetia pictifrons pictifrons (Karny, 1911)}

Figs 21 H-I, Map 1(pp)

Holotype (male): Papua New Guinea: Morobe Province, Huon Gulf, Sattelberg (6²8'S, $\left.147^{\circ} 44^{\prime} \mathrm{E}\right)$ —depository not traced, originally: Naturhistorisches Museum Wien (NMW).

Remark. The data in the original description indicate that the holotype should be stored in NMW. But it could not be traced over there. That specimen had been used as model for the colored image on a table in Karny (1912) painted by A. Baliani. However, Karny (1926, p. 197) mentions that the green color of the face faded away and became yellowish with a faint green tinge. Thus, he should have seen the specimen on a later occasion.

Description. Male [after Karny 1911, 1912, translated from Latin and German, with own comments in square brackets]. "Anal plate" [probably referring to the tenth tergite] circularly incised, with short acute lobes [in Fig. 21H it appears as though the apical projections of the tenth tergite and also the projections of the subgenital plate and the styli are pointing out of the plane of Karny's drawing and thus appear too short]. Male cerci curved inward, from base of internal margin with a clubbed process, in middle provided with a long thorn, at end globularly inflated and provided at inner margin with an acute tooth. Subgenital plate large, resembling the shape of a canoe, with short styli and between them [the styli] with two narrow, slightly S-shaped projections, which are two times longer than the styli.

Measurements (1 male after Karny, 1911):-Body: 24; pronotum: 7.5; tegmen: 19.5; hind femur: $16 \mathrm{~mm}$.

\section{Parahabetia pictifrons obtusa ssp. nov.}

Figs 21E-G, 22I, 23E-I, 24A-D, Map 1(po).

Holotype (male): Papua New Guinea: Morobe, Bulolo Gorge, McAdam Peak, (7¹6’'S, 146 $38^{\circ}$ E), 28.viii.1981, leg. G.K. Morris - depository: Naturalis Biodiversity Center, Leiden (NBC).

Other specimens studied: same data as holotype -1 female, 1 male paratypes (NBC).

Diagnosis. $P$. $p$. obtusa ssp. nov. differs from the nominate subspecies, $P$. p. pictifrons, by the male tenth abdominal tergite that has the apical area divided into two long triangular extensions instead of short lobes and the three internal projections of the male cerci differ in detail as shown in Figs 21E-F compared to Fig. 21H: the first projection inserts closer to the base of the cercus but farther away from the second process and the apical swelling of the cercus is smaller. From the subspecies P. p. acuta ssp. nov., the new subspecies differs by the apical projections of the tenth abdominal tergite that are at end little downcurved and with obtuse tip instead of being sub-straight 
and with acute tip. The male cerci differ in detail between both subspecies as shown in Fig. 21F compared to Fig. 21C. The stridulatory file on the underside of the left tegmen in P. p. obtusa is shorter than in P. p. acuta with less numerous teeth. The male titillators are similar in both subspecies but more strongly curved between basal and apical area in P. p. obtusa and the apical area is wider than in P. p. acuta.

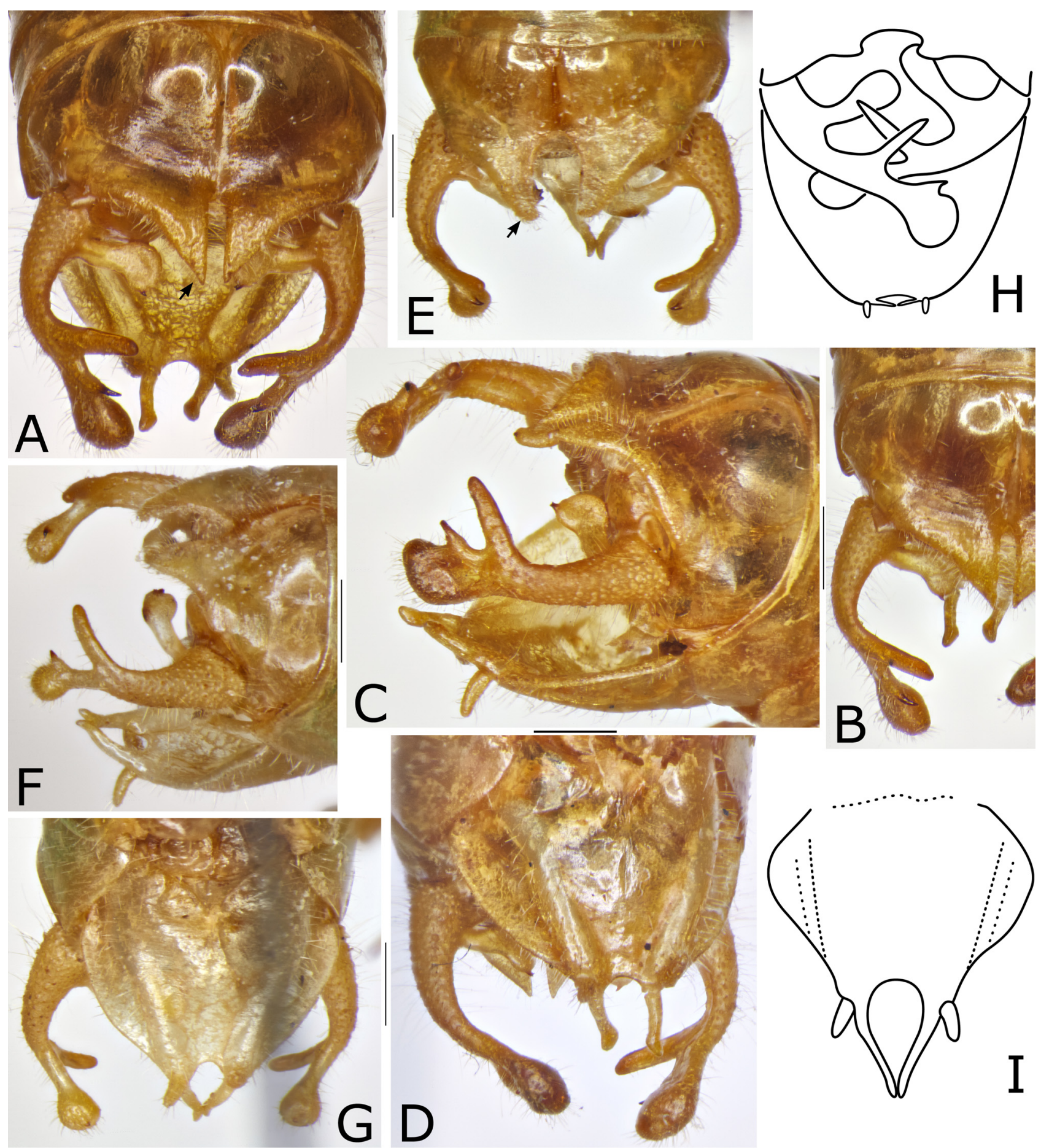

FIGURE 21. Parahabetia pictifrons (Karny, 1911) males: A-D, P. p. acuta ssp. nov. (Kokoda); E-G, P. p. obtusa ssp. nov. (McAdam Peak); H-I, P. p. pictifrons (redrawn from Karny 1911).-Abdominal apex in dorso-apical view (A, H), in strict dorsal view $(\mathrm{B}, \mathrm{E})$, in oblique lateral view $(\mathrm{C}, \mathrm{F})$ and in ventral view $(\mathrm{D}, \mathrm{G})$; male subgenital plate (I).- The arrows point at the tip of the projections of the tenth abdominal tergite. Scales $1 \mathrm{~mm}$.

Description. Femora with the following number of spines on ventral margins: (1) a 6-7, p 8; (2) a 7-8, p 3-4; (3) a $10-12, \mathrm{p} 12-20(\mathrm{n}=3)$.

Male. Stridulatory file on underside of left tegmen $1.39 \mathrm{~mm}$ long with about 154 teeth: 25 teeth at curved base; 
67 large teeth around mid-length; 62 teeth after step becoming white and indiscernible narrow toward end (Fig. 22I). Tenth abdominal tergite domed with medial furrow; apical area dorso-ventrally compressed and terminating into a pair of markedly spaced, elongate lobes with obtuse tip (Fig. 21E). Cerci elongate and narrow, curved around midlength, with three dorso-internal projections: the basal projection with a curved stem with globular end that carries a minute spinule, the second projection narrow, compressed and slightly curved, the third projection forming a short spine at base of the globularly swollen end of cercus (Fig. 21F). Subgenital plate above bases of styli with narrow projections that are longer than the styli and at end faintly out-curved (Figs 21E, 21G). Titillators with about basal half curved laterally and vaulted with convex distal and concave proximal surface, in roughly mid-length bent and apical half little widening towards end, at distal end swollen and with a lamellar crest at external side (Figs 21E-G). The lamellar crests are in situ the posterior ends of the titillators (Fig. 23I).

Female. Subgenital plate in central and apical areas flattened and divided along mid-line by a furrow that is bordered on both sides by carinae that are, behind mid-length, deviating from each other, do not reach the end of the subgenital plate, and are connected by a thin septum that also forms the pair of obtuse apical lobes; both halves of the subgenital plate are standing angularly to each other and have the lateral areas occupied by a large oval swelling; central area and lateral swellings with smooth surface, a broad band along apical margin coarse (Figs 24A, C). Ovipositor upcurved, the ventral margin markedly stronger curved than the dorsal margin; dorsal margin in apical area slightly re-curved and faintly concave before acute tip (Fig. 24B).

Measurements (2 males, 1 female).-Body w/o wings: male 21.0-21.5, female 27; pronotum: male 6.3-6.5, female 6.2; tegmen: male 18.5-19.0, female 20.5; hind femur: male 14.5, female 14.5; ovipositor length: female $12.5 \mathrm{~mm}$.

Etymology. The name of the new species refers to the shape of the obtuse apical lobes of the male tenth abdominal tergite; from Latin obtusus, obtusa $=$ obtuse, blunted.

\section{Parahabetia pictifrons acuta ssp. nov.}

Figs 21A-D, 22H, 23D, Map 1(pa).

Holotype (male): Papua New Guinea: New Guinea (NE), Northern, Kokoda, elev. 366 m ( $8^{\circ} 52^{\prime}$ S, $\left.1^{\circ} 7^{\circ} 45^{\prime} E\right)$, 1-30.ix.1933, leg. L.E. Cheesman — depository: The Natural History Museum, London (NHM).

Diagnosis. P. p. acuta ssp. nov. differs from the nominate subspecies, P. p. pictifrons by the male tenth abdominal tergite that has the apical area divided into two long, narrowly spaced extensions with acute tip instead of more widely spaced obtuse extensions and the three internal projections of the male cerci differ in detail, e.g., the basal process has the tip disc-shaped with a spinule instead of simply little widened, the apical two projections are closer together and the tip is oval instead of rounded. From the subspecies $P$. p. obtusa ssp. nov., the new subspecies differs by the apical extensions of the tenth abdominal tergite that run closer together, are straight and end into an acute tip instead of running more widely spaced, are downcurved and end into obtuse tips. The second and third internal projections of the male cerci stand closer together and the apical widening of the cercus is oval instead of globular. The male titillators are little narrower and less strongly curved in mid-length. The stridulatory file on the underside of the left tegmen is longer and carries more numerous teeth that are also in apical area clearly visible under a microscope. From both other subspecies, P. p. acuta also differs by the narrow apical extensions of the male subgenital plate that have the tip widened instead of narrowly rounded.

Description. Femora with the following number of spines on ventral margins: (1) a 7, p 9-10; (2) a 7, p 3; (3) missing $(\mathrm{n}=1)$.

Male. Stridulatory file (Fig. 22H) 1,64 mm long, with 160 teeth, of which are 29 at curved base, 66 large around mid-length, and 65 after step, narrowing and becoming white towards end; area with largest teeth in middle of file with 84 teeth per $0,5 \mathrm{~mm}$. Tenth abdominal tergite domed with faint medial furrow; apical area compressed, pointing posteriorly, and divided into a pair of acute lobes (Fig. 21A). Cercus curved mediad before second process and at end faintly laterad; with three dorso-internal projections: the basal projection consisting of a short stem and a compressed, disc-shaped apical area with a small spine at end; second projection narrow elongate with obtuse tip, followed shortly behind by an acute spine-like projection; cercus at end little widened and compressed but still swollen, with obliquely truncate end (Figs 21B-C). Subgenital plate at end only faintly incised, provided on both sides of incision and above insertion point of styli with a pair of narrow, slightly curved projections with little widened end (Fig. 21D). Titillators elongate and rather narrow; basal area slightly vaulted, curved laterad; central 
area elongate, nearly parallel-sided, not strongly sclerotized, with internal surface finely pubescent and rather soft; titillators at end strongly sclerotized, forming a hood carrying a compressed crest with little wavy margin that runs oblique against the surface of the apical area of the titillator (Fig. 23D).
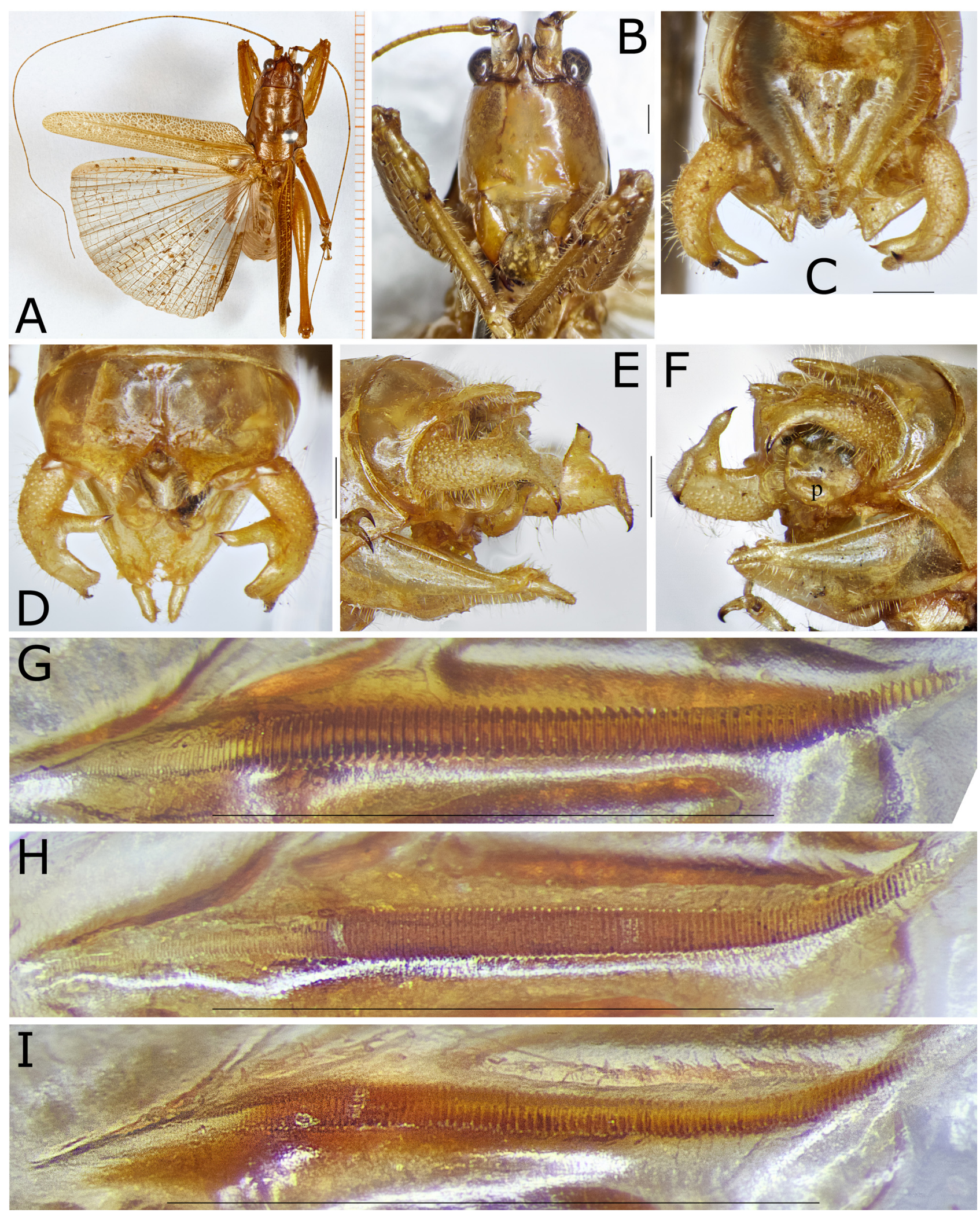

FIGURE 22. Details of male Parahabetia species: A-G: P. bispinosa sp. nov. (Wanigela); H, P. pictifrons acuta ssp. nov. (Kokoda); I, H. pictifrons obtusa ssp. nov. (McAdam Peak).- - Habitus dorsal view (A); face (B); male abdominal apex in ventral (C), dorsal (D), lateral (E), and oblique lateral view (F); stridulatory file on underside of left tegmen (G-I). Abbreviation: p paraproctus. Scales $1 \mathrm{~mm}$. 


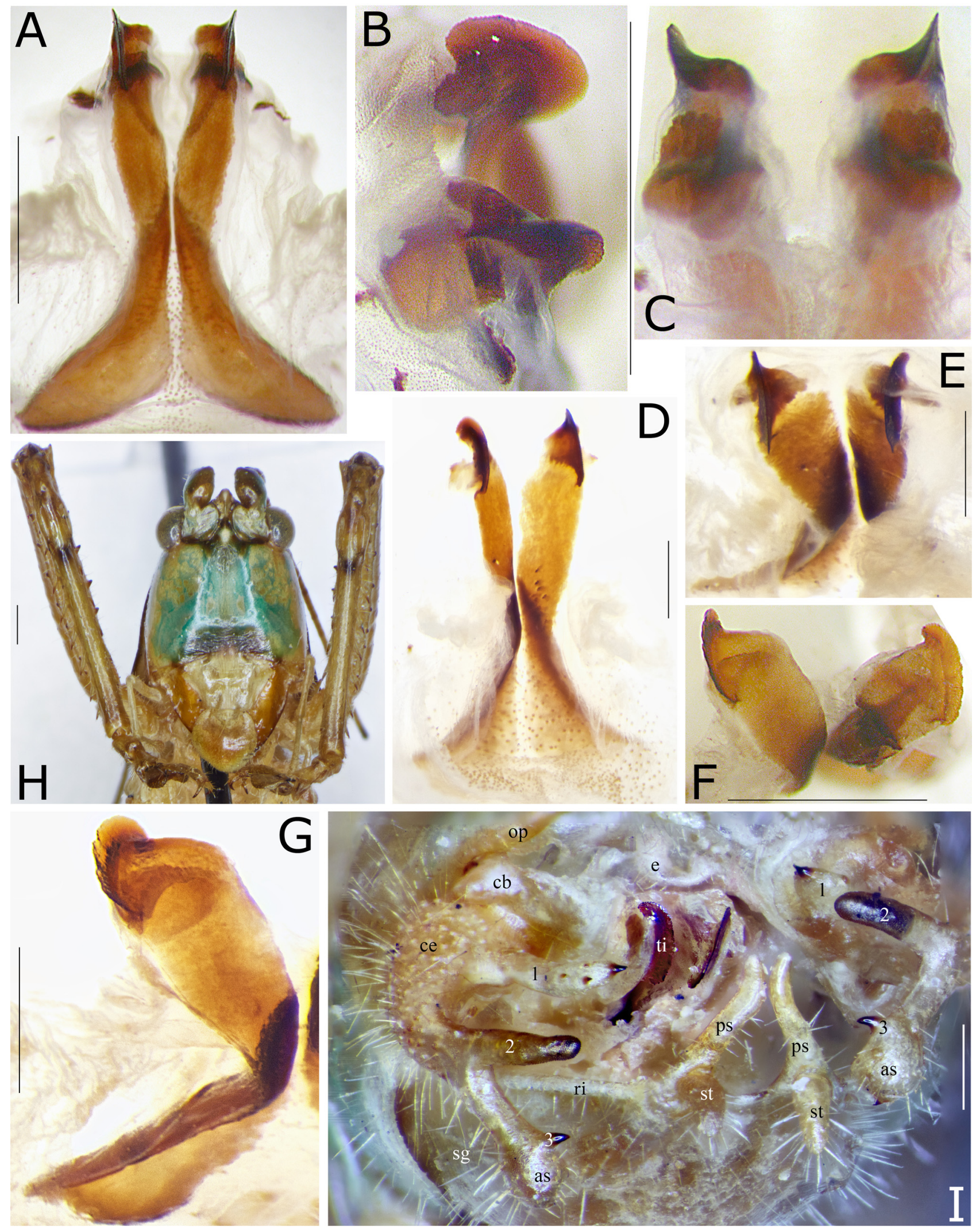

FIGURE 23. Parahabetia sp. males: A-C, P. bispinosa sp. nov. (Wanigela); D, P. pictifrons acuta ssp. nov. (Kokoda); E-I, $P$. p. obtusa ssp. nov. (McAdam Peak).- - Titillators in about ventro-apical view (A, D, G), views on apical areas of titillators (B-C, E-F); face (H); abdominal apex with appendages and end of titillators in situ (I). Abbreviations: 1, 2, 3 process 1-3 of cercus, as apical swelling of cercus, cb bulge around cercus base, ce cercus, e epiproct, op obtuse process of tenth tergite, ps process of subgenital plate, ri rim of subgenital plate, sg subgenital plate, st stylus, ti apical rim of titillator. Scales $1 \mathrm{~mm}$. 


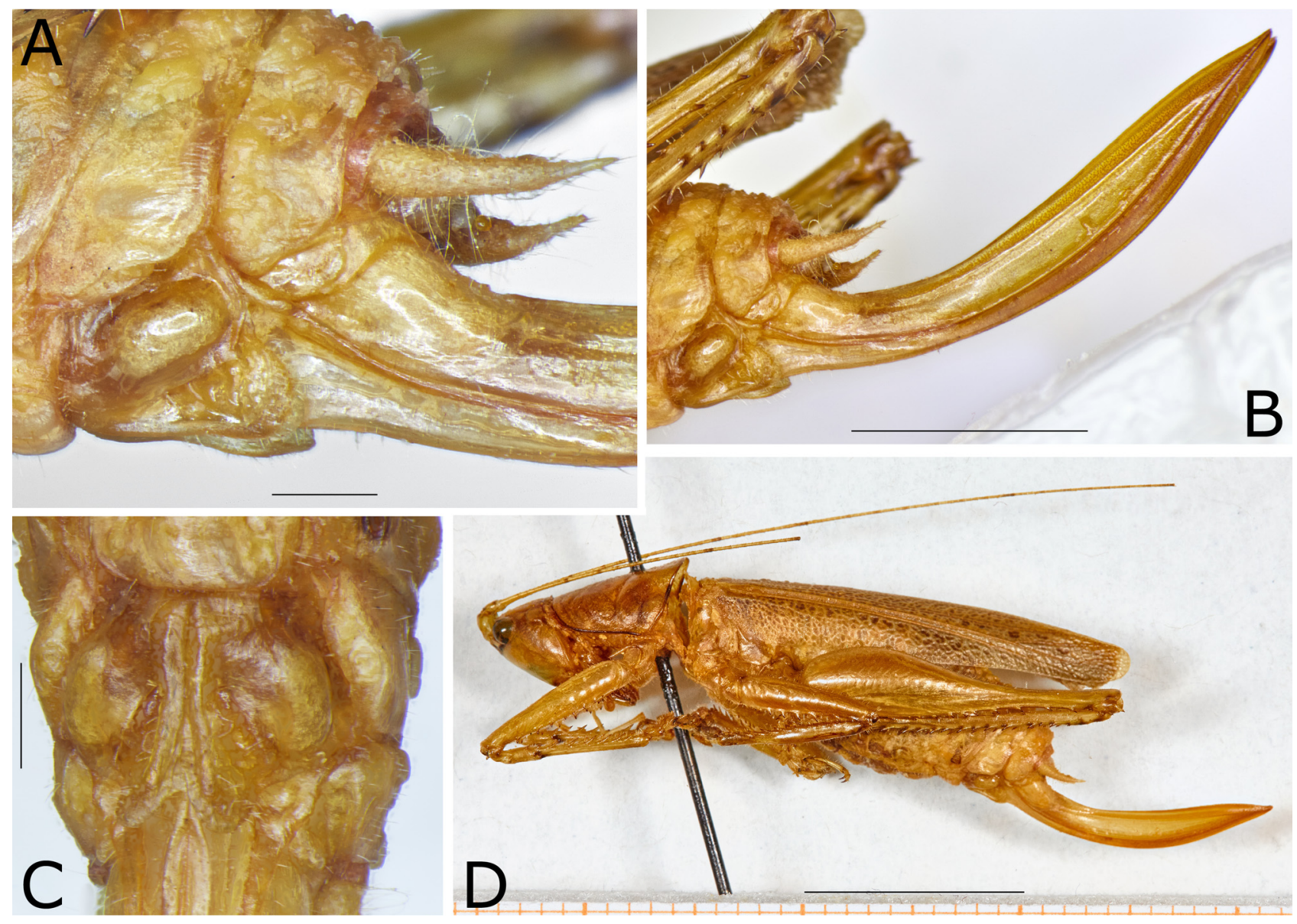

FIGURE 24. Parahabetia pictifrons obtusa ssp. nov. female (McAdam Peak).-Abdominal apex with cerci, subgenital plate, and base of ovipositor in lateral view (A); ovipositor (B); subgenital plate in ventral view (C), habitus in lateral view (D).Scales $1 \mathrm{~mm}$ (A, C), $5 \mathrm{~mm}$ (B), $10 \mathrm{~mm}$ (D).

Measurements (1 male)._-Body w/o wings: 23; pronotum: 7; tegmen: $19.5 \mathrm{~mm}$.

Etymology. The name of the new species refers to the shape of the acute apical lobes of the male tenth abdominal tergite; from Latin acutus, acuta = acute.

\section{Parahabetia bispinosa sp. nov.} Figs 22A-G, 23A-C, Map 1(pb).

Holotype (male): Papua New Guinea: Northern (Oro Province), Mai-u R., SW1, Wanigela, (9²2'S, 149¹0’E), 1-31.vii.1972, leg. R. Pullen_-depository: Naturalis Biodiversity Center, Leiden (NBC).

Diagnosis. The new species differs from all three subspecies of $P$. pictifrons by the male cerci that have only two instead of three projections and the apical lobe is compressed instead of swollen. The male subgenital plate is missing the apical projections that occur in all subspecies of $P$. pictifrons in addition to the styli, and the paraprocts are rather huge for the genus. The titillators are of similar basic shape in both species but in P. bispinosa sp. nov. they are longer and narrower and differ in fine details of the apical structures. Moreover, the stridulatory teeth on the underside of the left tegmen are larger and less numerus, thus more distinct than in P. pictifrons.

Description. Slender but not very long species; general habitus as described under genus. Prosternal spines rather short but distinct; mesosternal lobes with spinose tip, metasternal lobes rounded. Hind knee lobes bi-spinose. Femora with the following number of spines on ventral margins: (1) a 7, p 9; (2) a 7, p 3; (3) a 16 p 17 (n=1).

Male. Stridulatory file on underside of left tegmen $1.73 \mathrm{~mm}$ long (or $1.60 \mathrm{~mm}$ without the 15 extremely small teeth at end) with 115 teeth; in central $1 \mathrm{~mm}$ with 47 teeth, comprising the largest teeth, basal of that area with 15 smaller but distinct teeth, on subapical step with 5 teeth, followed by 33 narrow teeth plus 15 indistinct teeth at 
end (Fig. 22G). Tenth abdominal tergite domed with a weak medial furrow, apical area compressed and divided into a pair of rather short triangular projections with obtuse end (Fig. 22D). Epiproct with angular basal margin, converging and downcurved lateral margins and rather wide obtuse end. Paraproctes forming huge and stout plates (Fig. 22F). Cerci curved inwards in about mid-length, posterior area compressed and forming two successive semicircles with little concave internal surfaces; proximal semi-circle from anterior margin with a rounded and swollen dorsal process with acute spine at tip, distal semi-circle with a similar process with black apical spine from ventrodistal margin (Figs 22D-F). Subgenital plate rather wide in basal half with upcurved lateral areas, in about apical half with strongly narrowing lateral and slightly concave dorsal lateral margins; ventral disc also with swollen lateral margins; apical margin moderately incised between bases of styli (Fig. 22C); dorsal margins of upcurved lateral areas with a distinct, laterally projecting rim, followed below by a weak furrow (Fig. 22F). Titillators separate, elongate with basal areas curved laterally and widened; central area narrow, band-shaped but slightly sinuate and twisted; at lateral end with a compressed rounded edge forming a lamellar crest that looks in ventral view like a spine; on dorso-proximal side near end of titillators with a pair of small extra sclerites (Figs 23A-C).

Coloration. Preserved specimen uniformly yellowish to reddish brown. Face brownish, in middle with a light ochre to whitish brown band from fastigium frontis to upper area of clypeus, also mandibles with a light band of same color. Antennal scrobae in ventral area and rim of fastigium frontis black (Fig. 22B). Pronotum partly with dark rim. Tegmen in anterior area with brown cells and light, whitish veins and veinlets, towards posterior area cells becoming of lighter color, hardly darker than light veinlets (Fig. 22A).

Measurements (1 male). Body w/o wings: 25; pronotum: 7.6; tegmen: 22; hind femur: $17 \mathrm{~mm}$.

Etymology. The name of the new species refers to the fact that the cerci are provided with only two internal spines instead of three in the type species of the genus; from Latin bi- = prefix for "a pair of" and Latin spinus = thorn.

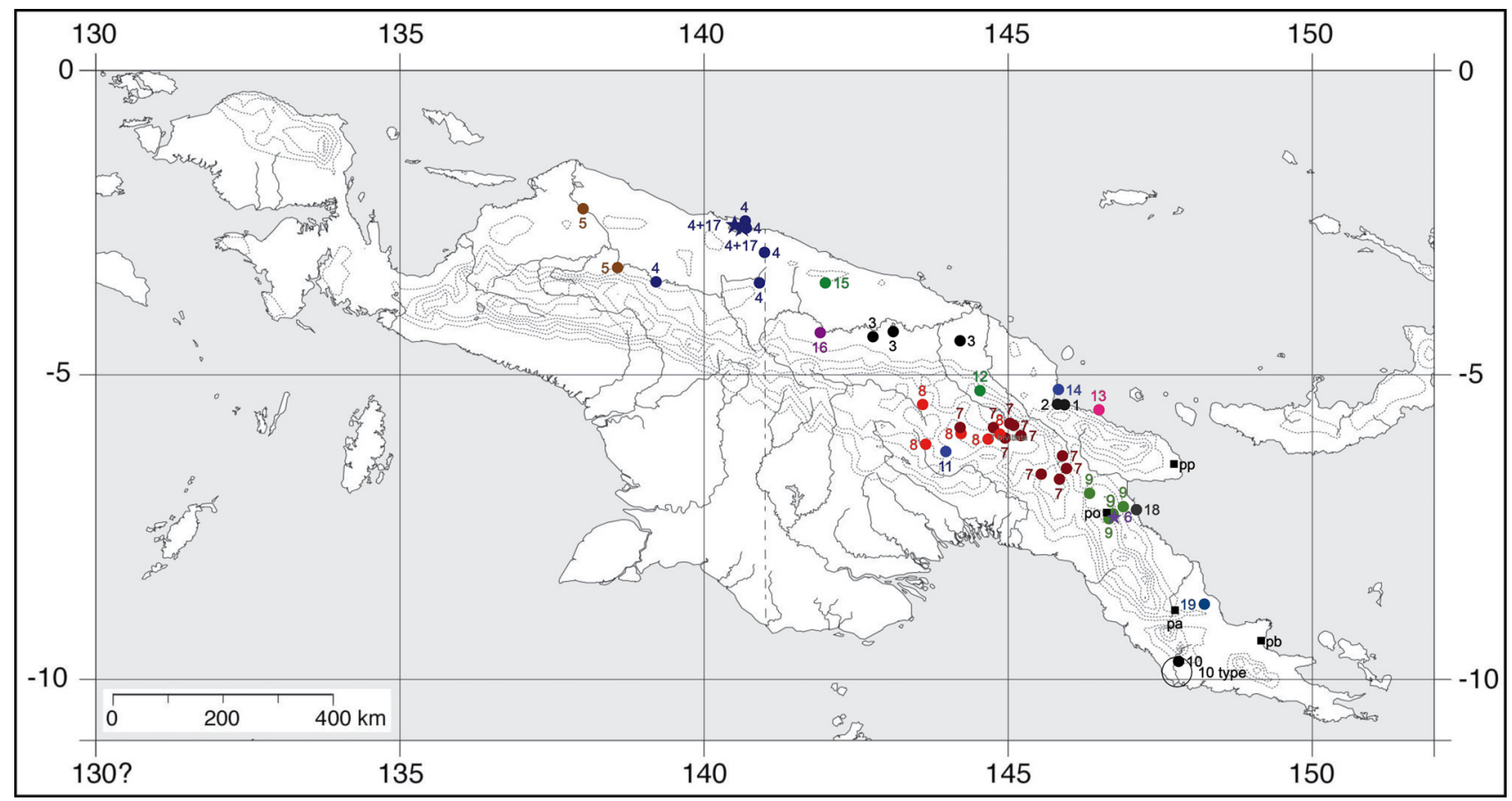

MAP 1. Known distribution of the species of the genera Habetia (circles and stars with numerals) and Parahabetia (squares with letters): (1) H. spada (Brunner, 1898); (2) H. imitatrix Karny, 1912; (3) H. tuta sp. nov.; (4) H. pallida sp. nov.; (5) H. curvata sp. nov.; (6) H. pilleata sp. nov.; (7) H. bivittata sp. nov.; (8) H. kondiu sp. nov.; (9) H. wau sp. nov.; (10) H. multispinulosa Griffini, 1908; (11) H. lalibu sp. nov.; (12) H. simbai sp. nov.; (13) H. dentata sp. nov.; (14) H. pinnigera sp. nov.; (15) H. pedala sp. nov.; (16) H. quatrispina sp. nov.; (17) H. sororcula sp. nov.; (18) H. elevata sp. nov.; (19) H. nigricauda sp. nov.; (pp) P. pictifrons pictifrons (Karny, 1911); (po) P. pictifrons obtusa ssp. nov.; (pa) P. pictifrons acuta ssp. nov.; (pb) P. bispinosa sp. nov. The open circle for 10 localizes the area within which the type of $H$. multispinulosa should have been collected. 


\section{Acknowledgements}

For the prolonged loan of specimens and the patience shown with the slow progress of the research or for guidance during visits of the museums I am grateful to the curators of the following collections: Bernice P. Bishop Museum, Honolulu, Hawaii, USA (Neal Evenhuis), Institut Royal des Sciences Naturelles de Belgique, Brussels, Belgium (Jerome Constant), Museo Civico di Storia Naturale "Giacomo Doria", Genoa, Italy (Roberto Poggi), Museum für Naturkunde Berlin, Germany (Kurt K. Günther, Jürgen Deckert), Museum Zoologicum Bogoriense, Bogor [now in Cibinong], Indonesia (Yayuk R. Suhardjono), Naturalis Biodiversity Center, Leiden, Netherlands (Luc Willemse), Naturhistorisches Museum Wien, Austria (Ulrike Aspöck), Senckenberg Museum für Tierkunde Dresden, Germany (Rainer Emmrich, Klaus-Dieter Klaas), The Natural History Museum, London, UK (Judith A. Marshall, George W. Beccaloni), Zoologische Staatssammlung München, Germany (Martin Baehr, Michael Raupach). Helpful discussions during the early stage of this revision with the late Dr. Fer Willemse (Eygelshoven) and loans from his private collection encouraged me to extend my studies of Asian Agraeciini to the very rich but poorly known Papuan Fauna. My stays at the Naturhistorisches Museum Wien, AT-TAF-2219, Naturalis Leiden, NL-TAF-3265, The Natural History Museum London, GB-TAF-4995, and the Royal Belgian Institute of Natural Sciences in Brussels BE-TAF-2608 were supported by SYNTHESYS.

\section{References}

Brunner von Wattenwyl, C. (1898) Orthopteren des Malayischen Archipels, gesammelt von Prof. Dr. W. Kükenthal in den Jahren 1893 und 1894. Abhandlungen der Senckenbergischen Naturforschenden Gesellschaft, Frankfurt, M 24, 193-288, pls. 16-20.

Carlotta (2021) Världskultur Museerna Etnografiska — Carlotta Databasen för museisamlingar. Available from: http://collections. smvk.se/carlotta-em/web/object/3248627 (accessed 23 March 2021)

Cigliano, M.M., Braun, H., Eades, D.C. \& Otte, D. (2020) Orthoptera Species File. Version 5.0/5.0. Available from: http://Orthoptera.SpeciesFile.org (accessed 30 May 2021)

Dimpflmeier, F. (2019) From Italy to British New Guinea and Back: The Life and (Field)work of Lamberto Loria. BéroseInternational Encyclopaedia of the Histories of Anthropology, Paris, 42 pp. Available from: https://hdl.handle.net/10670/ $1.5 \mathrm{~d} 5 \mathrm{p} 1 \mathrm{z}$ (accessed 4 March 2021)

Dohrn, H. (1905). Orthopterologisches aus dem Stettiner Museum. I. Neue und ungenügend bekannte Conocephaliden des indomalayischen Gebietes. Stettiner Entomologische Zeitung, 66, 237-246.

Google Maps (2020) Available from: https:/www.google.com/maps/ (accessed 30 March 2021)

Gressitt, J.L. (1982) Biogeography and ecology of New Guinea. Vol. 1. Dr W. Junk Publishers, The Hague, 982 pp. https://doi.org/10.1007/978-94-009-8632-9

Griffini, A. (1908) Sulle Agraecinae malesi ed austro-malesi del Museo Civico di Storia Naturale di Genova. Zoologische Jahrbücher, Abteilung für Systematik, Oekologie und Geographie der Tiere, 26, 541-566.

Hempenstall, P.J. (2016) Chapter 7. The Mainland: New Guineans under Company and Empire. In: Pacific Islanders Under German Rule: A Study in the Meaning of Colonial Resistance. ANU Press, Canberra, pp. 163-198. Online Version. Available from: http://www.jstor.org/stable/j.ctt1dgn5vg.17 (accessed 20 July 20210

Ingrisch, S. (1998) Monograph of the Oriental Agraeciini (Insecta, Ensifera, Tettigoniidae): Taxonomic revision, phylogeny, stridulation, and development. Courier Forschungsinstitut Senckenberg, 206, 1-387.

Lampe, K.-H., Riede, K. \& Ingrisch, S. (2005) Repatriation of knowledge about insects and types through the DORSA virtual museum-(Digital Orthoptera Specimen Access). Beiträge zur Entomologie, 55, 477-484. https://doi.org/10.21248/contrib.entomol.55.2.477-484

Karny, H.H. (1907) Revisio Conocephalidarum. Abhandlungen der zoologisch-botanischen Gesellschaft Wien, 4, 1-114.

Karny, H.H. (1909) Recensio Conocephalidarum in ,A synonymic catalogue of Orthoptera by W. F. Kirby contentarum. Verhandlungen der Zoologisch-Botanischen Gesellschaft in Wien, 59, $23-28$.

Karny, H.H. (1911) Descriptiones Conocephalidarum novarum. Verhandlungen der Zoologisch-Botanischen Gesellschaft in Wien, 61, 334-347.

Karny, H.H. (1912a) Orthoptera Fam. Locustidae Subfam. Agraeciinae. Genera Insectorum, 141, 1-47, pls. 1-8.

Karny, H.H. (1912b) Conocephaliden (Orthoptera Locustoidea) aus Neuguinea hauptsächlich gesammelt von Dr. O Schlaginhaufen. Abhandlungen und Berichte des zoologischen und anthropologisch-ethnographischen Museums zu Dresden, 14, 3-23.

Karny, H.H. (1926) Beiträge zur malayischen Orthopterenfauna XV. Die Conocephalinen (s.1.) des Buitenzorger Museums. Treubia, 9, 162-254, pls. 4-5.

Kiepe, H.J. \& Provinsky, P. (2011) Sammelgebiet Deutsche Kolonien: Deutsch-Neuguinea (I-II)—Deutsche BriefmarkenRevue 29-35. Available from: http://www.ag-deutsche-kolonien.de/content/download/kolonien/Deutsch-Neuguinea.pdf 
(accessed 20 July 2021)

Kirby, W.F. (1906) A synonymic catalogue of Orthoptera. Vol. II. Orthoptera Saltatoria. Part I. Achetidae et Phasgonuridae. The Trustees of the British Museum, London, viii $+562+25 \mathrm{pp}$.

Naskrecki, P. \& Rentz, D.C.F. (2010) Studies in the orthopteran fauna of Melanesia: New katydids of the tribe Agraeciini from Papua New Guinea (Orthoptera: Tettigoniidae: Conocephalinae). Zootaxa, 2664 (1), 1-35. https://doi.org/10.11646/zootaxa.2664.1.1

Nishida, G.M. (1979). Catalog of entomological types in the Bishop Museum: Orthoptera: Tettigoniidae. Pacific Insects, 20, $27-32$.

Otte, D. (1997) Orthoptera Species File 7. Tettigonioidea. Orthopterists' Society at the Academy of Natural Sciences of Philadelphia, Philadelphia, Pennsylvania, 373 pp.

Saussure, H. de (1899). Wissenschaftliche Ergebnisse der Reise in Madagaskar und Ostafrika in den Jahren 1889-95 von Dr. A. Voeltzkow. Orthoptera. Abhandlungen der Senckenbergischen Naturforschenden Gesellschaft, Frankfurt, M 21, 569-664, pls. 37-38.

The British Museum (2021) Available from: https://www.britishmuseum.org/collection/term/BIOG128620 (accessed 23 March 2021)

The Papua Insects Foundation (2008). The Papua Insects Foundation, Gazetteer.

Available from: http://www.papua-insects.nl/gazetteer/gazetteer.htm (accessed 3 March 2021)

Willemse, C. (1966) Descriptions of new and redescriptions of lesser known Orthoptera. Part II. Publicaties van het Natuurhistorisch Genootschap in Limburg, 16, 1-16.

World Airport Codes (2020) Available from: https://www.world-airport-codes.com (accessed 19 November 2020) 